Florida International University FIU Digital Commons

3-3-2014

\title{
Personnel Selection, Safety Performance, and Job Performance: Are Safe Workers Better Workers?
}

Erica N. Drew

Florida International University

DOI: $10.25148 /$ etd.FI14040884

Follow this and additional works at: https://digitalcommons.fiu.edu/etd

Part of the Industrial and Organizational Psychology Commons

\section{Recommended Citation}

Drew, Erica N., "Personnel Selection, Safety Performance, and Job Performance: Are Safe Workers Better Workers?" (2014). FIU Electronic Theses and Dissertations. 1231.

https://digitalcommons.fiu.edu/etd/1231 


\section{FLORIDA INTERNATIONAL UNIVERSITY \\ Miami, Florida}

PERSONNEL SELECTION, SAFETY PERFORMANCE, AND JOB PERFORMANCE: ARE SAFE WORKERS BETTER WORKERS?

A dissertation submitted in partial fulfillment of the requirements of the degree of DOCTOR OF PHILOSOPHY

in

PSYCHOLOGY

by

Erica Noelle Drew

2014 
To: Dean Kenneth G. Furton

College of Arts and Sciences

This dissertation, written by Erica Noelle Drew, and entitled Personnel Selection, Safety Performance, and Job Performance: Are Safe Workers Better Workers?, having been approved in respect to style and intellectual content, is referred to you for judgment.

We have read this dissertation and recommend that it be approved.

Thomas Reio

Jesse Michel

Chockalingam Viswesvaran

Valentina Bruk-Lee, Major Professor

Date of Defense: March 3, 2014

The dissertation of Erica Noelle Drew is approved.

\begin{tabular}{r} 
Dean Kenneth G. Furton \\
College of Arts and Sciences \\
\hline Dean Lakshmi N. Reddi \\
University Graduate School
\end{tabular}

Florida International University, 2014 


\section{DEDICATION}

This dissertation is dedicated to my husband and best friend, Dana Stunkel. Without your unwavering support, patience and unconditional love this dissertation would have never come to fruition. I also dedicate this dissertation to my parents, John Drew and Teresa Brandt. Thank you for always believing in me, supporting me, and motivating me to achieve my dreams. 


\section{ABSTRACT OF THE DISSERTATION \\ PERSONNEL SELECTION, SAFETY PERFORMANCE, AND JOB \\ PERFROMANCE: ARE SAFE WORKERS BETTER WORKERS?}

by

\section{Erica Noelle Drew}

Florida International University, 2014

Miami, Florida

\section{Assistant Professor Valentina Bruk-Lee, Major Professor}

The present dissertation consists of two studies that combine personnel selection, safety performance, and job performance literatures to answer an important question: are safe workers better workers? Study 1 tested a predictive model of safety performance to examine personality characteristics (conscientiousness and agreeableness), and two novel behavioral constructs (safety orientation and safety judgment) as predictors of safety performance in a sample of forklift loaders/operators $(\mathrm{N}=307)$. Analyses centered on investigating safety orientation as a proximal predictor and determinant of safety performance. Study 2 replicated Study 1 and explored the relationship between safety performance and job performance by testing an integrative model in a sample of machine operators and construction crewmembers $(\mathrm{N}=323)$. Both Study 1 and Study 2 found conscientiousness, agreeableness, and safety orientation to be good predictors of safety performance. While both personality and safety orientation were positively related to safety performance, safety orientation proved to be a more proximal determinant of safety performance. Across studies, results surrounding safety judgment as a predictor of safety performance were inconclusive, suggesting possible issues with measurement of 
the construct. Study 2 found a strong relationship between safety performance and job performance. In addition, safety performance served as a mediator between predictors (conscientiousness, agreeableness and safety orientation) and job performance. Together these findings suggest that safe workers are indeed better workers, challenging previous viewpoints to the contrary. Further, results implicate the viability of personnel selection as means of promoting safety in organizations. 


\section{TABLE OF CONTENTS}

CHAPTER

PAGE

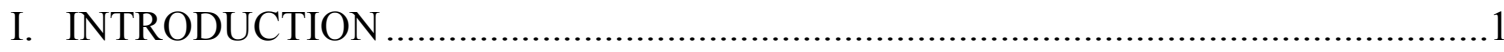

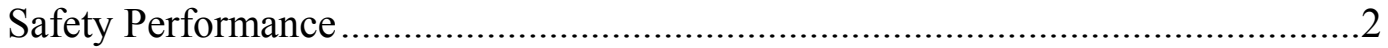

Organizational Approaches to Improving Safety Performance ...........................10

Personnel Selection and Safety Performance ...................................................... 12

The Nomological Network of Safety Performance ............................................ 14

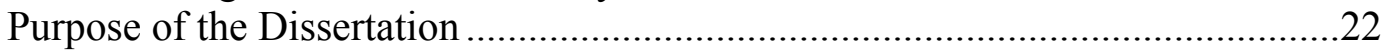

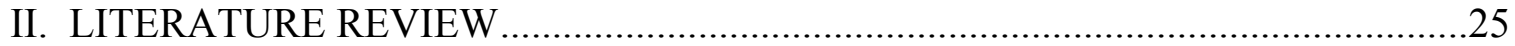

Accident Causation: Distinguishing Errors and Violations ..............................25

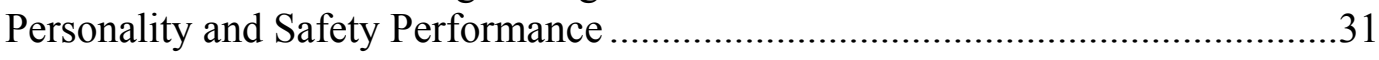

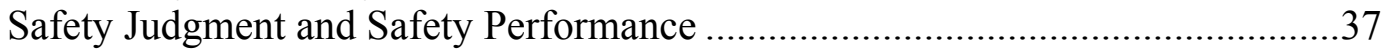

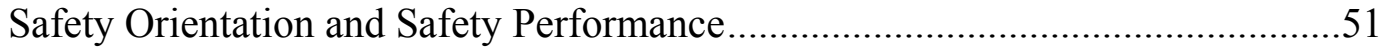

The Predictive Model of Safety Performance.......................................................57

The Integrative Model of Safety Performance and Job Performance....................60

Predictor Methods ......................................................................................63

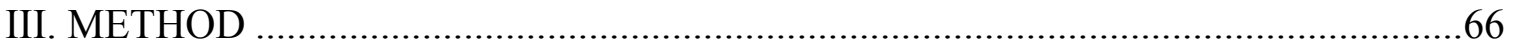

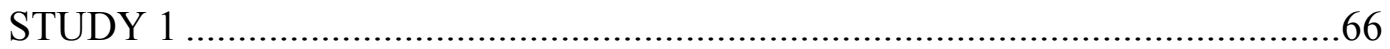

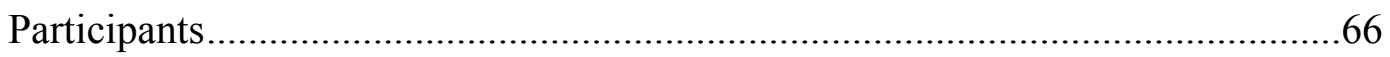

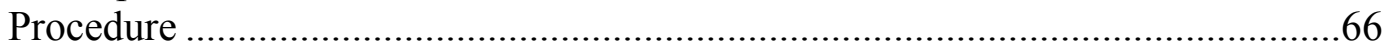

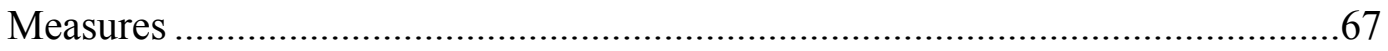

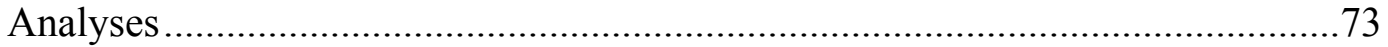

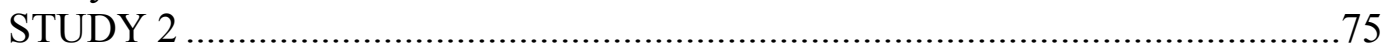

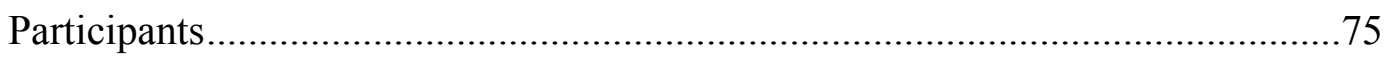

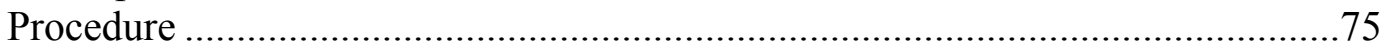

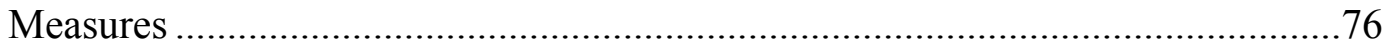

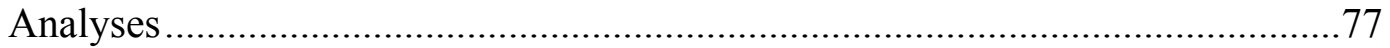

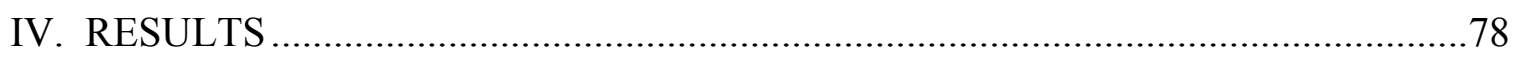

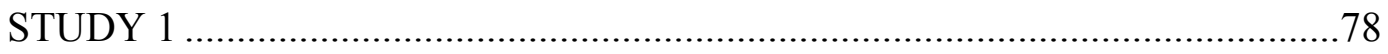

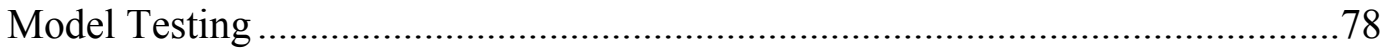

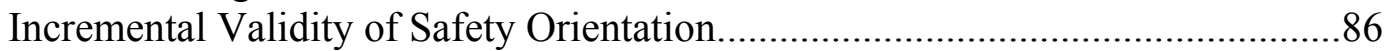

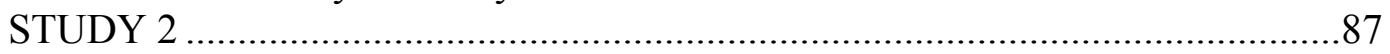

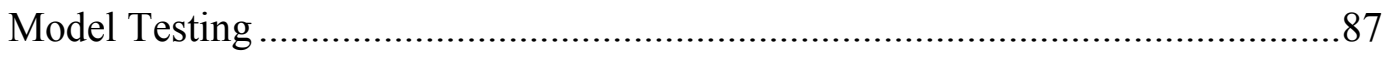

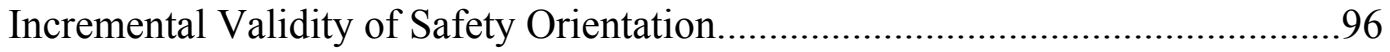

Safety Performance and Job Performance ........................................................ 97 


\section{TABLE OF CONTENTS}

CHAPTER PAGE

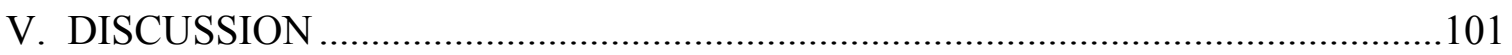

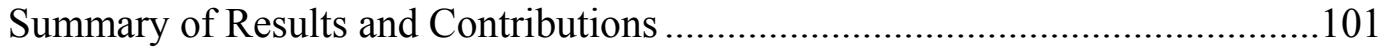

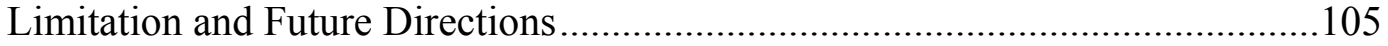

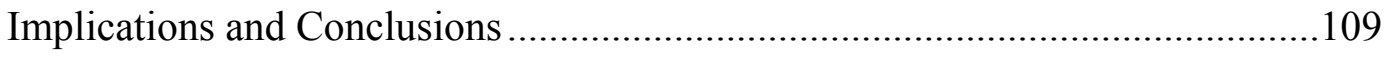

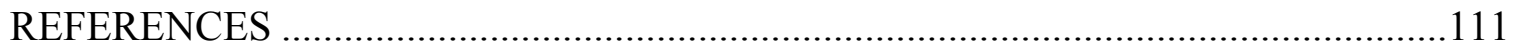

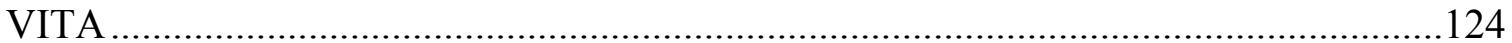




\section{LIST OF TABLES}

TABLE

PAGE

1. Study 1: Relationships Among Variables of Interest (Hypotheses 1 through 5)........78

2. Study 1: 95\% Confidence Intervals for Standardized Path Coefficients (Hypotheses 6 though 9)

3. Study 1: 95\% Bias-Corrected Confidence Intervals for Indirect Effects (Hypotheses 10 through 12).

4. Study 1: Joint Significance Test of Safety Orientation as a Mediator of the Relationship Between Conscientiousness and Safety Performance (Hypothesis 10) .84

5. Study 1: Joint Significance Test of Safety Orientation as a Mediator of the Relationship Between Agreeableness and Safety Performance (Hypothesis 11).....

6. Study 1: Study 1: Joint Significance Test of Safety Orientation as a Mediator of the Relationship Between Safety Judgment and Safety Performance (Hypothesis 12)

7. Study 1: Incremental Validity of Safety Orientation on Safety Performance Over Conscientiousness, Agreeableness and Safety Judgment (Hypothesis 13)

8. Study 2: Relationships Among Variables of Interest (Hypotheses 1 through 5)........88

9. Study 2: 95\% Bias-Corrected Confidence Intervals for Standardized Parameter Estimates (Hypotheses 6 through 9)

10. Study 2: 95\% Bias-Corrected Confidence Intervals for Indirect Effects (Hypotheses 10 through 12)

11. Study 2: Joint Significant Test of Safety Orientation as a Mediator of the Relationship Between Conscientiousness and Safety Performance (Hypothesis 10)..94

12. Study 2: Joint Significant Test of Safety Orientation as a Mediator of the Relationship Between Agreeableness and Safety Performance (Hypothesis 11) ........95

13. Study 2: Joint Significant Test of Safety Orientation as a Mediator of the Relationship Between Safety Judgment and Safety Performance (Hypothesis 12) ....96 
14. Study 2: Incremental Validity of Safety Orientation on Safety Performance Over Conscientiousness, Agreeableness and Safety Judgment (Hypothesis 13)

15. Study 2: 95\% Bias-Corrected Confidence Intervals for Indirect Effects (Hypotheses 14 and 15)

16. Study 2: Bias-Corrected 95\% Confidence Intervals For Indirect Effects (Hypothesis 16)

17. Study 2: Joint Significant Test of Safety Performance as a Mediator of the Relationship Between Safety Orientation and Job Performance (Hypothesis 16)

18. Study 2: Correlations Among Dimensions of Safety Performance and Performance Area Dimensions .100 


\section{LIST OF FIGURES}

FIGURE

PAGE

1. Neal and Griffin (2004) Framework for Conceptualizing Antecedents and Determinants of Safety Performance. .15

2. The Predictive Model of Safety Performance..........................................................56

3. The Integrative Model of Safety and Job Performance ...........................................61

4. Measurement Model of Conscientiousness ..............................................................69

5. Study 1 Model Testing: The Predictive Model of Safety Performance.......................80

6. Study 1 Model Testing: The Predictive Model of Safety Performance without

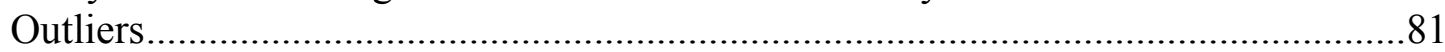

7. Study 2 Model Testing: The Integrative Model of Safety and Job Performance ........90

8. Study 2 Model Testing: The Integrative Model of Safety and Job Performance without Outliers 


\section{INTRODUCTION}

Workplace safety is a critical consideration for workers and the organizations that employ them. For organizations, workplace accidents and injuries impact financial and talent resources, which in turn, deteriorate competitive advantage. Across public and private sectors, the U.S. Bureau of Labor Statistics (BLS) reported 3.8 nonfatal workplace injuries and illnesses per 100 full-time employees in 2011 and approximately half of these cases involved days away from work. On average, an individual workplace injury resulting in time away from work costs an organization approximately $\$ 37,000$ (Miller, Waehrer, Leigh, Lawrence, \& Sheppard, 2002). The Liberty Mutual Workplace Safety Index reports that U.S. businesses paid a staggering $\$ 50.1$ billion in direct worker's compensation costs in 2009 (Liberty Mutual Research Institute for Safety, 2011). For workers, workplace accidents and injuries may cause pain and suffering, emotional distress, significant financial losses, and in particularly egregious circumstances, death.

To mitigate potential risks to employee and organizational safety, it is important to evaluate and identify the cause of workplace accidents and injuries. In general, there are three causes of workplace accidents: (1) failure of equipment and machinery; (2) failure of a process or procedure; and (3) human error. It is widely accepted that $80 \%$ - $96 \%$ of all occupational accidents are caused by human error (Hale \& Glendon, 1987; Heinrich, Peterson, \& Roos, 1980), necessitating the study of human behavior and safety in workplace.

The study of workplace safety is multidisciplinary and expands various fields including ergonomics, public health, human factors, and engineering. Empirical 
works from these disciplines tend to focus on specific occupational safety hazards (e.g., falling objects) and/or the injury or illness type (e.g., fall from elevated structure) associated with a particular occupation or industry rather than the role of human behavior. Industrial/Organizational (I/O) psychologists apply psychological principles in an attempt to understand, predict, and improve individual safety behavior and organizational safety systems. Specifically, research in this area is concerned with understanding and determining to what degree various organizational and individual characteristics influence worker safety performance.

The present chapter begins by defining safety performance. Next, methods used by organizations to improve safety performance will be summarized, with particular focus on personnel selection. A discussion of general personnel selection principles and job performance models will be presented to substantiate the use of selective hiring as means of improving safety performance. Next, the nomological network of safety performance will be described, leading into a discussion of how important constructs can be measured within the personnel selection context. The purpose of the present dissertation will be presented at the end of the chapter, providing a framework for Chapter II.

\section{Safety Performance}

Industrial/Organizational psychology is predominantly concerned with understanding and predicting job performance. Job performance can be generally defined as the extent to which an employee contributes to important individual and organizational outcomes. Similar to job performance, safety performance is a multidimensional construct that encompasses various worker behaviors that promote 
personal safety, the safety of others, and the safety of the organization as a whole. Although safety performance measures aspects of work behavior (i.e., safety behavior at work), it does not neatly fit into any one component of job performance (e.g., task, contextual). Thus, safety performance should not be treated as a separate domain of job performance, but rather a separate performance criterion in of itself (Burke, Sarpy, Tesluk, \& Smith-Crowe, 2002; Christian, Bradley, Wallace, \& Burke, 2009; Parker \& Turner, 2002).

Industrial/Organizational psychology distinguishes among different types of performance criteria. These distinctions do not represent components of performance but rather describe how performance is indexed, measured, and operationalized. Two general categories of performance criteria are commonly assessed. Objective criterion measures are concerned with results, such as productivity, and work quality. Subjective criteria measures require observation and judgment of individual behavior. Safety researchers have considered both objective criteria (i.e., number of accidents or injuries) and subjective criteria (i.e., self or supervisory ratings of individual safety behavior) as indicators of safety performance. Engineering, ergonomics and human factors literature have focused on objective criteria, while I/O and organizational health psychology have focused primarily on behavioral indicators of safety. Both types of criteria and their relative merit within the broader workplace safety literature are discussed in the following sections.

Safety Outcomes. Safety outcomes are a form of objective criteria that represent critical safety incidents such as the number of injuries or accidents that occurred within a particular period of time. There are several issues with this form of 
criteria including: (a) incident underreporting; (b) reporting system failures; (c) statistical and methodological issues; and (d) measurement deficiency.

First, work-related accidents and injuries are frequently not recorded because workers fear punishment or feel that management will fail to respond effectively (Pransky, Snyder, Dembe, \& Himmelstein, 1999). Often these unreported injuries require genuine medical or/and financial assistance. For example, Weddle (1996) reported that the majority of unreported minor injuries among hospital management workers required medical attention (64\%) or time away from work (44\%). Further, employees may avoid reporting injuries when medical treatment was received from external insurance or disability programs (Fingar, Hopkins, \& Nelson, 1992; Murphy, Sorock, Courtney, Webster, \& Leamon, 1996).

Second, many organizations fail to comply with required reporting systems and standards. Researchers have found that only $75 \%$ of organizations required to maintain an Occupational Safety and Health Administration (OSHA) Log of WorkRelated Injuries and Illnesses actually comply with reporting requirements (Seligman, Sieber, Pederson, Sundin, \& Frazier, 1988).

Third, because accidents, injuries and deaths are often infrequent and poorly documented, safety outcome criteria typically suffer from low base rates and skewed distributions (Smith et al., 2001; Zohar, 2004). To alleviate the effects of these methodological concerns, researchers must develop extensive longitudinal studies or rely on statistical remedies (e.g., non-parametric statistics, normalization formulae) that often lack sufficient power to detect meaningful effects (Smith et al., 2001). 
Lastly, objective measures of performance, in general, tend to be deficient because they only tap a small portion of the overall criterion space (Guion, 1965). For example, data on accident and injury rates do not provide important information regarding contextual circumstances or worker behavior preceding the incident, occurrences that nearly resulted in an accident or injury (near misses), or less severe injuries that did not require reporting (Pransky et al., 1999). Altogether, using safety outcomes as measurement criteria serves only to provide a deficient and spurious indication of safety performance.

In response to a call for research using worker surveys of unreported accidents and near misses (Pransky et al., 1999), Smith et al. (2001) created an injury selfreport assessment to obtain data on near-injury events (sample item: "I almost had an accident when I adjusted a machine while its parts were still moving”) and unreported injury events (sample item: "I was struck by equipment or an object") in addition to traditional recorded injury events. No relationship was found between self-reported injury events (i.e., near injury and unreported events) and organizational records ( $r=$ .03 - .14), demonstrating inadequacy of recorded data. Despite high scale intercorrelations $(r=.53-.60)$, the author's suggested that the near-injury and unreported injury event measures were assessing separate dimensions of the injury process. While the near-injury measure assessed individual safety behaviors that did not result in an accident (e.g., "I almost had an accident when I operated a machine without a safety guard"), the unreported injury measure focused exclusively on the specific error that resulted in injuries (e.g., "I hit part of my body on something"). 
Though gathering comprehensive data on injuries (reported and unreported) may be valuable in some regard, it does little to resolve to what degree day-to-day worker behaviors contribute to personal and organizational safety performance. Focusing on safety behaviors provides more relevant and accurate information needed to ensure the sustainability of workplace safety.

Traditionally, safety outcome criteria have been viewed as synonymous with safety behavior criteria. In other words, it was assumed that if an individual avoided accidents and injuries, then he or she must perform work tasks safely. However, objective outcomes cannot be synonymous with their behavioral antecedents because objective criteria reflect only a portion of individual differences in behavior (Campbell, 1990; Guion, 1965). Plainly, unsafe behavior does not always result in accidents and safe behavior does not ensure accidents will not occur. Campbell et al. (1993) stated that job performance "is the action itself not the consequence or the result of the action" (p. 40). Thus, performance is derived from worker behaviors, not from objective measures of worker results. Further, the degree of individual control is different across criterion types; behaviors are by definition entirely volitional whereas, results of behaviors may be affected by numerous contextual variables (Campbell et al. 1993). Thus, safety performance should be defined in terms of individual safety behaviors not by the negative outcomes of such behavior (i.e., accidents and injuries).

Research in the job performance literature supports the notion that objective and subjective criteria are not interchangeable. For example, Rich, Bommer, MacKenzie, Podsakoff, and Johnson (1999) determined the corrected correlation 
between objective and subjective job performance criteria to range from .28 to .45 . In regard to safety, various studies that have considered accidents and injuries as an outcome of safety behavior report only moderate correlations between the two criteria (e.g., Christian et al., 2009; Hofman \& Stetzer, 1996). For example, Hofman and Stetzer (1996) reported a non-significant relationship between measures of raw accidents and unsafe behavior $(r=.35)$. Similarly, Christian et al. (2009) reported a moderate negative association between safety performance and accidents and injuries $(r=-.31)$ Together, these results suggest that safety behavior and accidents and injuries are two distinct variables, each only accounting for a small amount of variance in the other.

Review of the safety performance literature illustrates a shift in criterion focus, presumably necessitated by the realization that safety performance cannot be defined merely by the absence of accidents. Although unsafe behavior may not consistently cause accidents, continued unsafe behavior increases the likelihood of hazardous working conditions, safety system vulnerability, and accidents (Fay \& Tissington, 2004). Therefore, all unsafe behavior is dangerous, despite the nature of its consequences. To accurately measure safety performance, it is important to consider the entire domain of safety behavior rather than mere instances where a particular behavior resulted in an accident or injury.

Safety behavior. Using behavior as criterion offers a commonsense approach to operationally defining individual workplace behaviors that control or eliminate hazards, decrease the likelihood of human error, and thus, prevent the occurrence of accidents (Raouf \& Dhillon, 1994). Behavioral safety performance criteria have 
quickly gained popularity, as literature demonstrating a direct link between safety behavior and workplace accident and injury occurrence continues to accumulate (e.g., Christian et al., 2009). Such measures of safety performance acknowledge that there is more to safety than the absence of accidents and address previously mentioned limitations of objective criteria by using behavioral indicators of safe and unsafe worker behavior.

The definition and measurement of safety performance is critical to understanding how workplace accidents and worker abilities are associated with safety behavior (Smith et al., 2001). Current conceptualizations of safety performance focus on understanding the nature and cause of unsafe behavior. Unsafe behavior is defined as, "behaviors that are not in accordance with safety rules and procedures... and thus, increase the likelihood of accidents" (Fay \& Tissington, 2004, p. 299). Burke et al. (2002) define general safety performance as "actions or behaviors that individuals exhibit in almost all jobs to promote the health and safety of workers, clients, the public and the environment" (p. 432).

Past research has focused solely on worker compliance to safety rules as indicators of safety performance (Fay \& Tissington, 2004). However, recent definitions include both adherence to organizational safety rules and regulations and voluntary safety behaviors that contribute to personal and organizational safety (Griffin \& Neal, 2000; Neal \& Griffin, 2000; Neal \& Griffin, 2006). Griffin and Neal's (2000) definition of safety performance includes compliance with mandated safety rules and procedures (safety compliance) and discretionary behaviors that support overall organizational safety such as helping coworkers, promoting 
workplace safety programs, and attending voluntary safety meetings (safety participation). In general, discretionary behaviors (e.g., organizational citizenship behavior, Organ, 1988; contextual performance, Borman \& Motowildo, 1993) are important to include in any conceptualization of performance because such behavior is related to key organizational effectiveness outcomes including productivity, efficiency, and reduced costs (Podsakoff, 2009). To mitigate high financial costs and depletion of talent resources associated with accidents and injuries, important characteristics of worker safety behavior beyond compliance with rules and regulations must be considered. Thus, the present dissertation will include a conceptualization of safety performance that encompasses both safety compliance and participation behaviors. Unlike Neal and colleagues, I make no distinction between components of safety performance in the present study. I acknowledge that both types of behaviors are important and consider these behaviors jointly in an overall measure of safety performance. Further, in the context of personnel selection, performance dimensions are rarely considered as separate criteria.

Extant measures of safety performance (e.g., Burke et al., 2002; Neal et al., 2001) have laid the foundation for more effective and accurate measurement of workplace safety. However, the majority of these measures have relied on selfreported worker behaviors (c.f. Burke et al., 2002); subsequently, the reported relationships between various antecedents and self-reported safety behavior remain questionable. Without a judgmental measure of safety behavior, it is difficult to determine the extent to which self-reported safety behavior corresponds to actual safety behavior. Supervisor ratings present information regarding observations of 
incumbent safety behavior, thereby provide a judgmental measure of safety performance.

The value of supervisors as a rating source hinges on the fact that supervisors possess expert knowledge of job and safety requirements, as well as organizational goals and objectives. Supervisors tend to be in close contact with their direct reports, and thus are best suited to differentiate between effective and ineffective subordinate behavior. Research has demonstrated that supervisor ratings are more highly related to job performance than any other source of feedback (Becker \& Klimoski, 1989). In an effort to minimize common method variance (Conway \& Huffcutt, 1997; Spector, 1994), increase reliability (Viswesvaran, Ones \& Schmidt, 1996), and validity (Harris \& Schaubroeck, 1988), ratings of individual safety performance provided by direct supervisors of participating incumbents are considered in the present dissertation.

\section{Organizational Approaches to Improving Safety Performance}

Organizational human resources functions add value throughout the employee life cycle by implementing strategic talent management processes such as personnel selection, new hire onboarding and socialization, training, and employee and leadership development. The human resources management literature has recently shifted focus from control-orientated approaches that emphasize the use of rules to enforce behaviors and ensure compliance, to commitment-oriented strategies that elicit effective performance through supportive work practices (Pfeffer, 1998; Zacharatos \& Barling, 2004).

Prevention of workplace accidents are most commonly addressed thorough three commitment-oriented strategies: (1) modification of environmental features 
(e.g., equipment design) to promote safety; (2) behavior modification techniques (i.e., reinforcements for safe behaviors and punishments for unsafe behavior) to encourage employees to perform job duties safely; and/or (3) safety climate improvement processes which entail assessment of current organizational safety climate and implementation of appropriate interventions (i.e., safety training) to address identified areas of concern. Limitations of these strategies are important to point out. First, modifying environmental features neglects the role of human behavior in accidents, injuries and near misses. Second, though behavior modification techniques have been successful in a number of organizations, disciplinary actions may not consistently change employee safety behavior (Zacharatos \& Barling, 2004). Third, both modification and safety climate intervention methods serve as a means of addressing safety performance issues of incumbents. While each of these strategies presents unique advantages and challenges, each generally addresses safety concerns after they have become a problem and offer minimal safeguards against hiring employees who are likely to pose a threat to existing safety systems by behaving unsafely on the job.

Selective hiring offers a proactive approach to maintaining workplace safety by removing employees who are more likely to engage in unsafe behaviors from the applicant pool. Selective hiring as a commitment-orientated approach has received the least empirical attention in the workplace safety literature (Zacharatos \& Barling, 2004). The lack of evidence surrounding selective hiring is surprising given early evidence to suggest selective hiring approaches may offer improvements to organizational safety systems. For example, Cohen (1977) and Smith, Cohen, Cohen, 
and Cleveland (1978) reported that organizations with lower injury incidents have more elaborate selection procedures than higher injury counterparts (e.g., Cohen, 1977; Smith, Cohen, Cohen, \& Cleveland, 1978). More recently, Kaplan and Tetrick (2010) called for further exploration of the utility of selecting for safety performance.

The authors suggested that considering safety performance in employee selection may be crucial as selective hiring decisions may have "...a more widespread impact on safety outcomes than usually recognized" (p. 460). Thus, research aimed at identifying important individual difference predictors of safety performance is needed to advance selection procedures designed to promote safer work environments.

\section{Personnel Selection and Safety Performance}

Personnel selection is a systematic process by which individuals in a relevant applicant pool are matched to a specific job through a selection procedure. Selection procedure refers to any process used in personnel decision-making including various types of: (a) test administration methods (e.g., traditional paper and pencil, assessment centers, work sample); (b) content areas (e.g., cognitive, ability, personality); and (c) processes (e.g., job performance appraisals, and estimates of potential). Personnel selection utilizes evidence-based techniques to determine the most qualified candidate from a pool of applicants. The goal of personnel selection is to use evidence collected from the selection procedure to make accurate predictions about candidate's future job performance.

In the selection context, critical constructs of job performance are identified through a job analysis. The Principles for the Validation and Use of Personnel Selection Procedures (Principles; Society for Industrial and Organizational 
Psychology, 2003) defines job analysis as a "method used to gain an understanding of the work behaviors and activities required, or the worker requirements and the context or environment in which an organization and individual may operate" (p. 66). Worker requirements are commonly described as knowledge, skill, abilities and other characteristics (KSAOs). Knowledge is defined as the degree to which an employee is required to know certain technical material. Skill represents adequate performance on tasks requiring the use of tools, equipment, and machinery. Abilities are physical and mental capacities to perform tasks not requiring the use of tools equipment and machinery. Lastly, other characteristics refer to personality, interests, or motivational attributes.

Information obtained through job analysis is then used to develop assessment content that will validly and reliably predict important organizational success criteria, such as safety performance. Assessment content includes various important constructs that reflect KSAO's identified in the job analysis. For example, an auto machine operator may require knowledge of OSHA compliance requirements, interpersonal skill, mechanical reasoning ability, safety orientation, thoroughness, and selfconfidence. There are a wide variety of predictor methods available to assess KSAO constructs such as personality tests, job knowledge tests, interviews, biographical data and situational judgment tests.

Arthur and Villado (2008) have argued for the distinction between predictor constructs and predictor methods. Whereas predictor constructs describe what behavioral domain is being sampled, predictor methods are the specific process or technique of measuring predictor constructs. The construct-method distinction 
acknowledges that any predictor method can be designed to assess a wide variety of predictor constructs, and vice versa, predictor constructs can be measured by a wide variety of predictor methods. Binning and Barret (1989) similarly argue that because predictor and criterion measures are ultimately linked to an underlying construct domain, validation of specific predictors cannot be dissociated from a discussion of what the predictor methods are designed to measure. Together, these ideas necessitate a discussion of how constructs are represented in predictive measures (Arthur \& Villado, 2008).

To this end, I briefly introduce important antecedents of safety performance in the following sections, leading into an explanation of how these more traditional constructs are represented by the novel predictor constructs considered in this study. A brief description of the purpose of the dissertation and specific predictor methods used in the present study will follow. More information regarding the relationships between predictor constructs and safety performance, as well as general predictor methods will be provided in Chapter II. Specific information on predictor methods will be provided in Chapter III.

\section{The Nomological Network of Safety Performance}

Neal and Griffin (2004) developed a framework for conceptualizing antecedents and determinants safety performance based on Campbell et al.'s (1993) theory of job performance (Neal \& Griffin, 2000; Neal et al., 2001). The framework is depicted in Figure 1. The Neal and colleagues' model of safety performance is described below. 
Figure 1

Neal and Griffin (2004) Framework for Conceptualizing Antecedents and Determinants of Safety Performance

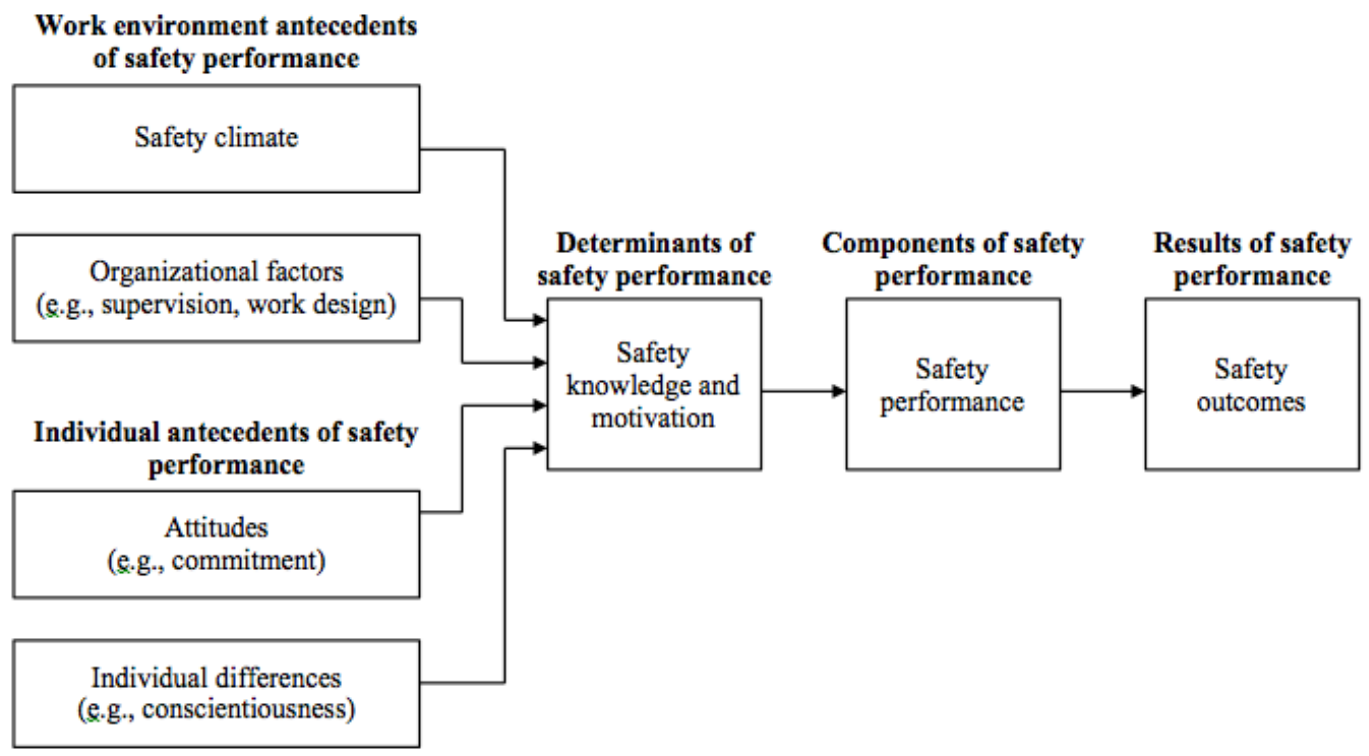

Campbell et al.'s (1993) model specifies the determinants and antecedents of job performance. Determinants of performance are factors that are directly responsible for individual differences in worker behavior, whereas antecedents have indirect effects on performance though determinants. Specifically, Campbell et al. (1993) proposed three determinants of job performance: (a) declarative knowledge; (b) procedural knowledge and skill; and (c) motivation. Declarative knowledge is the knowledge of facts, principles, and procedures or understanding of task requirements needed for successful performance (Anderson, 1985; Kanfer \& Ackerman, 1989). Procedural knowledge and skill is the combination of knowing what to do (declarative knowledge) and actually being able to do it. Procedural knowledge includes various acquired capabilities such as cognitive, psychomotor, physical, selfmanagement, and interpersonal skill (Campbell et al., 1993). Lastly, motivation, is the combined effect of three behavioral choices: (a) the choice to exert effort toward an 
intended outcome (direction); (b) the choice to apply a particular level of effort (intensity); and (c) the choice of how long to continue exerting effort (duration; Pinder, 1998). Using these arguments, Neal and colleagues (Griffin \& Neal, 2000; Neal \& Griffin, 2004; Neal, Griffin \& Hart, 2000) reasoned that safety performance must be determined by the knowledge and skill required to enact safety behaviors and the degree of motivation to behave safely. Neal and colleagues (Griffin \& Neal, 2001; Neal \& Griffin, 2004; Neal et al., 2000) used this rational to develop two predictive constructs that reflect volitional and knowledge factors related to safety performance: safety knowledge and safety motivation.

Safety knowledge is defined as simply knowing how to perform job duties safely (e.g., handling hazardous chemicals, proper emergency procedures). Safety knowledge is similar to Campbell and colleagues (1993) definition of declarative knowledge, and procedural knowledge and skill as it relates to workplace safety. Many empirical studies have demonstrated the relationship between safety knowledge and a wide range of safety behaviors (Burke et al., 2002; Christian et al. 2009; Eklof \& Torner, 2002; Griffin \& Neal, 2000; McGovern et al., 2000; Neal et al., 2000; Probst, 2004; Vinodkumar \& Bhasi, 2010).

Safety motivation reflects “an individual's willingness to exert effort to enact safety behaviors and the valence associated with those behaviors" (Neal \& Griffin, 2006, p. 947). Research has supported the proposition that safety behavior is determined by the value an individual places on safety, and their willingness to behave in a safe manner (Buck, 2008; Christian et al., 2009; Griffin \& Neal, 2000; Neal and Griffin, 2006; Probst \& Brubaker, 2001; Vinodkumar \& Bhasi, 2010). 
According to Campbell et al.'s (1993) model, both person and situational antecedents predict performance determinants. Specifically, individual differences in personality, ability, and interests combine and interact with education, training, and experience to shape declarative knowledge, procedural knowledge and skill, and motivation. Thus, the effect of antecedents on job performance is mediated by knowledge, skill, and motivation. Research across disciplines has suggested antecedents of safety performance include both aspects of the work environment (e.g., safety climate, supervision, work design) and individual characteristics (e.g., safety attitudes, personality, cognitive factors). Similar to Campbell et al. (1993), Neal and Griffin (2004) propose that both work environment and individual antecedents directly influence safety knowledge and safety motivation, which in turn, influence safety performance behaviors. In other words, situation- and person-based antecedents are indirectly related to safety performance through safety knowledge and safety motivation.

Empirical support. The framework proposed by Neal and Griffin (2004) has received significant empirical support. Determinants of safety performance have been shown to mediate the relationship between safety performance and various situationand person-based antecedents including safety climate (i.e., safety motivation and knowledge; Christian et al., 2009; Griffin \& Neal, 2000; Neal, Griffin \& Hart, 2000), job insecurity (safety motivation; Probst \& Brubaker, 2001), psychological climate (safety motivation; Larsson, Pousette, \& Torner, 2008), safety management practices (i.e., safety motivation and knowledge; Vinodkumar \& Bhasi, 2010) and 
conscientiousness (i.e., safety motivation and knowledge; Christian et al., 2009).

These antecedents are discussed in the sections to follow.

Work environment antecedents. A great deal of attention has been paid to situation-based antecedents (e.g., work environment, management practices) of safety in the workplace (e.g., Barling, Kelloway, \& Iverson, 2003; Cox \& Cheyne, 2000; Hayes, Perander, Smecko, \& Trask, 1998; Parker, Axtell, \& Turner, 2001). Much of the safety performance research has focused on the creation of an organizational safety climate to promote safe employee behavior and engender a controlled accident environment (e.g., Zohar, 2010). Safety climate is generally defined as shared employee perceptions of policies, procedures and practices relating to safety (Zohar, 1980). While safety climate is an important indicator of safe work practices (e.g., Griffin \& Neal, 2000; Hoffman \& Stetzer, 1996; Neal \& Griffin, 2006), and key health and safety outcomes (see Christian et al., 2009; Clarke, 2006, 2010; Nahrgang, Morgeson, \& Hofmann, 2011), the focus of safety climate is not on particular behaviors of individual employees but rather shared (aggregated) perceptions of safety. Personnel selection aims to predict how individual differences in KSAO's will influence subsequent on-the-job performance. Because safety climate is a unit-level, situation-based variable, it cannot be considered as a predictor of safety performance in the personnel selection context. Simply, it is difficult to predict how a candidate will perceive safety practices, policies, and procedures within an organization they have not yet worked for, or how incumbent's perceptions of safety climate will be influence applicant behavior if hired. Thus, safety climate will not be a focal variable of interest in the present study, because it is an inappropriate predictor for hiring 
purposes. Individual antecedents (e.g., personality, attitudes, safety knowledge and safety motivation) are more useful for hiring candidates into jobs where safety is a critical priority.

Individual difference antecedents. Individual differences represent personbased differences in KSAO's. Determining a person's standing on particular individual difference variables allows researchers to predict how well he or she will perform in a particular job, on the basis of an established relationship between the characteristic(s) under consideration and job performance. For example, because conscientiousness has been shown to be an important predictor of job performance (e.g., Barrick \& Mount, 1991), it is likely that an individual who demonstrates high conscientiousness in hiring proceedings will perform well on the job. The present dissertation focuses specifically on individual differences in personality, cognitive factors, and safety attitudes as antecedents of safety performance. These constructs are briefly described here.

Personality. Researchers have investigated the relationship between various individual differences and safety performance for decades (e.g., Hale \& Hale, 1972; Hansen, 1988; Lawton \& Parker, 1998). Several investigations have considered the association of Big Five personality traits (Costa \& McCrae, 1985) with both safety outcomes and behaviors. Specifically, conscientiousness and agreeableness factors have demonstrated negative relationships with driving accidents (e.g., Clarke \& Roberston, 2005, 2008) and positive relationships with safety behaviors (e.g., Buck, 2008; Christian et al., 2009). 
Cognitive factors. Cognitive factors relevant to individual safety behavior include thinking, reasoning, perceiving, decision-making, and judgment (Lawton \& Parker, 1998). Cognitive factors research has predominately focused on proneness to cognitive failure as a predictor of unsafe behavior and accidents (e.g., lapses of attention, distractibility, forgetfulness). Cognitive failure is defined as an enduring trait-like construct that involves a breakdown in cognitive functioning, resulting in cognitively based errors or mistakes (Broadbent, Cooper, Fitzgerald, \& Parkes, 1982). Research has supported the relationship between cognitive failures and driving accidents (Larson \& Merritt, 1991; Wallace \& Vondnovich, 2003b), workplace accidents (Larson, Alderton, Neideffer, \& Underhill, 1997; Wallace \& Vondnovich, 2003a, 2003b) unsafe behaviors and job performance (Wallace \& Vondanovich, 2003a).

Safety attitudes. After review of accident causation antecedents, Lawton and Parker (1998) suggested that in order to develop "a sophisticated explanation of the role of human factors in accident causation" (p. 11) attitudinal and motivational variables must be considered in addition to cognitive factors and personality because these variables explain why certain individuals choose to violate established safety procedures. To this end, safety attitudes are considered presently as an important antecedent of safety performance. Safety attitudes reflect individual beliefs and emotions toward general safety policies, procedures, and practices (Neal \& Griffin, 2004; Rundmo \& Hale, 2003) and involve both personal commitment to and a level of personal responsibility for workplace safety (Henning et al., 2008). Attitudinal 
safety measures have demonstrated a positive relationship with both safety outcomes and behaviors across various industries (e.g., Henning et al., 2008).

Present study constructs. The specific constructs considered in the present study combine traditional determinants (safety knowledge and safety motivation) and antecedents (safety attitudes and cognitive factors) into predictor variables likely to account for significant variance in safety performance. Specifically, safety judgment and safety orientation will be considered as predictors of safety performance in addition to personality factors of conscientiousness and agreeableness. Safety judgment refers to an individual's tendency to use sound judgment, utilize positive safety attitudes, and apply correct safety knowledge to potentially dangerous situations. Thus, safety judgment encompasses safety attitude and safety knowledge constructs.

Safety orientation refers to an individual's inclination to act safely at work and the degree to which they value safety. Recall that safety motivation signifies an individual's willingness to put forth effort to act in a safely and the value an individual places on safe behaviors (Neal \& Griffin, 2006). By this definition, safety orientation determines applicants' safety motivation by gathering information about their past behaviors. For example, an individual with high safety motivation would be likely to follow established safety rules and procedures, use required safety equipment, read and/or listen to safety warnings, take appropriate measures to avoid accidents, and place a large value on safety. 


\section{Purpose of the Dissertation}

The present dissertation sought to make both theoretical and practical contributions to the safety performance literature through two studies. Each is described below.

Study 1. First, a predictive model of safety performance was tested to examine the personality, safety orientation and safety judgment as predictors of safety performance. Second, safety orientation was investigated as a mediator of the relationships between personality and safety judgment with safety performance. The novelty of these predictors necessitates a discussion of safety judgment and safety orientation relative to widely cited safety constructs. As such, Chapter II focuses on describing relevant safety performance antecedents to which parallels are drawn to support of hypothesized relationships. Specifically, Chapter II summarizes evidence that demonstrates how the constructs that comprise safety judgment (safety attitudes and safety knowledge) and safety orientation (safety motivation) are associated with personality, safety performance and each other. Third, the ability of safety orientation to explain incremental variance in safety performance above and beyond personality and safety judgment was investigated.

Study 2. Study 2 replicated the predictive model tested in Study 1 and also extended the model to consider job performance as an outcome of safety performance. Specifically, safety performance was investigated as a mechanism to explain the relationship between job performance and antecedents and determinants of safety performance. Commonly, safety and productivity are viewed as two mutually exclusive choices, often in conflict with one another (Faverge, 1980; 
Janssens, Brett \& Smith, 1995; Kjellen, 1984; Leplat \& Rasmussen, 1984). The more an organization places an emphasis on production, the more workers feel pressure to ignore known safety procedures to meet production demands (Janssens et al., 1995). Heinrich (1980) argues that job performance and safety should not be so contentious given that problems are similar when safety and job performance are collectively low. Further, improving safety is likely to improve job performance. For example, safe behavior cuts time spent addressing system failures and accidents, decreases expenditures on workers compensation and production losses, thereby increasing overall job performance (Anasiewicz, 1962).

Summary. Several key contributions to the safety performance literature are made through these analyses. First, a comprehensive set of predictors was considered including facets of personality, and two novel behavioral constructs, safety judgment and safety orientation. Second, job-centered psychometric tests commonly used in selection contexts were used to assess these constructs. Specifically, safety judgment was measured by a situational judgment test (SJT) and safety orientation was measured by a biographical (biodata) test. Third, criterion measures of safety performance and job performance were gathered via supervisor rating forms. Fourth, to demonstrate that selecting for safety does not result in lowered prediction of job performance the relationship between safety and job performance was considered. Overall, the present dissertation aimed to provide evidence to support the viability of personnel selection as means of promoting safety in organizations.

Chapter II begins with an explanation of volitional differences in human error, which have a distinct impact on safety behavior and are thus differentially associated 
with predictors of interest. Next, the relationship between safety performance and conscientiousness, agreeableness, safety judgment and safety orientation is described. Lastly, two models are presented: (1) a predictive model of safety performance; and (2) an integrative model of safety performance and job performance. Before discussing participants, procedures, and measures in Chapter III, novel behavioral predictor methods used to assess safety judgment and safety orientation are generally reviewed. 


\section{LITERATURE REVIEW}

It has been well established that the majority of workplace accidents are the result of human error (Hale \& Glendon, 1987; Heinrich et al., 1980). Making mistakes and errors is a fundamental aspect of human behavior. Though mistakes can be a productive learning tool in some circumstances, errors made at work may lead to particularly egregious personal and organizational consequences, and thus should be expressly avoided. Control of human errors requires identification of what types of errors occur, and where and when they are likely to be committed.

\section{Accident Causation: Distinguishing Errors and Violations}

To advance the assessment of human error as it relates to safety behavior, researchers have recently proposed a useful distinction between human errors and violations (Lawton \& Parker, 1998; Parker, Reason, Manstead \& Stradling, 1995; Reason, Parker, \& Free, 1994). Errors are defined as "planned actions that fail to achieve a desired goal" (Lawton \& Parker, 1998, p. 5). These actions involve either unconscious (slips or lapses) or conscious cognitive processes (mistakes), though the outcomes of both are decidedly unintentional. Violations are defined as "deliberate deviations from the recognized safe method of working" (Lawton \& Parker, 1998, p.5). Further, research suggests that error types relate differently to antecedents of safety outcomes and behavior. Thus, a meaningful analysis of safety behavior at the individual level requires consideration of both cognitive factors involved in human errors and the attitudinal and motivational factors that influence individual's intentions to behave safely (Lawton \& Parker, 1998). The next section summarizes the literature on errors and violations, distinguishing between their different 
psychological causes and relationships with important antecedents of safety performance.

Error: Unintentional slips, lapses and mistakes. Researchers have developed various taxonomies to explain the cognitive mechanisms underlying the human error process (Rasmussen, 1983; Reason, 1990). Rasmussen (1982, 1983) proposed a cognitive control taxonomy that describes three levels of cognition involved in task performance: (a) skill; (b) rule; and (c) knowledge. Skill-based behavior represents sensory-motor performance and refers to automated behaviors applied to routine tasks and procedures. At this level, the individual automatically recalls stored patterns of information from past experiences and applies them to complete the task at hand. Rule-based performance is used when solving familiar problems, and involves utilizing stored rules and procedures of the "if (situation)... then (response)" form to determine subsequent behavioral responses. Rules stored in memory or "know-how" can originate from the individual's past experience, procedures communicated by another person's instructions or even a sequence of steps presented in a book (Rasmussen, 1983). When faced with a novel situation, rules or know-how may not be readily available, thus Rasmussen posits that this situation calls for goal-controlled or knowledge-based performance. To be successful, the individual must identify a goal that is based on conscious analysis of the problem and environment, determine a sequence of actions to achieve the goal, and effectively execute the plan.

Reason (1990) expanded Rasmussen's skill-rule-knowledge performance model to include error types committed at each level of task performance. The 
proposed generic error modeling system (GEMS; Reason, 1990) integrated two distinct areas of error literature: (a) slips and lapses, in which performed actions deviate from action intention (i.e., execution failures); and (b) mistakes, in which the plan to achieve a goal is inadequate or the actions were not carried out as planned (i.e., planning failures). Three error types were developed based on these conceptualizations: (a) skill-based slips and lapses; (b) rule-based mistakes; and (c) knowledge-based mistakes.

According to GEMS (Reason, 1990), errors at Rasmussen's skill-based level of task performance involve slips of action and lapses of attention. Specifically, slips of action refer to instances where a performed action deviates from the intended action, whereas lapses of attention refer to moments of inattention and/or memory lapses. Because performance at this level is automatized, Reason (1990) referred to these errors as execution failures. As such, execution errors are typically observed during routine actions where minimal cognitive resources are required. For example, in an analysis of 178 deaths and 99 serious accidents in Finland, Salimen and Tallberg (1996) found that the majority of human errors involved errors of execution. Though research has indicated that negative emotional states (e.g., stress) may influence the occurrence of slips and lapses (Wickens, 1996; Lawton \& Parker, 1998), Reason (1990) argued that the actual cause are individual differences in cognitive style that result in higher rates of absentmindedness or insufficient coping strategies for dealing with stressful situations. Earlier work by Broadbent et al. (1992) supported the effect of idiosyncrasies on error commission by demonstrating that 
some individuals are more prone to absentminded errors (cognitive failures), and more likely to report moments of inattention and/or frequent memory lapses.

Reason (1990) categorized errors made at Rasmussen's rule- and knowledgebased performance level as mistakes because both involve unintentional errors committed during problem solving activities. Specifically, these error types are referred to as planning failures because they occur when "actions [do] not go as planned or because the plan itself was deficient" (pp. 54-55; Reason, 1990). While slips and lapses occur from unintended activation of incorrect procedural routines, mistakes refer to more conscious and complex cognitive processes involved in judging available information, developing achievable goals and determining a plan of action. Specifically, rule-based mistakes occur in one of two ways; an individual either misapplies a good rule or correctly applies a faulty rule to perform a task. Knowledge-based mistakes occur because the individual did not know what the proper rule was, and thus cannot develop a proper method of completing a task.

Violations: intentional deviations. Not all accidents can be attributed to unintentional causes such as momentary lapses of concentration or slips of action. Further, though an accident itself may not have been intentional, the choice to enact a behavior in violation of known safety procedures is undoubtedly intentional in some cases. Violations are intentional errors, where an individual, knowing the correct rule or procedure, resolves to apply a different rule (Lawton \& Parker, 1998; Reason et al., 1990). Thus, it can be said that violations are committed at the rule- or knowledgebased level of behavior, as they require conscious selection of a rule or procedure to apply. Though violations may not result in error, any subsequent consequence cannot 
be categorized as a mistake, as the deviation from procedure was a choice. Despite involving deliberate deviations from safe operating procedure, violations do not typically involve malevolent intent (e.g., sabotage; Reason et al., 1990)

Violations have two important consequences: (a) they increase the probability of a subsequent error; and (b) they increase the likelihood of deleterious outcomes (e.g., accident, injury or death; Free, 1994; Parker, Reason, Manstead, \& Stradling, 1995). When violations do not carry consequences, the effect can be even more damaging. Typically in this case, workers will begin to develop attitudes and beliefs that maintain violations as harmless. Such negative safety attitudes can lead to routine violations and lack of motivation to comply with safety procedures and rules, further escalating the likelihood of accidents and errors.

A substantial amount of research across industries has demonstrated the ubiquity of violations (e.g., Reason et al., 1990). What remains unanswered is why workers engage in violations when the potential for system failure and damaging consequences is so high. In order to address this issue and further define the nature of violations, Reason et al. (1994) differentiated among three types of violations: (a) shortcuts that become habitual (routine violations); (b) deviations that are part of an individual's performance style (optimizing violations); and (c) nonconformity with established rules and procedures to get the job done (situational violations). These violation types seek to accomplish inherently different goals. Routine and optimizing violations achieve nonfunctional goals (e.g., being the first to finish work or enjoying the rush of risky behavior). However, situational violations are functional instances of 
noncompliance that occur because of organizational constraints (e.g., improper safety rules and procedures or unavailable equipment).

Safety performance antecedents, errors, and violations. Besides actor intention, a further distinction between errors and violations lies in observed differences in how each is differentially related to antecedents of safety performance (Hofmann, Jacobs, \& Landy, 1995; Lawton \& Parker, 1998). Reason, Manstead, Stradling and Baxter (1990) found distinct psychological origins for errors and violations. The authors concluded that violations require explanation in terms of attitudinal and motivational factors while errors (slips, lapses and mistakes) require explanation in terms of cognitive factors. Lawton and Parker (1998) reiterated these findings in a review by stating that cognitive factors represent individual differences in committing errors and attitudinal and behavioral factors represent individual differences in committing violations. Further, Lawton and Parker (1998) discuss how personality factors influence both cognitive and behavioral antecedents and thus influence error and violation commission.

In order to attend to these issues properly, it is important to identify how antecedents and determinants of safety performance are related to the commission of errors and violations. First, cognitive factors are related to errors or unintentional slips, lapses or mistakes resulting in execution and planning failures. These failures are typically a result of information processing errors or skill/knowledge deficiencies that diminish safety performance and increase the probability of accidents. Because deficiency in knowledge of safety rules and procedures is likely to cause unintentional mistakes, cognitive factors (i.e., safety knowledge) relate to commission 
of errors. Second, safety attitudes and safety motivation explain why individuals choose to behave unsafely when they understand proper procedures and thus, represent violations or deliberate actions that lead to unsafe behavior. Taken together, safety judgment explains the error and violations process, while safety orientation solely focuses on the violation process. Lastly, personality factors are likely to affect commission of both errors and violations (Lawton \& Parker, 1998). For example, Wallace and Vondonovich (2003a) have found that low conscientious individuals are more prone to cognitive failures (error). On the other hand, highly conscientious individuals are less likely to violate safety rules and regulations (violations). In order to advance the prediction of safety performance a comprehensive set of antecedents and their demonstrated relationships to accidents and safety behavior will be described in the sections to follow.

\section{Personality and Safety Performance}

Stemming from the observation that a small portion of employees was often responsible for the majority of workplace accidents, early investigations regarding individual difference antecedents of safety behavior were concerned with the “accident prone person” (Greenwood \& Woods, 1919; Shaw \& Sichel, 1971). However, as a result of a lack of empirical support and indications that accident proneness was a mere artifact of inadequate statistical analysis, the accident proneness hypothesis has become obsolete (Zohar, 2004). Subsequent examinations have focused on how various dimensions of personality relate to safety outcomes and behavior. 
Personality represents a combination of intangible individual characteristics that describe what motivates individual behavior. Facets of personality have been shown to provide significant utility in predicting job performance across occupations and industries (Barrick \& Mount, 1991; Salgado, 1997). The most common and comprehensive measurement of personality is the Big Five Model, which consists of five dimensions including conscientiousness, agreeableness, neuroticism (v. emotional stability), extroversion, and openness to experience (Costa \& McCrae, 1985).

Various personality traits have been investigated as predictors of safety performance and accident occurrence. Cumulative evidence from recent metaanalyses suggests that conscientiousness (Clarke \& Roberston, 2005) and agreeableness consistently demonstrate relationships with accident occurrence (Clarke \& Roberston, 2005, 2008) and safety performance (Christian et al., 2009). Specifically, Clarke and Robertson (2005) found openness ( $\rho=.32)$, low conscientiousness $(\rho=.27)$, low agreeableness $(\rho=.26)$, neuroticism $(\rho=.21)$ and extraversion $(\rho=.16)$ to be related to accident involvement. However, only credibility values for low conscientiousness and low agreeableness exceeded zero. Thus, authors concluded that low conscientiousness and low agreeableness were valid and generalizable predictors of accident involvement. Clarke and Robertson (2008) found openness ( $\rho=.50)$, low agreeableness $(\rho=.44)$, low conscientiousness $(\rho=$ $.31)$, and neuroticism $(\rho=.30)$ to be positively correlated with accident involvement. Though both neuroticism and low agreeableness credibility values exceeded zero, artifacts associated with neuroticism (38\%) indicated probable situational specificity 
(see Hunter \& Schmidt, 1990). Artifacts accounted for $96 \%$ of the variability in low agreeableness suggesting that the relationship between low agreeableness and accident involvement consistent across organizational settings. Lastly, Christian and colleagues (2009) focused solely on conscientiousness as a predictor of safety performance because most studies considering personality predictors of safety performance have focused on this factor of the Big Five. Given these results, research associated with agreeableness and conscientiousness will be described in the following sections.

Conscientiousness. Conscientiousness is characterized by competence, order, achievement striving, self-discipline, and deliberation. Conscientious individuals are organized, conforming, dutiful, detail conscious and dependable (Barrick \& Mount, 1991; Goldberg, 1990). In general, the literature demonstrates a negative relationship between conscientiousness and accident involvement, such that low scorers on conscientiousness are more likely to be involved in accidents (e.g., Arthur \& Graziano, 1996; Cellar, Nelson, York, \& Bauer, 2001; Clarke \& Robertson, 2005, 2008; Wallace \& Vodonovich, 2003a). Related to deliberation and order facets, low thoroughness has also been associated with lack of future or contingency planning, and lack of logical and/or systematic decision making, all of which relate to accident involvement (West, Elander, \& French, 1993). Further, low scores on the dutifulness facet relate to lack of respect for authority, social maladjustment (Hansen, 1989) and social deviance (West et al., 1993). West et al. (1993) demonstrated that individuals high on social deviance were more likely to be involved in driving accidents because of an increased tendency for speeding. Speeding is a type of optimizing violation, 
wherein the action serves a nonfunctional goal and becomes an integral part of an individual's performance style. Thus, individuals higher on social deviance (low conscientiousness) would be more likely to engage in this negative form of rulerelated behavior.

Beyond accident involvement, conscientiousness is generally more likely to predict behaviors when individuals have control over their behavior (e.g., Salgado, 2002). For example, Clarke and Robertson (2005) reported that conscientiousness was a significant predictor of vehicle crashes but not of occupational injuries. Drivers have direct control over actions whereas workplace accidents are often influenced by contextual circumstances that exert limits on individual control over actions and consequences. Citing Clarke and Robertson's (2005) study, Geller, Clarke, and McKenna (2006) suggest that because individuals have a large degree of control over their safety behavior, conscientiousness is likely to play a role in safety performance.

Research has supported an association between conscientiousness and behavior in line with Gellar et al.'s (2006) suggestion. For example, individuals low in conscientiousness tend to engage in impulsive behaviors, ignoring potential consequences to themselves or others (West et al., 1993). In addition, individuals low in conscientiousness may lack self-control and demonstrate carelessness (Suchman, 1970), ignore potential risks to themselves or coworkers (West, et al., 1993), and fail to follow organizational policies and regulations (Arthur \& Doverspike, 2001). Conversely, research has shown that individuals high on conscientiousness are less likely to commit violations and more likely to exhibit effective safety performance. Wallace and Vodonovich (2003a) reported a significant, negative relationship 
between conscientiousness and unsafe behaviors $(r=-.33)$. In a recent meta-analytic investigation, Christian et al. (2009) reported a small but significant, positive relationship between conscientiousness and safety performance $(r=.18)$. Thus, it was expected that conscientious individuals would be more likely to attend to rules, standards, and procedures related to safety.

Hypothesis 1: Conscientiousness will be positively related to safety performance.

Agreeableness. Agreeableness is characterized by trust, altruism, compliance, and modesty (Barrick \& Mount, 1991). Individuals who are high on agreeableness are pleasant, tolerant, helpful, non defensive and generally easy to get along with (Hough, 1992). Extant literature generally reports that individuals with high levels of agreeableness are less likely to be involved in accidents (Cellar et al., 2001). Further, Clarke and Robertson $(2005,2008)$ have found low agreeableness to be a valid and generalizable predictor of occupational and vehicular accidents. Altruism and compliance, subfactors of low agreeableness, have received particular attention in studies of personality and accidents. Studies considering low altruism report significant positive relationships between accident involvement and egocentricity (Conger et al., 1959; Davids \& Mahoney, 1959; Shaw, 1965) as well as selfishness (Shaw \& Scichel, 1971). Further, high levels of aggression (low compliance) have been found to increase the frequency of accidents across a variety of occupations (Sah, 1989; Conger et al., 1959; Roy \& Choudhary, 1985).

Barrick and Mount (1991) postulate that agreeableness is most salient in interpersonal situations that involve collaboration with coworkers. The literature 
demonstrates that individuals low in agreeableness may be less able to cooperate with others and are more likely to respond aggressively to situations. It was expected that individuals high on agreeableness would be more likely to place importance on the safety of coworkers and maintain compliance with safety related organizational policies and managerial mandates to avoid conflict.

Hypothesis 2: Agreeableness will be positively related to safety performance.

Summary. The literature presented here demonstrates that conscientiousness and agreeableness are important antecedents of safety performance. Though these personality variables were expected to correlate with safety performance, they were not modeled to be directly related to safety performance in the proposed model. This decision is consistent with basic personnel selection principles and the safety performance framework proposed by Neal and Griffin (2004). First, though personality does provide valuable insight into a candidate's disposition, it only accounts for $10-30 \%$ of the variance in performance (Barrick \& Mount, 1991). Accordingly, organizations that employ evidence-based practices as means of selecting top performers rarely rely on personality as a sole predictor of effectiveness criteria. For example, Hunter and Burke (1994) note many unsuccessful attempts at using solely personality measures to select safe pilots.

Second, in a review of the vehicular accident literature, Beirnss (1993) concluded that despite overwhelming evidence that personality factors influence accident occurrence, the "contribution of personality factors to crash involvement is likely to be indirect, mediated by other factors and behaviors" (Lawton \& Parker, 1998; p. 4). Accordingly, Griffin and Neal (2004) and Christian et al. (2009) have 
found personality to be indirectly related to safety performance, through safety performance antecedents (e.g., safety knowledge and safety motivation). Together the evidence highlights the importance of including additional predictors of safety performance beyond personality factors to better understand the nature of the criterion space and the extent to which these predictors explain unique variance.

\section{Safety Judgment and Safety Performance}

Alkov (1996) defined good judgment as the general ability to make safe decisions. Similarly, safety judgment is characterized by making positive decisions such as performing job duties safely, advocating safe work practices and using sound judgment when deciding what to do in unsafe situations. Safety judgment has been of expressed interest to safety researchers within the aviation industry. The majority of empirical examinations within this area have considered methods to improve pilot safety judgment as a means of increasing overall in-flight safety performance (e.g., Dillman \& Lee, 2006; Hunter, 2003). In the general safety literature, however, very few studies have considered safety judgment as a predictor of safety performance. The operationalization of safety judgment to be used in this study is described below. Then, research describing traditional safety performance antecedents (i.e., safety knowledge, safety attitudes) is presented.

Safety judgment is a construct that recognizes the complexity of safe and unsafe behavior. Reason et al. (1990) notes that though errors and violations are distinct and commonly considered as independent unsafe acts, it is often the case that safety incidents are the result of both error types. Thus, by evaluating the process in which safety judgments are made, attitudes toward safety (mechanism of the 
violations process) and safety knowledge (mechanism of the error process) can be inferred. For example, a behavior may involve a deviation from established rules (violation resulting from negative safety attitudes), when in fact the action was derived from an inaccurate judgment of the situation and potential consequences (error in judgment and/or lack of requisite safety knowledge; Reason et al., 1990). Hence, faulty judgment can be the result of inadequate knowledge regarding what to do in a potentially dangerous situation and negative attitudes towards safety. The following sections summarize literature that has investigated how safety knowledge and safety attitudes are related to safety performance as means of providing evidence to support relationships between safety judgment and variables of interest.

Safety knowledge. Naturally, a precondition to behaving safely is having the knowledge of how to perform safely. Research has consistently demonstrated the importance of safety knowledge in regard to safety behavior. For example, Griffin and Neal (2000) investigated safety knowledge as a mediator between safety climate and two dimensions of safety performance (compliance and participation) in two studies. Across Study 1 and Study 2, incumbents who reported high safety knowledge were more likely to report following safety rules and regulations (compliance; $r s=$ $.50, .60$, respectively) and promoting safety in their organization (participation; $r s=$ $.53, .70$, respectively). Similarly, Probst (2004) found a positive relationship between safety knowledge and safety compliance $(r=.58)$ using Griffin and Neal's (2000) measures. In a recent meta- analysis, Christian et al. (2009) reported a significant correlation between safety knowledge and safety performance (mean $r=.61$ ). This correlation was, in fact, the highest reported relationship between safety performance 
and other person factors analyzed, including conscientiousness and job attitudes. Further, evidence demonstrated no difference in how safety knowledge related to Griffin and Neal's (2000) factors of safety performance (compliance and participation). Similarly, Vinodkumar and Bhasi (2010) reported a positive relationship between safety knowledge and safety compliance $(r=.65)$ and participation $(r=.52)$.

Research has also demonstrated a positive relationship between specific knowledge areas and safety behavior. Sjoberg and Drottz-Sjoberg (1991) found that nuclear plant workers who lacked general radiation knowledge experienced greater perceived risk (e.g., subjective probability of negative safety outcome). Similarly, McGovern et al. (2000) found that hospital workers with higher knowledge of HIV transmission were more likely to display general safety compliance behaviors than those participants who failed to demonstrate adequate knowledge. Eklof and Torner (2002) found a positive relationship between sufficiency of technical knowledge of equipment and self-reports of activity in safety work (sample item: "I try to find methods and equipment to improve safety"), a performance construct similar to safety participation. Further, technical knowledge accounted for $29 \%$ of the variance in activity in safety work, suggesting that knowledge may be a key determinant of safety participation.

Other researchers have differentiated between Campbell et al.'s (1993) knowledge determinants to better understand the role of knowledge in behavior. Burke et al. (2002) examined the relationship between two knowledge constructs, breadth of knowledge and depth of knowledge, and supervisor rated safety 
performance among hazardous waste workers. Breadth of knowledge represented Campbell's definition of declarative knowledge, and was indicated by the number of different courses a worker had taken and passed (e.g., lead control, lock and tag, packaging and transport, radiological control) to gauge the variety of topics the workers were familiar with. Depth of knowledge represented "the mastery and maintenance of procedural knowledge and skills" (p. 440, Burke et al., 2002) and was indicated by the number of general safety training and refresher courses a worker had taken and passed. Thus, depth of knowledge was concerned with safety specific knowledge. Findings suggested that general knowledge of safety procedures and how to enact safety behaviors (depth of knowledge) was more a determinant of safety performance than having a wide range of knowledge in various specific safety topics (breadth of knowledge). Breadth of knowledge was not related to overall safety performance $(r=.07)$ however; the composite of depth of knowledge factors (knowledge of using PPE, engaging in work practices to reduce risk and general safety) demonstrated a significant positive relationship with overall safety performance $(r=.22)$. The authors concluded that lack of support for the breath of knowledge - safety performance relationship was likely a result of the nature of the criterion, which was more focused on routine tasks that likely have been proceduralized. Further, the authors proposed that breath of knowledge would be related to safety performance in unfamiliar situations where an individual would be forced to rely on available resources (declarative knowledge). These findings also lend support to Rassmussen's definition of knowledge-based performance. Recall that each stage in Rassmussen's (1983) model of task performance, knowledge is applied 
in various capacities to perform routine tasks and procedures (skill level), and problem solving in familiar (rule level) and unfamiliar situations (knowledge level). In addition, resource allocation models of skill acquisition and performance also suggest that an individual's response to an unfamiliar task will be heavily dependent on available resources (e.g., declarative knowledge and cognitive abilities; Kahneman, 1973; Kanfer \& Ackerman, 1989).

Safety attitudes. Safety attitudes offer a plausible explanation for why some individuals choose to violate safety rules and procedures while others choose to comply. Safety attitudes are often observable through safety behaviors; while positive safety attitudes tend lead to safe behaviors, negative safety attitudes may cause unsafe behaviors. For instance, Kilborne (2009) proposed that individuals with positive safety attitudes are more likely to take responsibility for personal and coworker safety, know and follow safety rules, use required protective equipment, pay attention to hazards, report safety hazards that cannot be fixed and participate in safety training. In contrast, Kelley (1996) suggests negative safety attitudes might be observed through undesirable worker behavior characteristics such as apathy, complacency, hostility, impatience, impulsiveness, impunity, invulnerability, negligence, over-confidence, recklessness, and lack of ownership.

The workplace safety literature has examined various perceptions, attitudes, behaviors and dispositions towards safety (Clarke, 2006; Neal \& Griffin, 2004). Researchers have created different measures that vary in terms of content and intended industry applications. Often these measures do not differentiate between perceptions of safety (safety climate) and feelings and beliefs about safety (safety 
attitudes). In fact, many measures in the literature claim to measure safety attitudes, but rather are measuring safety climate constructs (e.g., Alexander, Cox, \& Cheyne, 1995; Cox \& Cox, 1991; Mearns et al., 1995, 1998, 2001; Rundmo, 1994; Williamson, Feyer, Cairns, \& Biancotti, 1997). Several of these empirical examinations have provided evidence to suggest that safety attitudes predict safety performance and substantiated the claim that individuals who hold more positive attitudes towards safety are more likely to engage in proper safety behaviors and less likely to be involved in an accident or incur an injury (e.g., Donald \& Canter, 1994; Tomas, Melia, \& Oliver, 1999). In most cases, the focus of these measures was not to assess individual attitudes toward safety, but rather assess perceptions of environmental and organizational factors such as management commitment and coworker involvement.

For the purposes of the present dissertation three related distinctions are made between safety attitudes and safety climate based on their definitions, level of analysis and appropriateness for assessment in the personnel selection context. First, though safety attitudes are positively related to safety climate constructs they are also distinct from such environmental/organizational factors (Dedobbeleer \& Beland, 1991; Henning et al., 2008). Second, by definition safety climate is a construct that considers incumbent perceptions of a particular organization while, safety attitudes consider individual attitudes toward safety in general. In the personnel selection context, it is not possible to assess an individual's feelings about a hiring organization he/she has not yet developed evaluative dispositions toward. Lastly, the safety climate and safety attitudes are appropriately analyzed at different levels of analysis. As 
mentioned previously, safety climate is an aggregate of individual level perceptions of an organization's safety polices and procedures (e.g., Burke et al., 2002). Safety attitudes represent individual feelings and beliefs about safety. In personnel selection, unit-level analyses are inappropriate. Hence, the present dissertation considers safety attitudes to be demonstrated through an individual's level of safety judgment.

Safety attitude measures that include both attitudinal and perceptual (i.e., safety climate) content make it difficult to present described relationships with safety performance accurately. To illustrate the importance of attitudes in predicting safety performance, the literature must first be disentangled to solely demonstrate the relationship between safety attitudes and safety performance. Much of the safety attitude literature suggests the utility of using individual attitudinal constructs in predicting safety outcomes and performance. For example, Hofmann and Stetzer (1996) found an individual attitudinal factor, personal responsibility for safety, was more proximally related to safety performance than contextual factors within the same measure. Similarly, Mearns, Flin, Gordon, and Fleming (2001) found a factor of safety attitudes, pressure for production, to be significantly predictive of safety outcomes and behaviors, accounting for $12 \%$ of the variance in accidents/near misses and $57 \%$ of the variance in self-reported safety behavior. Mearns and colleagues' (2001) safety attitudes scale included five factors: (1) incident reporting; (2) pressure for production; (3) supervisor commitment to safety; (4) rules and regulations; and (5) management commitment to safety. Of the five safety attitude factors considered, pressure for production is the only factor that can be considered a purely attitudinal construct. Unfortunately, pressure for production included items considering both 
individual attitudes toward commission of violations (sample item: "If I didn't take a risk now and again the job wouldn't get done") and perceptions of organizational pressures (sample item: "My supervisor sometimes turns a blind eye when safety rules are broken"). However, the individual attitude items loaded onto the factor more strongly $(.77-.69)$ than organizational items $(.56-.41)$ suggesting that the majority of the factor was accounted for by individual attitudes. Though these findings suggest that individual attitudes toward safety are predictive of safety performance and accidents, the reported effects are likely confounded by inconsistencies in construct definitions.

Other empirical examinations have investigated safety attitudes using measurement methods that focus solely on individual feelings and beliefs toward safety, thereby accurately demonstrating the effect of attitudes on subsequent safety behaviors and outcomes. The majority of these studies consider the relationship of various specific safety attitudes (e.g., toward risk, wearing seat belts, traffic safety) with risk taking (a behavioral criterion synonymous with unsafe behavior) and safety compliance behaviors. Holt, Boehm-Davis, Amendola, and Sweeney (1994) found undergraduate attitudes toward driving safety to be significantly positively correlated with seat belt usage, and negatively correlated with moving violations and accidents (as cited in Hunter, 2005). Similarly, Chen (2009) found negative attitudes toward traffic safety were associated with risky driving behaviors in Taiwanese motorcyclists. McGovern et al. (2000) found health care workers who reported negative attitudes toward risky behavior (sample item: "I prefer new and exciting 
experiences even if they might be dangerous") were more likely to comply with universal precaution practices regarding exposure to blood borne pathogens.

Rundmo (1996) found negative attitudes toward safety to influence various risk behaviors including: ignoring safety regulations, carrying out forbidden activities, performing work duties incorrectly, taking chances to get the job done, not using protective equipment, and breaking rules and established procedures. Brown, Willis, and Prussia (2000) investigated the influence of social, environmental, and human factors on safe behavior by exploring attitudes toward safety as an innate tendency toward risk-taking (i.e., cavalier attitudes). Cavalier attitudes were operationalized as the "extent to which an employee feels that he or she can ignore safety procedures without incurring the risk of an accident or injury" (Brown et al., 2001, p. 449). Indicators of cavalier attitudes included working without safety rules, ignoring safety rules to save time, and viewing safety procedures as unnecessary. Results indicated individuals who reported low caviler attitudes were more likely to demonstrate effective safety behaviors.

\section{Risk perception: Link between safety attitudes and knowledge. Fazio}

(1986) suggests that attitudes influence behaviors by selectively activating various thought processes held in memory. Thus, when individuals with different attitudes are confronted with a potentially dangerous situation, they are likely to regard different aspects of the situation as salient or important. These findings suggest that individuals with positive safety attitudes are likely act differently than individuals with negative safety attitudes, determined by their differential focus on particular features of the situation. In addition, individuals with varying levels of safety knowledge may 
choose to address hazardous situations differently, applying rules, and procedures that reflect their relative safety expertise.

Risk perception is closely related to how variations in safety attitudes and safety knowledge influence behavior. Specifically, risk perception represents the ability of workers to recognize environmental hazards that may result in accident or injury and take action to minimize those hazards. Individual variations in risk perception are likely to differentially affect attitudes towards risk. Individuals with low risk perception feel that encountered hazards are familiar, controllable, understood, preventable and consequential. Conversely, individuals who perceive high risk feel that the hazard encountered is unusual, catastrophic, unknown, and uncontrollable. Naturally, individuals who perceive high risk are likely to respond differently to encountered hazards than those who perceive low risk in the same situation. Further, McLain (1995) demonstrated that individuals with high-risk perception were more likely to experience task distraction, due to overattention to existing hazards, thereby increasing accident involvement.

Findings also suggest that, together, safety knowledge and safety attitudes play a significant role in risk perception process. Gellar (1996) suggests risk perception is related safety knowledge in that the more a person knows about risk, the less threatening it becomes, thereby increasing the likelihood that the situation will be handled appropriately. Further, Mearns and Flin (1995) developed a risk perception process model to describe the causal progression by which hazard perception and risk assessment lead to attitudes toward risk, unsafe behavior, and accidents. The model suggests that the ability of an individual to sense a hazard involves knowledge of 
risks associated with the referent hazard. Knowledge of risk is determined by an individual's experience with similar hazards, and how much training he or she has received regarding proper judgment of risk and appropriate handling of such hazards. Further, knowledge of risk is a determining feature of an individual's attitude toward risk in the model. Similar to the propositions made by Means and Flin (1995), Donald and Canter (1994) suggest that, collectively, the frequency of workplace accidents, knowledge of the ways in which accidents occur, and their relative degree of hazardousness contribute to the formation of safety attitudes. Further, biased perception of risk can cause misjudgments of potentially dangerous situations. Rundmo (1996) notes the poor judgment of risks are likely to cause unsafe behavior resulting from inappropriate responses to dangerous situations, inappropriate decisions with regard to which safety measures to apply, and accidents and injuries.

The risk perception process described here involves specific judgments of the situation, in this case, proper assessments of hazardous situations. Safety judgment is a similar concept, as is concerned with the manner in which individuals assess a situation when faced with a safety threat. The construct differs from risk perception however, because it considers specific behaviors enacted to address not only catastrophic, but common safety threats such as failing to report minor injuries or using short cuts. In sum, the evidence presented here clearly shows a link between safety attitudes, safety knowledge, and safety performance. Further, because safety judgment is comprised of these factors, it is expected that it will also be related to safety performance. 


\section{Hypothesis 3: Safety judgment will be positively related to safety}

performance.

Safety judgment and personality. As a result of specific features of the predictor method used to assess safety judgment in the present study (i.e., situational judgment test, SJT) and demonstrated relationships between attitudes and personality, it is expected that safety judgment will be positively related to personality. First, McDaniel and colleagues (McDaniel, Hartman, \& Grubb, 2003; McDaniel \& Whetzel, 2007) demonstrated that the format of SJT response instructions lead to greater associations with individual difference constructs. Specifically, response instructions (used in the present study) that ask applicants to select the behavior they would most likely display in a given situation (behavioral tendency instructions) are

more likely to be related to personality constructs, whereas response instructions that ask applicants to indicate the best option among answer choices (knowledge instructions) are typically more related to cognitive ability.

Second, evidence suggests that personality is related to attitudes. McCrae and Costa (1996) argue that individual differences influence the development of characteristic adaptations. Specifically, the authors suggest that basic personality tendencies guide behavior in specific situations, resulting in the development of habits, knowledge and attitudes. McCrae and Costa's (1996) proposition has been supported in relation to safety attitudes. For example, Ulleberg and Rundmo (2003) found facets of low agreeableness (aggression), and low contentiousness (normlessness, similar to dutifulness facet; Kohn \& Schooler, 1983) to be negatively related to attitudes toward traffic safety. Further, altruism, a facet of high 
agreeableness, was positively related to traffic safety attitudes. Similarly, Henning et al. (2008) reported general safety attitudes were related to both agreeableness $(r=$ .46) and conscientiousness $(r=.36)$. Because the construct of safety judgment includes safety attitudes, it is expected that safety judgment will be related to both conscientiousness and agreeableness based on these findings.

Hypothesis 4: Conscientiousness will be positively related to safety judgment.

Hypothesis 5: Agreeableness will be positively related to safety judgment.

Possible mediators of the relationship between attitudes and behavior. A common assumption is that attitudes are directly related to behavior. However, Gellar et al. (2006) cautions against a simplistic "attitudes influence behavior" explanation of the relationship between attitudes and behaviors. Put simply, an individual's behavior cannot be predicted by simply knowing that the worker holds a positive attitude toward safety, thus suggesting possible mediators of this relationship must be considered.

A significant amount of empirical investigation has been devoted to developing theories to explain the mechanism by which attitudes influence behavior. These theories and definitions of attitudes commonly cite motivation as a mechanism to explain how attitudes relate to behavior. For example, Fishbein and Ajzen (1975) define attitudes, as a learned tendency to act in a consistent manner towards a particular object or situation. Notably, the definition implies that attitudes are determined by a tendency to act in a particular manner, implying that attitudes influence motivation required for behavior. Further, the tendency to act is consistent, 
in that past behavior and attitudes are likely to be observed through future behavior and attitudes.

A theory proposed later by the same authors expands upon the previously stated attitude definition. The Theory of Planned Behavior (TPB: Ajzen, 1985, 1991; Fishbein \& Ajzen, 1975) describes the importance of motivational and contextual factors in the attitude-behavior link. The theory posits that attitudes lead to behavior through behavioral intention, which is defined as an individual's intention to perform behavior. Thus, behavioral intention represents the degree to which an individual is motivated to act. According to TPB, behavioral intentions are determined by individual attitudes toward particular behaviors, perceived social pressure to perform or not perform the behavior (subjective norm), and the ease or difficulty associated with performing the behavior (perceived behavioral control). Attitudes toward behavior represent an individual's evaluation of the degree to which a behavior will result in a positive or negative consequence (behavioral beliefs) and his or her evaluations of outcomes associated with those consequences (outcome evaluation). The influence of subjective norms is determined by the individual's perception of the extent to which others think they should engage in the behavior (normative beliefs) and the degree to which they are motivated to comply with other's perceptions. Relevant to the present study, TPB indicates that the relationship between safety attitudes and safety behavior is mediated by safety motivation. In other words, positive safety attitudes will not produce safe behaviors, unless the intention to act safety (safety motivation) exists. 
Summary. Literature regarding safety knowledge and safety attitudes suggests that safety judgment is an important predictor of safety performance. Though empirical evidence exists to support safety knowledge as a determinant of safety performance (Burke et al., 2002; Christian et al., 2009; Larsson et al., 2008; Griffin \& Neal, 2000; Neal et al., 2000; Vinodkumar \& Bhasi, 2010), it is clear that mediating forces are present when it comes the relationship of safety attitudes and safety behavior (e.g., Ajzen, 1985, 1991; Fishbein \& Ajzen, 1975, 1977). Thus, safety judgment is more likely to be an antecedent of safety performance, rather than a determinant. The next section examines safety orientation as the key determinant of safety performance in the predictive model proposed later in the current chapter.

\section{Safety Orientation and Safety Performance}

Safety orientation is defined as the inclination to act safe at work as

demonstrated through worker behavior. A worker with high safety orientation would follow established safety rules, use required safety equipment, read and/or listen to safety warnings, and avoid on-the-job accidents. Effectively, safety orientation operates on the basic hiring principle that past behavior is the best predictor of future behavior. As such, if an individual has demonstrated a tendency to act safely in the past, it can be inferred that they will likely behave safely in the future. Safety orientation is expressly important to personnel selection as it offers a first line defense against hiring unsafe workers by providing decision makers the opportunity to identify poor safety performers on the basis of their past behavior.

Earlier, it was suggested that safety orientation represents safety motivation, namely due to the consistent relationship between motivation and behavior. Research 
introduced in Chapter I and summarized in detail within the section to follow demonstrates that the likelihood of effective safety behavior is extremely low without to motivation to act safely (e.g., Buck, 2008; Christian et al., 2009; Griffin \& Neal, 2000; Neal \& Griffin, 2006; Probst \& Brubaker, 2001; Vinodokumar \& Bhasi, 2010). Safety motivation signifies an individual's willingness to put forth effort to act in a safely and the value an individual places on safe behaviors (Neal \& Griffin, 2006), thus, safety orientation is similar to safety motivation, in that it represents the degree to which an individual is motivated to act safety.

Though alike, safety motivation (e.g., Griffin \& Neal, 2000; Neal \& Griffin, 2006) and safety orientation differ in how behavioral tendencies are assessed. Specifically, safety motivation represents an individual's feelings and beliefs toward the value and importance of specific compliance (e.g., "It is important to consistently use the correct personal protective equipment”; Griffin \& Neal, 2000) and participatory (e.g., "I believe it is important to promote our safety program"; Griffin \& Neal, 2000) safety behaviors. Conversely, safety orientation considers an individual's past safety behavior, and uses this information to infer the degree to which that individual is motivated to perform safely, and the likelihood that he or she will demonstrate effective safety performance in the future.

Because safety orientation is a novel construct, the following section will present literature on safety motivation as support for later hypotheses. It should be noted that Zachartos, Barling, and Iverson (2005) used a construct similarly named "personal safety orientation" as an indicator of safety performance, to investigate the relationship between high-performance work systems and occupational safety. In the 
study, personal safety orientation was modeled as a latent variable, indicated by determinants of safety performance (i.e., safety knowledge and safety motivation) and components of safety performance (i.e., compliance and participatory safety behaviors) as operationalized by Neal and colleagues. Though similar in name, personal safety orientation and the safety orientation construct considered presently are not the same, namely as a consequence of how the constructs are treated and defined. In the present study, safety orientation is not treated as an outcome, but rather a predictor of supervisor-rated safety performance. Because safety incidents (i.e., injuries requiring first aid and near misses) were also considered as an outcome in the model, Zachartos et al. (2005) did not report the relationship between these latent variables; the authors only reported intercorrelations between indicator measures (e.g., the relationship between safety motivation and near misses). Further, the present conceptualization of safety orientation does not directly assess safety knowledge, as did personal safety orientation.

Safety motivation. Empirical findings have consistently demonstrated the relationship between safety motivation and safety performance. Griffin and Neal (2000) considered the relationship between components of safety performance (compliance and participation) and two dimensions of safety motivation: motivation to perform safety related tasks (compliance; sample item: "It is important to consistently use the correct personal protective equipment"), and motivation to take part in activities that support safety in the organization (participation; sample item: "I believe that it is important to promote our safety program"). Compliance motivation was moderately correlated with both safety compliance $(r=.32)$ and safety 
participation $(r=.26)$. Participation motivation was moderately correlated with both safety compliance $(r=.29)$ and safety participation $(r=.53)$. Taken together, these findings suggest that individuals who report a high willingness to perform job duties safely will be more likely to report behaving safely on the job. Christian et al. (2009) supported this notion in a recent meta- analysis, where overall safety motivation was found to be strongly associated with overall safety performance (mean $r=.57$ ). Vinodokumar and Bhasi (2010) demonstrated a positive relationship between safety motivation and safety compliance $(r=.39)$ and participation $(r=.43)$ behaviors. Similarly, Buck (2008) reported safety motivation was positively associated with safety compliance $(r=.51)$ and participation $(r=.47)$.

Longitudinal investigations have provided evidence to suggest that, over time, individuals high on safety motivation may demonstrate positive changes in safety performance. Probst and Brubaker (2001) found that safety motivation had a lagged effect on safety compliance 6 months later. It is important to note that safety motivation in this case was defined extrinsically as "the employees degree of incentive to adhere to their organizations safety regulations" (p. 140; Probst \& Brubaker, 2001). Lagged effects were also reported by Neal and Griffin (2006), who measured safety motivation and safety performance at two time points, over a period of four years. Individual safety motivation at Time 1 was associated with positive changes in individual safety participation in Time 2 . However, there was no observed effect of Time 1 motivation on safety compliance at Time 2 . Thus, employees who are motivated to act safely are more likely to engage in activities that contribute to 
overall workplace safety. However, over time, this willingness does not change the likelihood that employees will comply with safety rules and procedures.

Unlike the consistent relationships demonstrated between safety motivation and safety performance, evidence of a relationship between safety motivation and safety outcomes has been mixed. Some evidence suggests that individuals who value safety and are motivated to put forth effort to act safely are less likely to be involved in accidents. For example, Newnam, Griffin and Mason (2008) reported individual safety motivation was negatively associated with work-related motor vehicle accidents, such that workers who were more willing to follow driving rules regulations were less likely to be involved in an accident. Other researchers have failed to find a relationship between safety motivation and objective safety indicators (i.e., injuries requiring first aid and near misses; Zacharatos et al., 2005). These results can be taken to suggest that because motivation is a determinant of behavior, relationships with objective measures of performance are likely to be indirect, mediated by safety performance. Further, these findings explain why the majority of researchers have considered safety performance as a mediator between predictors of safety performance (i.e., antecedents and determinants) and objective outcomes. Using safety motivation as a mediator in a recent meta-analysis, Christian et al. (2009) reported that the indirect effect of safety motivation on accidents and injuries was -.16, while the direct effect of safety performance on accidents and injuries was -.31. These results suggest safety motivation leads to effective safety performance, which in turn, reduces the risk of accidents and injuries. 
In sum, given the consistent relationship between safety motivation and safety performance, it is expected that safety orientation will be related to safety performance.

Hypothesis 6: Safety orientation will be positively related to safety performance.

The past sections described relationships between predictor constructs of interest and safety performance, leading to hypotheses in accordance with those findings. Models jointly reflecting these literatures are described in the next and final section of the present chapter. Specifically, evidence to support hypothesized direct and indirect effects are described in support of two proposed structural models: (1) a predictive model of safety performance (Figure 2); and (2) an integrative model of safety and job performance (Figure 3).

Figure 2

The Predictive Model of Safety Performance

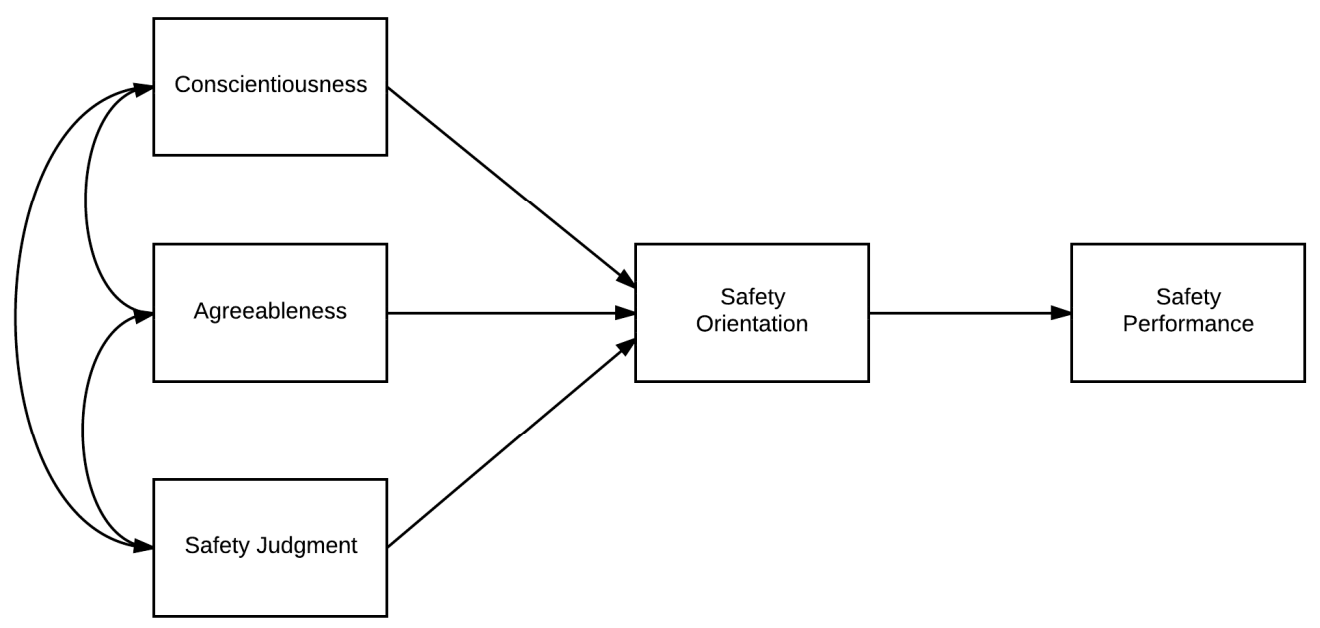




\section{The Predictive Model of Safety Performance}

On the basis of previous models of job and safety performance (Chapter I) and literature regarding safety performance antecedents and determinants (Chapter II), two general postulations regarding the proximity of constructs to safety performance are made in Figure 2. First, the model proposes that conscientiousness, agreeableness, and safety judgment are antecedents of safety performance. Second, the model proposes that safety orientation is a determinant of safety performance. Theoretical rationale for the proposed direct effects and indirect effects depicted in Figure 2 are described below, leading into a discussion of the second proposed model.

Direct effects. Four direct effects are proposed in Figure 2. Moving from left to right, each is described here. First, personality factors of conscientiousness and agreeableness were expected to be directly related to safety orientation. Previous research has consistently demonstrated that individual differences in personality are related to safety motivation, lending support to this statement. For example, in a recent meta-analysis, Christian et al. (2009) reported a significant relationship between conscientiousness and safety motivation $(\rho=.16)$. Further, Buck (2008) found safety motivation to be positively related to facets of conscientiousness $(r s=.25-.39)$, and facets of agreeableness $(r s=.17-.34)$. These results suggest that highly agreeable and conscientious individuals are more likely to report behavior consistent with a tendency to act safely.

Hypothesis 7: Conscientiousness will be positively related to safety orientation.

Hypothesis 8: Agreeableness will be positively related to safety orientation. 
Second, safety judgment was expected to be directly related to safety orientation. Earlier in the present chapter, the close theoretical relationship between attitudes and motivation was described. Empirical evidence suggests that an individual's attitude to safety and motivation to act safety are positively related, such the positive safety attitudes are likely to influence high safety motivation (Newnam et al., 2008). In addition, to the relationship between safety attitudes and motivation, various tests of Neal and Griffin (2004) models have demonstrated a positive relationship between safety knowledge and safety motivation (Christian et al. 2009; Probst \& Brubaker, 2001). Because safety judgment is comprised of safety attitudes and knowledge, it was expected that safety judgment and safety orientation would be related.

Hypothesis 9: Safety judgment will be positively related to safety orientation.

Lastly, hypothesis 6 suggested that safety orientation would be directly related to safety performance. This hypothesis is modeled in Figure 2 as a direct effect. Research presented earlier in this chapter clearly demonstrates that individuals with a high inclination to act safety are more likely to demonstrate effective safety behavior.

Indirect effects. In addition to direct effects, three indirect effects that serve to pose safety orientation as a determinant of safety performance in the model are proposed. First, it was expected that safety orientation would mediate the relationship between conscientiousness, agreeableness, and safety performance. Literature presented earlier demonstrates that the relationship between personality and safety performance is mediated by safety performance determinants (Beirnss, 1993; Christian et al., 2009; Griffin \& Neal, 2004; Lawton \& Parker, 1998). Specifically, 
this evidence establishes safety motivation as a proximal predictor of safety performance, as the construct consistently yields larger relationships with safety performance than personality (Christian et al., 2009) and other person-based factors (Neal \& Griffin, 2006).

Particularly relevant to the present dissertation, research has also demonstrated that facets of agreeableness and conscientiousness are indirectly related to safety performance though safety motivation. Buck (2008) tested Neal and Griffin's (2004) model and showed safety motivation mediated the relationships between a dimension of agreeableness (morality) and both safety compliance and safety participation. In a separate analysis, safety motivation mediated the link between a dimension of conscientiousness (cautiousness) and dimensions of safety performance. Given this evidence, it was expected that safety orientation would mediate the relationship between personality factors and safety performance.

Hypothesis 10: Safety orientation will mediate the relationship between conscientiousness and safety performance.

Hypothesis 11: Safety orientation will mediate the relationship between agreeableness and safety performance.

Second, safety orientation was expected to explain the relationship between safety judgment and safety performance. As noted earlier, the Theory of Planned Behavior (Ajzen, 1985, 1991; Fishbein \& Ajzen, 1975) demonstrates that attitudes lead to behavior, though a motivational construct, behavioral intention. In the safety context, TPB implies that having a positive attitude toward safety is not sufficient to produce safety behavior without the intention or motivation to do so. In support of 
this notion, Newnam et al. (2008) found evidence to suggest that individual motivations are a more proximally related to safety outcomes than attitudes. Specifically, the authors found that attitudes towards rule violations (e.g., speeding) were positively related to safety motivation, which in turn predicted self-reported driving accidents at work.

Hypothesis 12: Safety orientation will mediate the relationship between safety judgment and safety performance.

Taken together, evidence supporting hypothesized indirect effects suggests that safety orientation is a more proximal predictor of safety performance than personality factors (hypothesis 10 and hypothesis 11) and safety judgment (hypothesis 12). Thus, it was expected that safety orientation would explain additional variance in safety performance above and beyond personality and safety judgment.

Hypothesis 13: Safety orientation will predict safety performance over and above a) conscientiousness, b) agreeableness and c) safety judgment.

\section{The Integrative Model of Safety Performance and Job Performance}

Safety performance is not the sole performance outcome important to organizations. Beyond working safety, employees are expected to deliver products and services that contribute to organizational success. To demonstrate that selecting safe workers does not negatively affect job performance, the predictive model of safety performance was extended to include the relationship between safety performance and job performance in a second proposed model (see Figure 3). In addition to the direct and indirect paths hypothesized in the first model, it was 
proposed that: (1) conscientiousness would be positively related to job performance (direct effect); (2) safety performance would be positively related to job performance (direct effect); and (3) safety performance would serve as a mechanism to explain the relationship between predictors of safety performance and job performance (indirect effect). Evidence of this kind would further support the utility of selecting individuals using safety predictors in industries where workplace safety is critical.

Figure 3

The Integrative Model of Safety Performance and Job Performance

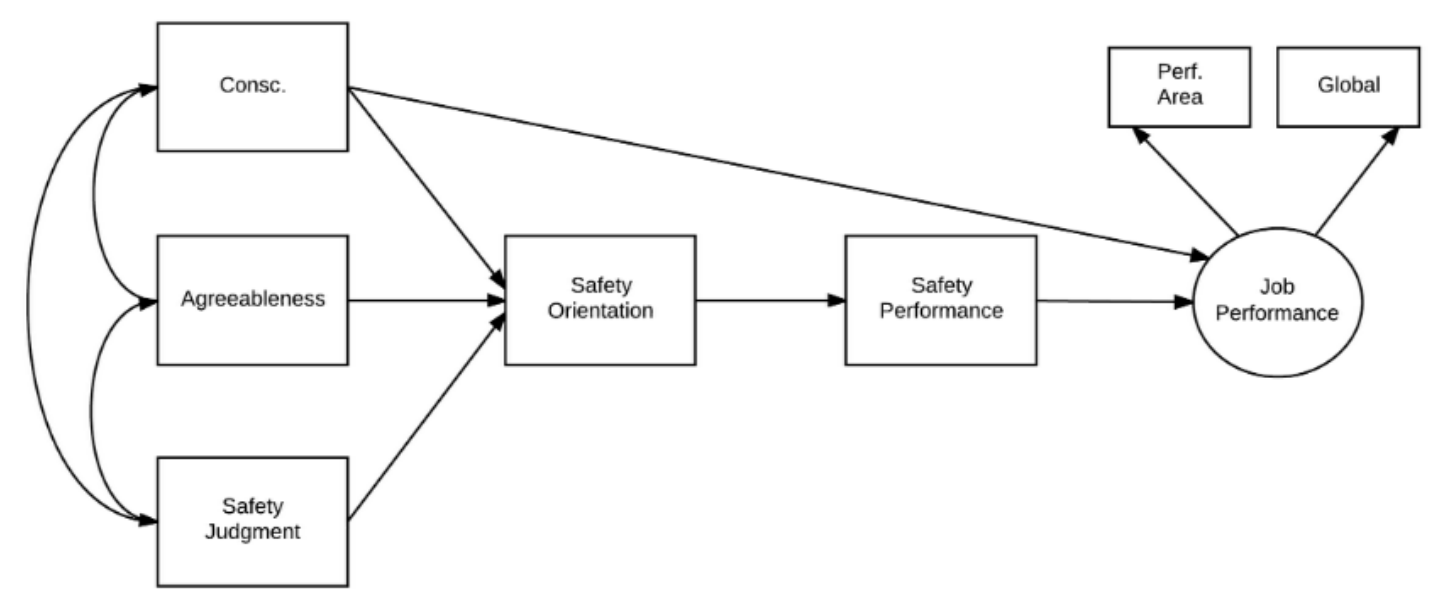

First, extant research demonstrates that across a variety of jobs, conscientiousness is a strong and consistent predictor of job performance (Barrick, Mount, \& Judge, 2001). As such, conscientiousness was expected to be directly related to job performance. Safety specific predictors, including safety judgment and safety motivation, were not expected to be directly associated with job performance, but rather indirectly related to job performance through their relationship with safety performance. Further, agreeableness was not expected to be directly related to job performance, as it is a more safety-relevant personality factor (e.g., Cellar et al., 
2001; Clarke \& Robinson, 2005, 2008) and has not been empirically related to job performance (Barrick et al., 2001).

Hypothesis 14: Conscientiousness will be positively related to job performance.

Second, many empirical examinations have focused on the conflict between safety performance and production, an objective indicator of job performance (e.g., Anasiewicz, 1962; Faverge, 1980; Heinrich, 1950; Janssens, Brett, \& Smith, 1995; Kjellen, 1984; Leplat \& Rasmussen, 1984; Wallace \& Chen, 2006), citing many instances where the amount of tasks completed (productivity) is often in contention with complying with safety-related rules and regulations (safety performance). Thus, reported relationships between these two criteria are often negative, such that gains in productivity result in unsafe behaviors. Productivity is not concerned with behavior however, but rather the quantity of work. Further, quantity of work does not always mean that the outcome of such productivity is desirable or satisfactory. Current conceptualizations of job performance (e.g., Campbell et al., 1993) view performance as reflecting behaviors, rather than reflecting outcomes. For example, job performance behaviors could include: demonstrating effort, driving for results, producing high work quality, and demonstrating integrity and professionalism. These behaviors are likely to demonstrate a positive relationship with safety performance, because of the positive nature of behavior comprised in both criteria. For example, an employee who complies with safety rules and avoids short cuts (positive safety performance behaviors) will also be likely to demonstrate integrity and dependability (positive job performance behaviors). 
Very few studies have considered the relationship between safety and job performance behaviors. However, those that have lend support the expectation that individuals who demonstrate effective safety performance will also demonstrate effective overall job performance. For example, Casillas, Robbins, McKinniss, Postlethwaite, and Oh (2009) reported that measures of safety behavior and task performance were positively related $(r=.33)$, supporting a similar finding by Schmidt, Thoreson, Le, Ilies and Holland (2001; as cited by Casillas et al., 2009). Hypothesis 15: Safety performance will be positively related to job performance.

Finally, from a practical standpoint, there is significant utility in demonstrating that safety performance is related to job performance. A positive association between both performance outcomes would substantiate use of safety performance predictors in selection. Validity, or the relationship between a predictor and criterion, is the cornerstone of legal defensibility. For the validity of a safety-based selection method to hold up to scrutiny, predictors must be predictive of both safety performance and job performance. Here, it is proposed that safety performance predictors (e.g., conscientiousness, agreeableness, safety judgment, and safety orientation) are related to job performance through their relationship with safety performance.

Hypothesis 16: Safety performance will mediate the relationship between predictors of safety performance and job performance. 


\section{Predictor Methods}

Many selection tests are construct centered in that they are designed to measure a specific construct (e.g., conscientiousness, agreeableness) and are therefore labeled on the basis of the construct(s) that they are intended to measure (e.g., personality test). In contrast, predictors such as structured interviews, biodata and SJTs are frequently developed using a job-centered approach, such that these tests are designed to simulate aspects of the work itself rather than measure a specific predictor construct (Roth, Bobko, McFarland, \& Buster, 2008). Job-centered approaches to measurement do not neatly assess one specific construct; rather they may tap into various important constructs simultaneously (Christian, Edwards, \& Bradley, 2010; Weekly \& Jones, 1999).

Both SJTs and biodata are behavioral assessments, where applicants indicate the behavior they would display in a hypothetical situation (SJT) or how they had behaved in the past (biodata). As such, an individual's standing on constructs measured by each method can be inferred by the selected answer choice. Below, both predictor methods are defined and their general use in personnel selection is described as means of introducing the novelty of these predictor methods for selecting safer employees. Chapter III will provide more specific detail on the measurements used in the present study.

Biographical data. Typically, biodata assesses characteristics of an applicant's life including education and previous work experience to distinguish between effective and ineffective performers. As a predictor of job performance, biodata has demonstrated high criterion-related validity $(r=.34$; Hunter \& Hunter, 1984). Within 
the safety context, empirical investigations have primarily focused on demographic biodata questionnaires including questions about the individual's tenure, experience, training, age, and gender (e.g., Hansen, 1989, McGovern et al., 2000; Paul \& Maiti, 2007). However, the method can be developed to assess a wide variety of applicant characteristics to suit the requirements of the job in question.

Situational judgment test. Situational judgment tests (SJT) are designed to assess an applicant's judgment of job related situations (Weekley \& Ployhart, 2005) and typically include constructs that assess declarative and/or procedural knowledge (Christian et al., 2010). As a predictor of job performance, SJTs have demonstrated reasonable criterion-related validity in meta-analyses (mean $r=.26$; McDaniel et al., 2001) and parallel form reliability (.76; Chan \& Schmitt, 2002). Similar to biodata, SJTs can be designed to assess a variety of constructs. Situational judgment tests have been used in the aviation context to assess judgment and decision-making changes after training (Driskill, Weissmuller, Quebe, Hand, \& Hunter, 1998; Hunter, 2003) but there is no known published work reports on the use of safety-based SJT's to select candidates into jobs. 


\section{METHOD}

\section{STUDY 1}

Given the lack the lack of information on selection as an effective safety management practice, Study 1 tested predictors of safety performance appropriate for use in selection procedures via the model depicted in Figure 2. The study also investigated the incremental validity of safety orientation above and beyond that of personality and situational judgment. Thus, Study 1 examined hypotheses $1-13$.

\section{Participants}

The sample included 290 forklift/loader operators and auto yard workers from a large automotive organization (approximately 2500 employees) headquartered in the southwest United States. The majority of participants were male (90\%), and about half were under the age of 40 (58\%). Participants self-reported race to be White/Caucasian (51\%), Hispanic/Latino (26\%), Black/African American (8\%), or Asian (2\%).

\section{Procedure}

A job analysis yielded a competency model that identified safety orientation, safety judgment, and personality characteristics such as thoroughness, reliability, and sense of duty as critical features of successful performance for forklift/loader operators and auto yard workers. Incumbents were sent a link to an online assessment containing measures of personality, safety orientation, and safety judgment as part of a concurrent validation study. Supervisory safety performance ratings were collected via an online rating form. Performance data were collected for 347 participants. Incumbent and supervisor data were matched resulting in 307 pairs. Eligibility 
requirements stipulated that supervisor raters oversaw the employee for at least 3

months, were familiar with the employee, knowledgeable about their performance, and in frequent contact. Seventeen participants were ineligible based on these criteria, and were removed from further analyses.

\section{Measures}

Personality. The Global Personality Inventory-Adaptive (GPI-A) was used to assess participant personality characteristics, based on the Big Five factors of personality. The GPI-A is a computer adaptive general assessment of personality for use in selection and development of employees across a wide range of job levels and types. The measure included 13 dimensions of normal adult personality, 5 of which were used in this particular study because of their relation to the personality variables of interest: achievement striving, collaboration, sense of duty, reliability, and thoroughness. The 5 selected GPI-A dimensions were rationally mapped to the two Big Five dimensions of personality considered in this study. Four of these dimensions were mapped to conscientiousness for the purposes of the present study: (1)

achievement striving; (2) sense of duty; (3) reliability; and (4) thoroughness. A score for agreeableness included only a score for the collaboration dimension.

Within each dimension, items were comprised of two statements that represent different levels of the particular personality trait. Participating incumbents were instructed to select which of the two statements were more descriptive of them. Given the adaptive format of the assessment, the next item was comprised of two additional statements, selected using an updated trait level estimate based on previous 
incumbent responses. Subsequent sequences of statement pairs were selected in a manner that maximized item information for the particular dimension.

The GPI-A demonstrates criterion-related validity across a variety of job levels (PreVisor, 2010). Further, GPI-A scales have a near-zero relationship with general cognitive ability, demonstrating divergent validity. Reliability for the GPI-A was set at .85 . With adaptive personality scales, the test administration engine can be programmed to end the test once a desired reliability score is reached. In the present study, a stopping rule ended the administration of items for each personality dimension when a standard error of .38 was reached. The standard error of .38 is equivalent to reaching a "static" internal consistency reliability of .85 for each person, on each of the personality dimensions. Overall, test reliabilities tend to vary slightly from the .85 value due to a second stopping rule that was used in conjunction with the standard error stopping rule. If an individual had not met the .38 standard error rule by the time they had completed items for each personality dimension, the test ended. Use of reliability as a stopping rule introduces the notion of "controlled reliability", greatly improving the accuracy of CATs over traditional/static tests.

To investigate the factor structure of conscientiousness further, the measurement model depicted in Figure 4 was evaluated using structural equation modeling. Examination of univariate indices of skewness revealed no absolute skewness values above 1.26. All univariate indices of kurtosis revealed no absolute kurtosis values above 1.59, however, kurtosis for sense of duty was 2.67. In addition, multivariate normality was evaluated using Mardia's index. The multivariate kurtosis score was over the absolute value of 1.96 (8.28), indicating multivariate non- 
normality. Thus, the measurement model of conscientiousness was evaluated using bootstrapping with 2000 bootstrap replicates to allow for control of multivariate nonnormality.

Figure 4

Measurement Model of Conscientiousness

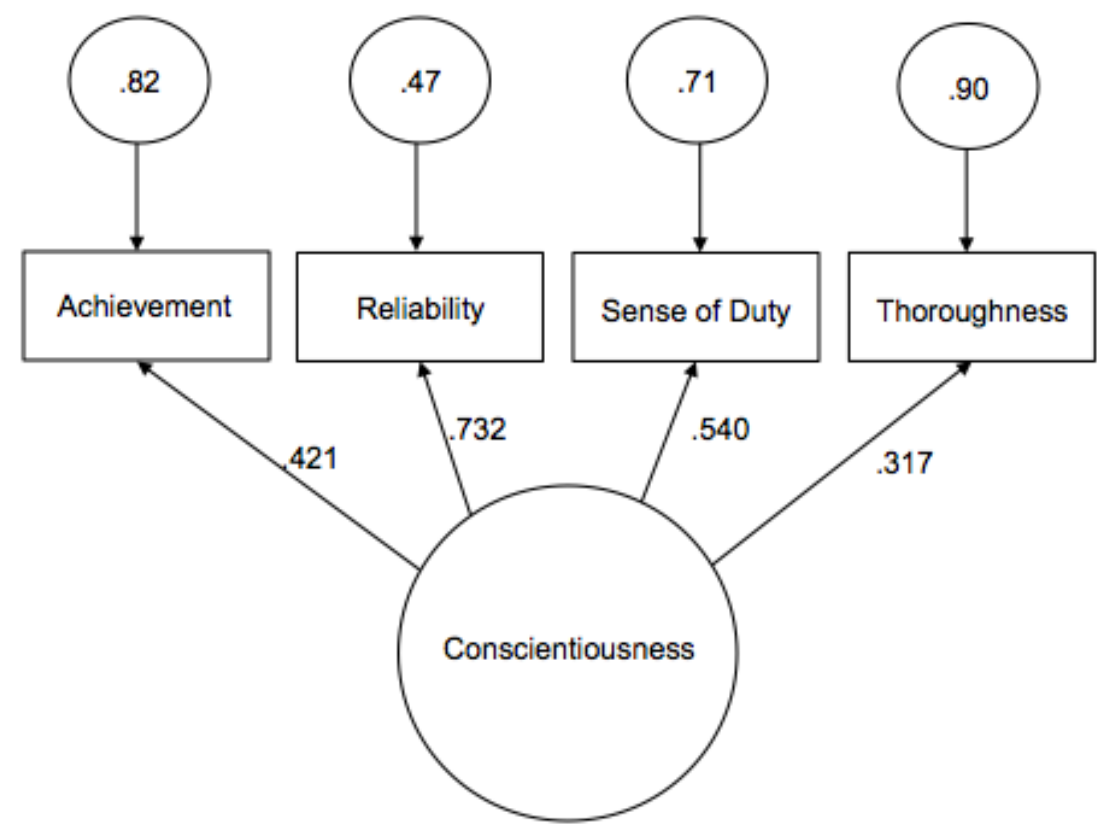

The fit of the model was evaluated using AMOS 20. The model was statistically overidentified. A variety of indices of model fit were evaluated. The Bollen-Stine overall chi-square test of model fit was statistically non-significant (.092). The Root Mean Square Error of Approximation (RMSEA) was. 071. The $p$ value for the test of close fit was less than .242. The Comparative Fit index was .971 and the Tucker-Lewis Index was .912. The indices uniformly point towards acceptable model fit. Inspection of the residuals and modification indices revealed no points of ill fit in the model. Figure 4 presents the standardized parameter estimates for the measurement model. Though the measurement model fit and the indicators 
loaded onto the latent variable adequately, the residuals for each of the observed variables were moderately high suggesting that conscientiousness may not be fully captured by indicators used in the present study. Because including the latent variable of conscientiousness in the model would introduce unnecessary measurement error, conscientiousness was calculated by creating a composite of average scores and included in the model as an observed measure. Each of the four dimensions was standardized prior to creating the composite.

Safety Judgment. The Safety Judgment Scale (SJS) is a situational judgment test comprised of 8 items that measures the tendency to make good judgments about how to safely and effectively meet job demands in unpredictable and/or dangerous environments. Four items that were written to specifically tap into situations involving safety were selected for use in the present study. Each SJS item positioned participants in various real-life scenarios that represent potentially dangerous situations common across industries where safety is a critical priority (e.g., preventing accidents on the first day of work). Examinees were instructed to select one of four potential answer choices as the best response to the scenario (e.g., ask new supervisor for resources). The SJS demonstrated criterion-related validity across jobs where safety is required (PreVisor, 2010).

Reliability of the 4-item measure as indicated by Cronbach's alpha was .38. In general, SJTs tend to underestimate reliability, thus low internal stability estimates for SJTs are widely reported in the literature (McDaniel \& Whetzel, 2007). It has been suggested that Cronbach's alpha may not be the most appropriate reliability estimate for SJTs because they assess multiple constructs (Cronbach, 1949, 1951). Test-retest 
reliability tends to be a better estimate, however it is rarely reported given the difficulty of gathering such information.

Safety Orientation. The Safety Orientation scale (SOC) is a biographical data test comprised of 24 items that measures the work history, personal experiences, and achievements related to occupational success in industries and jobs where safety is a critical consideration. Nine items that were written to specifically assess situations involving safety were selected for use in the present study. Behaviors characteristic of safety orientation include participation in safety training, knowing and following established safety rules and procedures, using required safety equipment, and demonstrating care and caution in dangerous situations. Answers for each item were provided on a 5-point scale with anchors corresponding to each question. Reliability of the measure as indicated by Cronbach's alpha was .48. As noted earlier, low internal stability estimates are common due to the multidimensional nature of biodata assessments.

Safety Performance. Participant's safety performance ratings were obtained from their immediate supervisors. The safety performance measure initially included 30 key performance indicators of behavior representative of seven general categories of employee behaviors: reliability, safety advocacy, adverse safety behavior, proactive safety behavior, observable safety behavior, comparison to other employees, and reported accidents and injuries.

To align with current definitions of safety performance (i.e., Neal et al., 2000) categories relating to reported accidents and injuries, comparisons among coworkers, 
and reliability were removed, resulting in 16 items. All items were rated on a 4 to 5 point scale with anchors corresponding to the respective item's context.

The 16 safety behavior items were subjected to principal components factor analysis using SPSS Version 18. Pairwise deletion was used for missing data. Principal components analysis was used because it is more psychometrically sound and conceptually less complex than factor analysis (Field, 2009). Orthogonal varimax rotation was used to facilitate identification of each variable with a single factor. Three components had eigenvalues greater than 1, explaining $26 \%, 20 \%$, and $15 \%$ of the variance, respectively. These three factors explained a cumulative $61 \%$ of the variance in safety performance.

Seven items loaded onto factor 1. Factor 1 was named Safety Compliance because it included items that evaluate worker compliance with organizational safety polices. Five items loaded onto factor 2. Factor 2 was named Safety Participation because it included items that evaluate discretionary helping behaviors related to safety. These two factors aligned with the model proposed by Neal and colleagues' (Griffin \& Neal, 2000; Neal \& Griffin, 2004; Neal et al. 2001). The third factor included three items that assessed demonstration of knowledge in organizational safety policies, rules, guidelines, and procedures. These behaviors are reflective of safety knowledge, a common predictor of safety performance discussed extensively in Chapter II as a component of safety judgment. To avoid overlap between the predictor and criterion space, these three items were removed. The 12 remaining items were standardized and averaged to create an overall safety performance composite $(\alpha=.91)$. In addition, items within each safety performance factor (safety 
compliance and safety judgment) were standardized and averaged for use in exploratory analyses.

\section{Analyses}

Data were entered into SPSS for analysis. Correlations were computed among all variables of interest to assess hypotheses 1 through 5. A hierarchal regression was run to assess the incremental validity of safety orientation over and above conscientiousness, agreeableness and safety judgment. Safety performance served as the dependent variable. Agreeableness, conscientiousness, and safety judgment were entered in the first step. Safety orientation was entered in the second step. An increase in $R^{2}$ from Step 1 to Step $2\left(\Delta R^{2}\right)$ indicated the incremental validity of safety orientation.

The predictive model of safety performance depicted in Figure 2 was tested using AMOS 20 to obtain parameter estimates for proposed direct effects (hypotheses 6 through 9) and to test strength of the proposed mediated relationships or indirect effects (hypotheses 10 through 12). Following the recommendations of Bollen and Long (1993), a variety of global fit indices were evaluated, including indices of absolute fit, indices of relative fit and indices of fit with a penalty function for lack of parsimony. These include the traditional overall chi-square test of model fit (a statistically non-significant result demonstrates acceptable fit), the Root Mean Square Error of Approximation (RMSEA; less than 0.08 demonstrates acceptable fit), the pvalue for the test of close fit (a statistically non-significant result demonstrates acceptable fit), the Comparative Fit Index (CFI; greater than 0.95 demonstrates acceptable fit); the Tucker-Lewis Index (TLI: greater than 0.95 demonstrates 
acceptable fit), and the standardized root mean square residual (less than 0.05 demonstrates acceptable fit).

To evaluate direct effects, standardized and unstandardized path coefficients were evaluated along with $95 \%$ confidence intervals. To evaluate indirect effects, more specific tests of mediation were pursued. Mediation reflects a relationship where an independent variable $(\mathrm{X})$ causes a mediator variable $(\mathrm{M})$ that, in turn, causes the dependent variable (Y). The indirect effect refers to a product of coefficients for paths that exist between $\mathrm{X}$ and $\mathrm{M}$ (i.e., $a$ path) and between $\mathrm{M}$ and $\mathrm{Y}$ (i.e., $b$ path). Various methods have been proposed to test the statistical significance of mediated models. For the purposes of this dissertation, statistical significance of mediated effects was evaluated primarily using bootstrapping to obtain confidence intervals for indirect effects. In addition, the joint significance test of $\alpha$ and $\beta$ was also performed to provide supportive evidence of mediation for hypotheses 10 through 12 . The joint significance test is a casual steps approach to testing mediation, wherein a series of regressions are performed to demonstrate mediation. The first regression tests whether X predicts $\mathrm{M}$; this direct relationship represents path $a$. The second regression tests when $\mathrm{M}$ predicts the $\mathrm{Y}$ including $\mathrm{X}$ in the regression; this direct relationship represents path $b$. If path $a$ and $b$ are jointly significant, one can conclude that mediation exits. The joint significance test differs from the Baron and Kenny (1986) method because the significance of the direct path between the $\mathrm{X}$ and $\mathrm{Y}$ is not required to continue to further steps. The direct relationship between $\mathrm{X}$ and $\mathrm{Y}$ qualifies the mediated effect as either full or partial as it corresponds to path $c^{\prime}$, or the total effect of $\mathrm{X}$ on $\mathrm{Y}$. If $\mathrm{X}$ significantly predicts $\mathrm{Y}, \mathrm{M}$ partially mediates the 
relationship between $\mathrm{X}$ and $\mathrm{Y}$. If $\mathrm{X}$ does not significantly predict $\mathrm{Y}, \mathrm{M}$ fully mediated the relationship between $\mathrm{X}$ and $\mathrm{Y}$. Both methods control Type 1 error adequately and provide more robust tests of mediation as compared to the traditional Baron and Kenny method (MacKinnon et al., 2002).

\section{STUDY 2}

To determine if safe workers are better workers, the relationship between safety performance and job performance must be investigated. Study 2 attempted to replicate the findings of Study 1, and examined job performance as an outcome of safety performance in a second model depicted in Figure 3. Thus, Study 2 tested hypotheses 15 and 16, in addition to the original hypotheses (1 through 14) tested in the first study.

\section{Participants}

The sample included 323 incumbents from the construction industry. Participants were sampled from a large organization (approximately 2000 employees) headquartered in the Midwestern United States. Job titles included machine operator and construction crewmember. Machine operators manufacture building materials and construction crewmembers carry out various building projects. The majority of participants were male (98\%), and about half were under the age of 40 (53\%). Most participants were White/Caucasian (95\%) and an additional 3\% were Hispanic.

\section{Procedure}

Incumbents were sent a link to an online assessment containing measures of personality, safety orientation, and safety judgment as part of a concurrent validation study. Supervisory performance ratings were collected via an online rating form. 
Performance data was collected for 376 participants. Incumbent and supervisor data were then matched, resulting in 368 pairs. Eligibility requirements required that supervisor raters oversaw the employee for at least 3 months, were familiar with the employee, knowledgeable about their performance, and in frequent contact. Fortyfive participants were ineligible based on these criteria, and were thus removed from further analyses.

\section{Measures}

All Study 1 measures were used in Study 2. Internal consistency estimates for repeated measures were as follows: safety judgment $\alpha=.39$ and safety orientation $\alpha=$ .25. For safety performance, the principal components analysis conducted in Study 1 was replicated using the 12 final items to determine if the criterion structure held up within the new sample. Two components had eigenvalues greater than 1, explaining $53 \%$ and $11 \%$ of the variance, respectively. All 12 items loaded highly onto one of the two factors. The 12 items were standardized and averaged to form an overall safety performance composite $(\alpha=.91)$. In addition, items within each safety performance factor (safety compliance and safety judgment) were standardized and averaged for use in exploratory analyses. Added measures of job performance are described below.

Job Performance. Participants were rated on eight performance area dimensions and three indicators of global performance. Items from both performance area ratings and global performance ratings were standardized and averaged to create an overall job performance composite to be used in correlational analyses $(\alpha=.95)$. 
In the model, job performance was tested using a latent variable indicated by performance area ratings and global performance ratings.

Performance area ratings. Supervisors rated eight performance area dimensions on a 7-point scale. Raters were provided with behaviorally anchored rating scales depicting incidents of ineffective (1-2), effective (3-5) and superior performance (6-7). The rating form included the following performance dimensions: effort and productivity, dependability, integrity and professionalism, working with others, drive for results, confidence and independence, organization, and work quality.

Global performance ratings. Supervisors were asked to assess incumbent's global performance based on the employee's re-hireability, overall capability match, and productivity level. All responses were indicated on a 5-point scale with point anchors corresponding to the respective item context.

\section{Analyses}

Analyses were conducted consistent with the methods employed in Study 1. In addition to retesting hypotheses presented in Study 1, Study 2 also sought to understand the relationship between predictors, safety performance, and job performance through model testing (hypotheses 14 through 16). 


\section{RESULTS}

\section{STUDY 1}

Table 1 reports the intercorrelations among variables of interest.

Conscientiousness was positively related to safety performance $(r=.15)$ supporting hypothesis 1 . Agreeableness $(r=.04)$ and safety judgment $(r=.02)$ were not significantly related to safety performance, thus hypotheses 2 and 3 were not supported, respectively. Both conscientiousness $(r=.23)$ and agreeableness $(r=.22)$ were significantly related to safety judgment, providing support for hypotheses 4 and 5 , respectively.

Table 1

Study 1: Relationships Among Variables of Interest (Hypotheses 1 through 5)

\begin{tabular}{|c|c|c|c|c|c|c|c|c|}
\hline & $M$ & $S D$ & 1 & 2 & 3 & 4 & 5 & 6 \\
\hline 1. Agreeableness & 5.84 & .68 & - & & & & & \\
\hline 2. Conscientiousness & 6.15 & .42 & $.32 * *$ & - & & & & \\
\hline 3. Safety Judgment & 4.30 & 2.00 & $.23 * *$ & $.22 * *$ & - & & & \\
\hline 4. Safety Orientation & 9.15 & 1.62 & $.27 * *$ & $.33 * *$ & $.16^{* *}$ & - & & \\
\hline $\begin{array}{l}\text { 5. Safety } \\
\text { Compliance }\end{array}$ & 2.60 & .64 & -.01 & $.14 *$ & -.02 & $.14 * *$ & - & \\
\hline $\begin{array}{l}\text { 6. Safety } \\
\text { Participation }\end{array}$ & 2.18 & .62 & .10 & $.14^{*}$ & .06 & $.15^{*}$ & $.59 * *$ & - \\
\hline $\begin{array}{l}\text { 7. Safety } \\
\text { Performance }\end{array}$ & 2.30 & .56 & .04 & $.15^{*}$ & .02 & $.16^{* *}$ & $.89 * *$ & $.88 * *$ \\
\hline $\begin{array}{l}\text { Note. } \\
*=p<.05 \\
* *=p<.001\end{array}$ & & & & & & & & \\
\hline
\end{tabular}

\section{Model Testing}

The model depicted in Figure 5 was evaluated using Structural Equation Modeling (SEM) in AMOS 20 to obtain parameter estimates for proposed direct effects (hypotheses 6 through 9), and to test the significance of proposed mediated 
relationships (i.e., indirect effects; hypotheses 10 through 12). Prior to analyses the dataset was evaluated for missing data, outliers, and non-normality.

As expected, after the matching predictor scores to criterion scores, missing data among variables was minimal (less than $2 \%$ for any variable in the model). The Expectation-Maximization (EM) algorithm was used to address missing data (Dempster, Laird, \& Rubin, 1977; Little \& Rubin, 1987; Schafer, 1997). The EM algorithm is an iterative method for finding maximum likelihood estimates of model parameters. Unlike mean imputation methods, the EM algorithm does not result in values for individual missing cases. Rather, mean estimates and the variancecovariance matrix of the variables of interest are obtained to create parameter estimates. These parameter estimates are then used to obtain model parameters.

The data for the covariance matrix were evaluated for multivariate outliers (non-model based) by examining leverage indices for each individual and defining an outlier as a leverage score four times greater than the mean leverage. According to this standard, two outliers were observed. Further tests for model-based outliers were also pursued by examining standardized dfbeta values associated with each variable in the model. All standardized dfbetas were under the absolute value of 1, thus no statistically significant model-based outliers were identified. Analyses were ran including non-model based outliers (Figure 5) and excluding non-model based outliers (Figure 6) to determine if non-model based outliers were influencing results. The results of these tests are reported respectively in the paragraphs to follow.

First, the model was tested with outliers. Examination of univariate indices of skewness and kurtosis revealed no absolute skewness values above .64 and no 
absolute kurtosis values above 1.10. Multivariate normality was evaluated using Mardia's index. The multivariate kurtosis score was 1.46. The fit of the model depicted in Figure 5 was evaluated using AMOS 20 using a maximization likelihood algorithm. The model was statistically overidentified. A variety of model fit indices were evaluated. The chi-square test of model fit was statistically non-significant $\left(X^{2}(3)=3.95, p=.266\right)$. The Root Mean Square Error of Approximation (RMSEA) was .033. The p-value for the test of close fit was not significant (.540). The Comparative Fit Index (CFI) was .991, and the Tucker-Lewis Index (TLI) was .969. The Standardized Root Mean Square Residual (SRMR) was .026. Overall, the indices uniformly point towards good model fit. More focused analyses revealed no absolute standardized residuals greater than 1.96. Figure 5 presents the standardized and unstandardized (in parenthesis) parameter estimates.

Figure 5

Study 1 Model Testing: The Predictive Model of Safety Performance

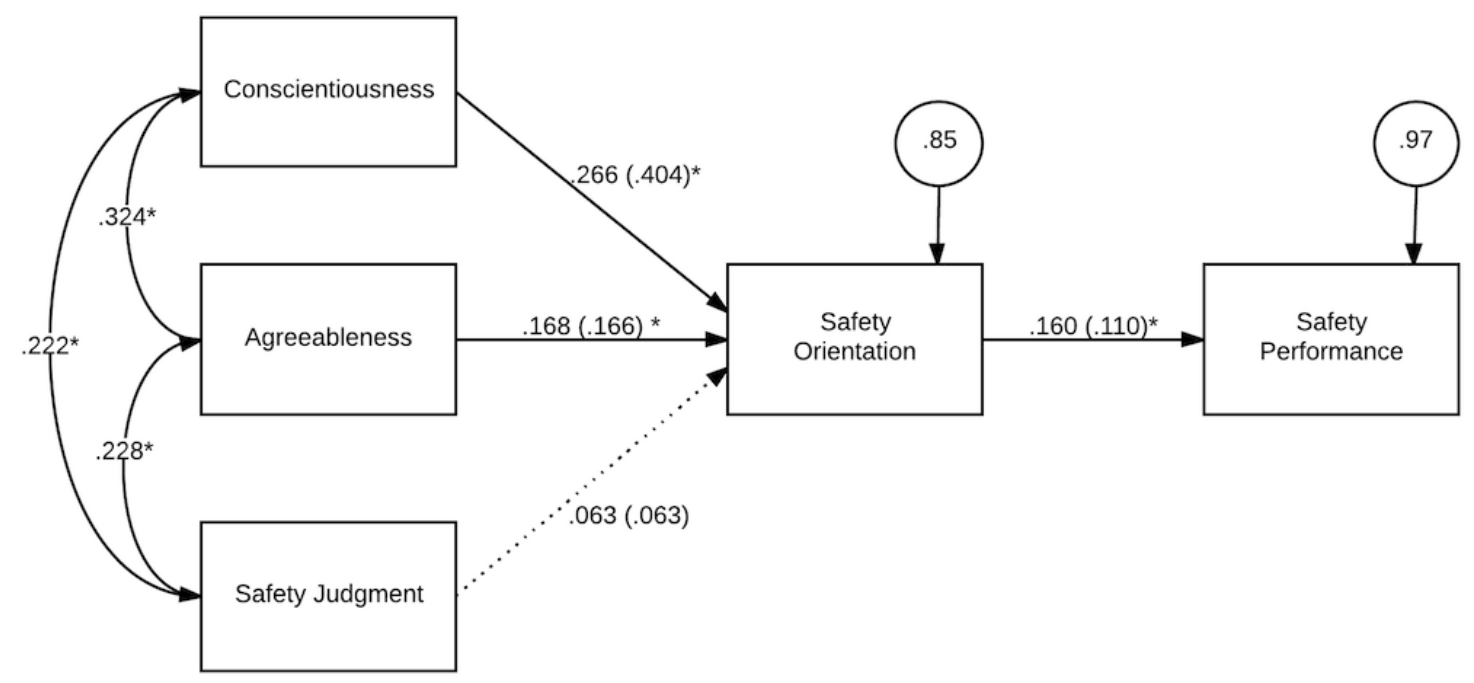

Note.

$*=p<.05$ 
Second, the model was tested without the two non-model based outliers. The fit of the model depicted in Figure 6 was evaluated using AMOS 20 using a maximization likelihood algorithm. Examination of univariate indices of skewness and kurtosis revealed no absolute skewness values above .368 and no absolute kurtosis values above .748. Multivariate normality was evaluated using Mardia's index. The multivariate kurtosis score was .045 . The model was statistically overidentified. A variety of model fit indices were evaluated. The chi-square test of model fit was statistically non-significant $\left(X^{2}(3)=2.43, p=.488\right)$. The RMSEA was .000. The p-value for the test of close fit was non-significant (.733). The CFI was 1.00, and the TLI was 1.03 . The SRMR was .020. The indices uniformly point towards good model fit. More focused analyses revealed no absolute standardized residuals greater than 1.96 . Figure 6 presents the standardized and unstandardized (in parenthesis) parameter estimates.

Figure 6

Study 1 Model Testing: The Predictive Model of Safety Performance without Outliers

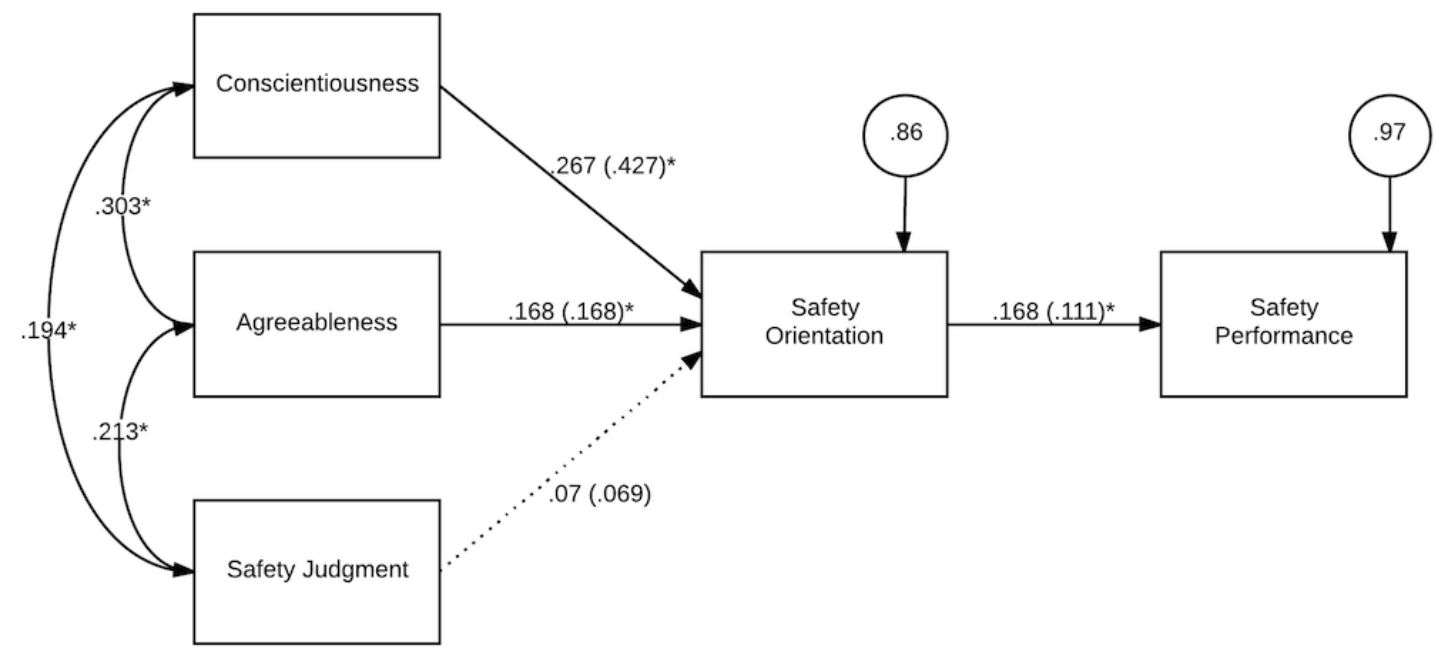

Note.

$*=p<.05$ 
Comparing the two models (Figure 5 and Figure 6), it appears that including outliers did not influence fit statistics or parameter estimates, thus hypothesis testing was conducted using the results from the first model including outliers (Figure 5). Overall, the model depicted in Figure 5 accounted for $2.6 \%$ of the variance in safety performance. All path estimates, but the path from safety judgment to safety orientation (hypothesis 9), were significant lending support to hypotheses 6 through 8. Standardized estimates of direct effects are reported below in reference to supported hypotheses. For every 1 unit increase in safety orientation, safety performance increased by .160 units (hypothesis 6). For every 1 unit increase in conscientiousness, safety orientation increased by .266 units (hypothesis 7). For every 1 unit increase in agreeableness, safety orientation increased by .168 units (hypothesis 8). Table 2 presents the $95 \%$ confidence intervals for the standardized path coefficients (direct effects) in the model.

Table 2

Study 1: 95\% Confidence Intervals for Standardized Path Coefficients (Hypotheses 6 through 9)

\begin{tabular}{lccc}
\hline \multicolumn{1}{c}{ Path } & Estimate & Lower Bounds & Upper Bounds \\
\hline $\begin{array}{l}\text { Safety Orientation to } \\
\text { Safety Performance }\end{array}$ & .160 & .039 & .278 \\
$\begin{array}{l}\text { Conscientiousness to } \\
\text { Safety Orientation }\end{array}$ & .266 & .163 & .366 \\
$\begin{array}{l}\text { Agreeableness to } \\
\text { Safety Orientation }\end{array}$ & .168 & .057 & .272 \\
$\begin{array}{l}\text { Safety Judgment to } \\
\text { Safety Orientation }\end{array}$ & .063 & -.040 & .172 \\
\hline
\end{tabular}


Tests of indirect effects. Bootstrapping using 2000 replicates was implemented to test mediation hypotheses (hypotheses 10 through 12). When bootstrapping methods are used, an indirect effect is determined to be significant if the bias-corrected confidence interval does not include zero. Hypotheses 10 through 12 predicted that safety orientation would mediate the relationship between safety performance and conscientiousness, agreeableness, and safety judgment, respectively. Safety orientation significantly mediated the relationship between conscientiousness and safety performance (95\% CI: .012 to .088, $p=.003$ ), supporting hypothesis 10 . Safety orientation also significantly mediated the relationship between agreeableness and safety performance (95\% CI: .006 to .063, $p=.006)$, supporting hypothesis 11 . However, the indirect effect of safety judgment on safety performance through safety orientation (hypothesis 12) was not significant (95\% CI: $-.005-.036, n s)$. Table 3 reports the $95 \%$ bias-corrected confidence intervals for indirect effects.

Table 3

Study 1: 95\% Bias-Corrected Confidence Intervals for Indirect Effects (Hypotheses 10 through 12)

\begin{tabular}{lccc}
\hline \multicolumn{1}{c}{ Mediated Effect } & Lower Bounds & Upper Bounds & $\begin{array}{c}\text { Two-Tailed } \\
\text { Significance }\end{array}$ \\
\hline $\begin{array}{l}\text { Conscientiousness to } \\
\text { Safety Performance }\end{array}$ & .012 & .088 & .003 \\
$\begin{array}{l}\text { Agreeableness to } \\
\text { Safety Performance }\end{array}$ & .006 & .063 & .006 \\
$\begin{array}{l}\text { Safety Judgment to } \\
\text { Safety Performance }\end{array}$ & -.005 & .036 & .150 \\
\hline
\end{tabular}

The joint significance test of $\alpha$ and $\beta$ was also performed to provide supportive evidence of mediation as predicted in hypotheses 10 through 12 . The results of joint significance testing for hypotheses 10 through 12 are reported in 
Tables 4 through 6, respectively. Hypothesis 10 predicted that safety orientation would mediate the relationship between conscientiousness and safety performance. Conscientiousness ( $\beta=.323$ ) significantly predicted safety orientation (path $a$ ) and safety orientation ( $\beta=.123$ ) significantly predicted safety performance including conscientiousness in the model (path $b$ ). Thus, both $a$ and $b$ paths included in the mediated effect were jointly significant, providing further supportive evidence for hypothesis 10 . The direct relationship between conscientiousness ( $\beta=.154$ ) and safety performance (path $c^{\prime}$ ) was also significant suggesting that the mediated effect is partial.

Table 4

Study 1: Joint Significance Test of Safety Orientation as a Mediator of the Relationship Between Conscientiousness and Safety Performance (Hypothesis 10)

\begin{tabular}{|c|c|c|c|}
\hline Independent Variable(s) & $R^{2}$ & $\beta$ & $t$ \\
\hline \multicolumn{4}{|c|}{ Path $a$ : Conscientiousness to Safety Orientation } \\
\hline Conscientiousness & $.112 * *$ & .334 & $5.98 * *$ \\
\hline \multicolumn{4}{|c|}{ Path $b$ : Safety Orientation to Safety Performance } \\
\hline Conscientiousness & $.039 *$ & .117 & 1.90 \\
\hline Safety Orientation & - & .123 & $1.99 *$ \\
\hline \multicolumn{4}{|c|}{ Path $c^{\prime}$ : Conscientiousness to Safety performance } \\
\hline Conscientiousness & $.024 *$ & .154 & $2.65^{*}$ \\
\hline
\end{tabular}
Note.

$*=p<.05$

$* *=p<.001$

Hypothesis 11 predicted that safety orientation would mediate the relationship between agreeableness and safety performance. Agreeableness $(\beta=.265)$ significantly predicted safety orientation (path $a$ ) and safety orientation $(\beta=.161)$ significantly predicted safety performance including agreeableness in the model (path 
b). Thus, both paths of the mediated effect were jointly significant, providing further supportive evidence for hypothesis 11 . The direct relationship between agreeableness ( $\beta=.041$ ) and safety performance (path $c^{\prime}$ ) was not significant, suggesting that safety orientation fully mediated the relationship between agreeableness and safety performance.

Table 5

Study 1: Joint Significance Test of Safety Orientation as a Mediator of the Relationship Between Agreeableness and Safety Performance (Hypothesis 11)

\begin{tabular}{lccc}
\hline Independent Variable(s) & $R^{2}$ & $\beta$ & $t$ \\
\hline Path $a$ : Agreeableness to Safety Orientation & & \\
Agreeableness & $.072^{* *}$ & .269 & $4.71^{* *}$ \\
Path $b$ : Safety Orientation to Safety Performance & & \\
Agreeableness & $.026^{*}$ & .004 & 0.06 \\
Safety Orientation & - & .161 & $2.66^{*}$ \\
Path $c^{\prime}:$ Agreeableness to Safety Performance & & \\
$\quad$ Agreeableness & .002 & .041 & 0.69 \\
\hline
\end{tabular}

$$
\begin{aligned}
& \text { Note. } \\
& *=p<.05 \\
& * *=p<.001
\end{aligned}
$$

Hypothesis 12 predicted that safety orientation would mediate the relationship between safety judgment and safety performance. Safety judgment $(\beta=.160)$ significantly predicted safety orientation (path $a$ ) and safety orientation $(\beta=.164)$ significantly predicted safety performance including safety judgment in the model (path $b$ ). Thus, both paths of the mediated effect were jointly significant, providing further supportive evidence for hypothesis 12 . The direct relationship between safety judgment ( $\beta=.015$ ) and safety performance (path $c^{\prime}$ ) was not significant, suggesting that safety orientation fully mediated the relationship between safety judgment and 
safety performance. These results will be discussed in light of the indirect effect findings in the discussion section.

Table 6

Study 1: Joint Significance Test of Safety Orientation as a Mediator of the Relationship Between Safety Judgment and Safety Performance (Hypothesis 12)

\begin{tabular}{lccc}
\hline Independent Variable(s) & $R^{2}$ & $\beta$ & $t$ \\
\hline Path $a$ : Safety Judgment to Safety Orientation & & \\
$\quad$ Safety Judgment & $.026^{*}$ & .160 & $2.74^{*}$ \\
Path $b$ : Safety Orientation to Safety Performance & & \\
$\quad$ Safety Judgment & $.027^{*}$ & -.012 & -0.19 \\
Safety Orientation & - & .164 & $2.77^{*}$ \\
Path $c$ : Safety Judgment to Safety performance & & \\
$\quad$ Safety Judgment & .000 & .015 & 0.25 \\
\hline Note. & & \\
$*=p<.05$ & &
\end{tabular}

\section{Incremental Validity of Safety Orientation}

The incremental validity of safety orientation on safety performance over and above conscientiousness, agreeableness, and safety judgment (hypothesis 13) was tested using hierarchical regression. Results are presented in Table 7. Personality predictors and safety judgment were entered in step 1 , and safety orientation was entered in step 2 . Safety orientation explained $1.50 \%$ of the variance in safety performance above and over conscientiousness, agreeableness, and safety judgment, supporting hypothesis 13. 
Table 7

Study 1: Incremental Validity of Safety Orientation on Safety Performance Over Conscientiousness, Agreeableness and Safety Judgment (Hypothesis 13)

\begin{tabular}{lccc}
\hline & \multicolumn{3}{c}{ Safety Performance } \\
\hline Independent Variables & $\beta$ & $R^{2}$ & $\Delta R^{2}$ \\
\hline Step 1 & & .026 & \\
$\quad$ Conscientiousness & $.164^{*}$ & & \\
$\quad$ Agreeableness & -.001 & & $.015^{*}$ \\
$\quad$ Safety Judgment & -.014 & $.040^{*}$ & \\
Step 2 & & & \\
$\quad$ Safety Orientation & $.130^{*}$ & & \\
\hline Note. & & & \\
$*=p<.05$ & & &
\end{tabular}

\section{STUDY 2}

Table 8 reports the intercorrelations among variables of interest.

Conscientiousness was positively related to safety performance $(r=.16)$ supporting hypothesis 1 . Unlike Study 1 , agreeableness $(r=.13)$ was also significantly related to safety performance supporting hypothesis 2 . Similar to Study 1 , safety judgment $(r=$ .05) was not significantly related to safety performance, thus hypothesis 3 was not supported. Both conscientiousness $(r=.31)$ and agreeableness $(r=.27)$ were significantly related to safety judgment, providing support for hypotheses 4 and 5 , respectively.

\section{Model Testing}

Similar to Study 1, the model depicted in Figure 7 was tested in AMOS 20 to obtain parameter estimates for proposed direct effects (hypotheses 6 through 9) and to test strength of the proposed mediated relationships or indirect effects (hypotheses 10 
Table 8

Study 2: Relationships Among Variables of Interest (Hypotheses 1 through 5)

\begin{tabular}{|c|c|c|c|c|c|c|c|c|c|c|c|}
\hline & $M$ & $S D$ & 1 & 2 & 3 & 4 & 5 & 6 & 7 & 8 & 9 \\
\hline 1. Agreeableness & 5.82 & .66 & - & & & & & & & & \\
\hline 2. Conscientiousness & 6.04 & .44 & $.41 * *$ & - & & & & & & & \\
\hline 3. Safety Judgment & 4.41 & 2.10 & $.27 * *$ & $.31 * *$ & - & & & & & & \\
\hline 4. Safety Orientation & 8.55 & 1.84 & $.31 * *$ & $.55 * *$ & $.16^{* *}$ & - & & & & & \\
\hline 5. Safety Compliance & 2.47 & .59 & $.13 *$ & $.17^{* *}$ & .02 & $.20 * *$ & - & & & & \\
\hline 6. Safety Participation & 2.21 & .59 & .10 & $.13 *$ & .07 & $.17 * *$ & $.68 * *$ & - & & & \\
\hline $\begin{array}{l}\text { 7. Overall Safety } \\
\text { Performance }\end{array}$ & 2.34 & .54 & $.13 *$ & $.16^{* *}$ & .05 & $.20 * *$ & $.92 * *$ & $.91 * *$ & - & & \\
\hline 8. Performance Area & 4.98 & 1.04 & $.12 *$ & $.23 * *$ & .11 & $.17 * *$ & $.51 * *$ & $.60 * *$ & $.61 * *$ & - & \\
\hline 9. Global Performance & 2.47 & .90 & $.13 *$ & $.20 * *$ & .08 & $.14^{*}$ & $.55 * *$ & $.56^{* *}$ & $.60 * *$ & $.78 * *$ & - \\
\hline $\begin{array}{l}\text { 10. Overall Job } \\
\text { Performance }\end{array}$ & 4.29 & .96 & $.13 *$ & $.23 * *$ & .01 & $.17^{* *}$ & $.55 * *$ & $.62 * *$ & $.64 * *$ & $.98 * *$ & $.88 * *$ \\
\hline
\end{tabular}


through 12). In addition to retesting these hypotheses, Study 2 also sought to understand the relationship between predictors, safety performance and job performance (hypotheses 14 through 16). Results are presented here in order of hypotheses. Prior to analyses the dataset was evaluated for missing data, outliers, and non-normality. These preliminary analyses are described in the sections below.

As expected, after the matching predictor scores to criteria scores, missing data among variables was minimal (less than $1 \%$ for any of the variables included in the model). Like Study 1, the Expectation-Maximization (EM) algorithm was used to address missing data (Dempster, Laird, \& Rubin, 1977; Little \& Rubin, 1987; Schafer, 1997).

The data for the covariance matrix were evaluated for multivariate (non-model based) outliers by examining leverage indices for each individual and defining an outlier as a leverage score four times greater than the mean leverage. According to this standard, one outlier was observed. Further tests for model-based outliers were also pursued by examining standardized dfbeta values associated with each variable in the model. All standardized dfbetas were under the absolute value of 1 , thus no statistically significant model-based outliers were identified. Analyses were ran including non-model based outliers (Figure 7) and excluding non-model based outliers (Figure 8) to determine if non-model based outliers were influencing results. The results of these tests are reported respectively in the paragraphs to follow.

First, the model was tested with the non-model based outlier. Multivariate normality was evaluated using Mardia's index. The multivariate kurtosis score was 1.56. Examination of univariate indices of skewness and kurtosis revealed no absolute 
skewness values above 2.0 but one absolute value of kurtosis greater than 2.0 (2.09 for agreeableness). Because of the identified non-normality, the model was evaluated using bootstrapping with 2000 bootstrap replicates. The model was statistically overidentified. A variety of model fit indices were evaluated. The Bollen-Stine was statistically non-significant $(p=.839)$. The RMSEA was .000 . The p-value for the test of close fit was not significant (.863). The CFI was 1.00 , and the TLI was 1.01 . The SRMR was .025. The indices uniformly point towards good model fit. More focused analyses revealed no absolute standardized residuals greater than 1.96. Figure 7 presents the standardized and unstandardized (in parenthesis) parameter estimates.

Figure 7

Study 2 Model Testing: Integrative Model of Safety and Job Performance

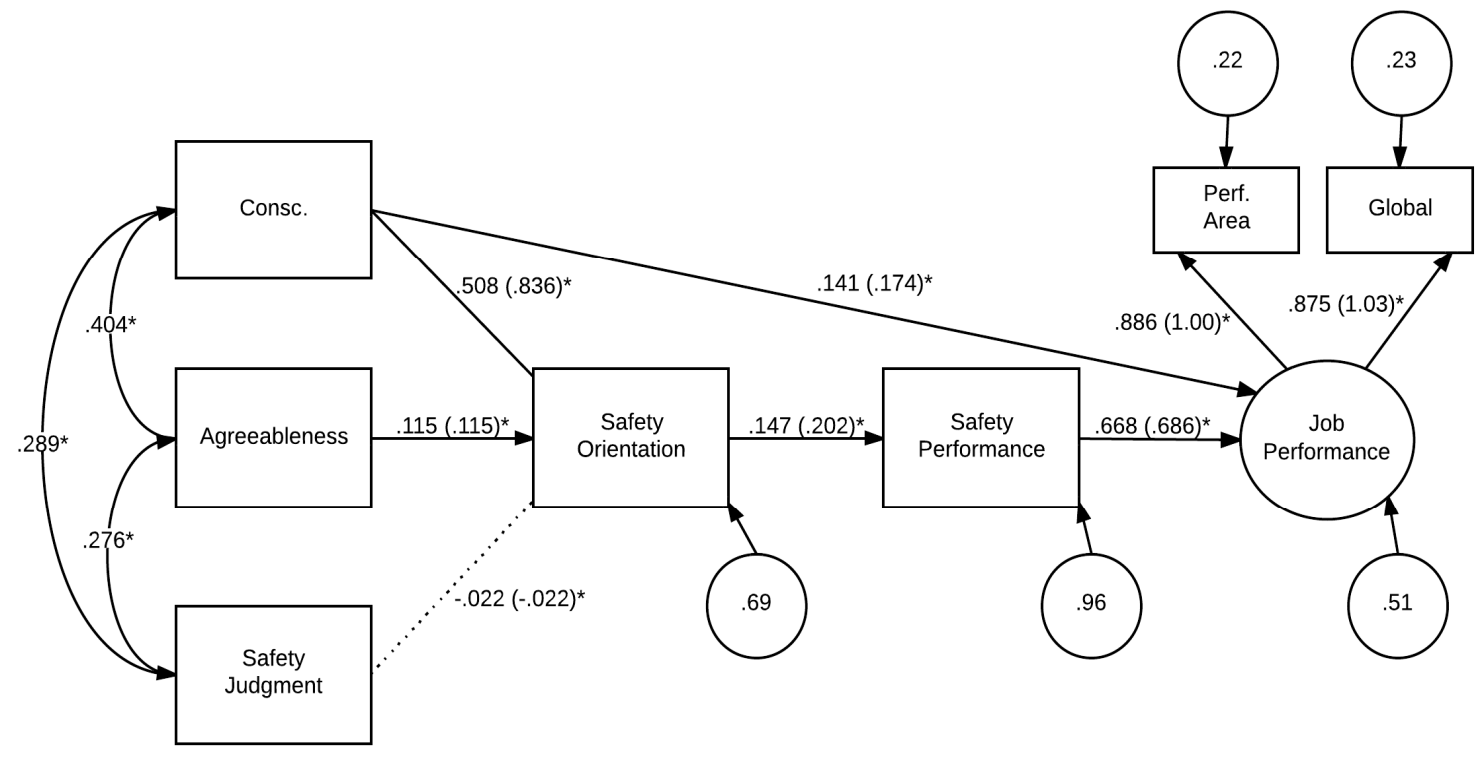

Note.

$*=p<.05$

Second, the model depicted in Figure 8 was tested in AMOS excluding the non-model based outlier. Examination of univariate indices of skewness and kurtosis revealed no absolute skewness values above .442 and no absolute kurtosis values 
above 1.18. Multivariate normality was evaluated using Mardia's index. The multivariate kurtosis score was 1.09 . The model was statistically overidentified. A variety of model fit indices were evaluated. The chi-square test of model fit was statistically non-significant $\left(X^{2}(10)=6.26, p=.793\right)$. The RMSEA was .000 . The $\mathrm{p}$ value for the test of close fit was not significant (.978). The CFI was 1.00, and the TLI was 1.01. The indices uniformly points towards good model fit. More focused analyses revealed no absolute standardized residuals greater than 1.96. Figure 8 presents the standardized and unstandardized (in parenthesis) parameter estimates.

Figure 8

Study 2 Model Testing: Integrative Model of Safety and Job Performance without Outliers

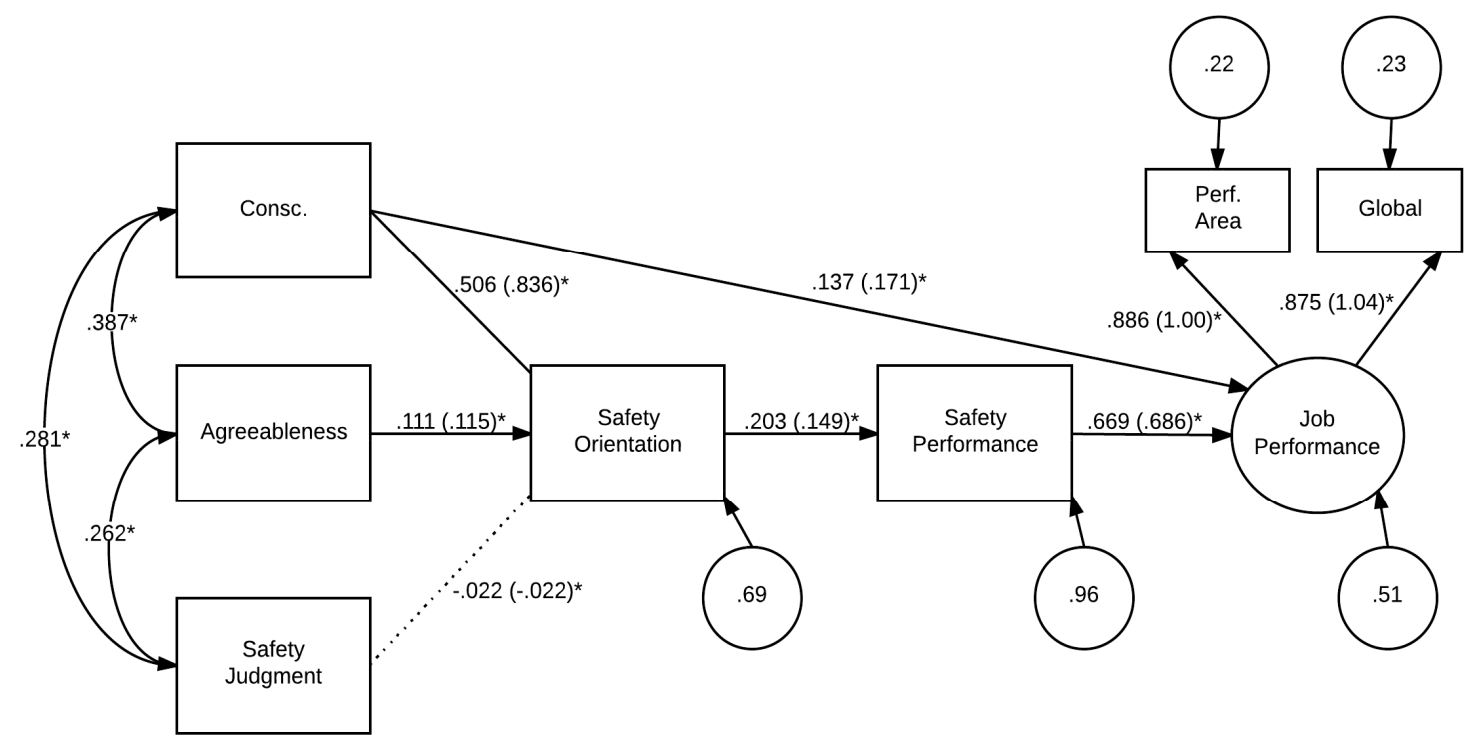

Note.

$*=p<.05$

Comparing the two models (Figure 7 and Figure 8), the largest difference between the models seems to be univariate normality; without the outlier agreeableness was not kurtotic (under an absolute value of 2). However, the kurtosis of agreeableness tested in Figure 7 was only slightly over the cut off and alleviated by 
the use of bootstrapping. In addition, including the outlier did not significantly influence fit statistics or parameter estimates, thus hypothesis testing was conducted using the results from the first model including the non-model based outlier (Figure 7).

Overall, the model depicted in Figure 7 accounted for $4.1 \%$ of the variance in safety performance. All path estimates, but the path form safety judgment to safety orientation (hypothesis 9), were significant lending support to hypotheses 6 through 8. Standardized estimates of direct effects are reported here in reference to supported hypotheses. For every 1 unit increase in safety orientation, safety performance increased by .202 units (hypothesis 6). For every 1 unit increase in conscientiousness, safety orientation increased by .508 units (hypothesis 7). For every 1 unit increase in agreeableness, safety orientation increased by .115 units (hypothesis 8 ). Table 9 presents the $95 \%$ confidence intervals for the standardized path coefficients (direct effects) in the model.

Table 9

Study 2: 95\% Bias-Corrected Confidence Intervals for Standardized Parameter Estimates (Hypotheses 6 through 9)

\begin{tabular}{lcccc}
\hline \multicolumn{1}{c}{ Path } & Estimate & $\begin{array}{c}\text { Lower } \\
\text { Bounds }\end{array}$ & $\begin{array}{c}\text { Upper } \\
\text { Bounds }\end{array}$ & $\begin{array}{r}\text { Two-Tailed } \\
\text { Significance }\end{array}$ \\
\hline $\begin{array}{l}\text { Safety Orientation to } \\
\text { Safety Performance }\end{array}$ & .202 & .092 & .304 & .001 \\
$\begin{array}{l}\text { Conscientiousness to } \\
\text { Safety Orientation }\end{array}$ & .508 & .410 & .602 & .001 \\
$\begin{array}{l}\text { Agreeableness to } \\
\text { Safety Orientation }\end{array}$ & .115 & .006 & .221 & .032 \\
$\begin{array}{l}\text { Safety Judgment to } \\
\text { Safety Orientation }\end{array}$ & -.022 & -.120 & .080 & .645 \\
\hline
\end{tabular}


Indirect effects. The statistical significance of mediated effects was evaluated using bootstrapping to obtain confidence intervals for indirect effects to test mediation hypotheses (hypotheses 10 through 12) and the joint significance test of $\alpha$ and $\beta$ was also performed to provide supportive evidence of mediation. Hypotheses 10 through 12 predicted that safety orientation would mediate the relationship between safety performance and conscientiousness, agreeableness, and safety judgment, respectively. Safety orientation significantly mediated the relationship between conscientiousness and safety performance (95\% CI: .045 to .165, $p=.001)$, supporting hypothesis 10 . Safety orientation also significantly mediated the relationship between agreeableness and safety performance (95\% CI: .003 to $.055, p$ $=.020$ ), supporting hypothesis 11 . However, the indirect effect of safety judgment on safety performance through safety orientation (hypothesis 12) was not significant (95\% CI: $-.025-.016, n s)$. Table 10 reports the $95 \%$ bias-corrected confidence intervals for indirect effects.

Table 10

Study 2: 95\% Bias-Corrected Confidence Intervals for Indirect Effects (Hypotheses 10 through 12)

\begin{tabular}{lccc}
\hline \multicolumn{1}{c}{ Mediated Effect } & Lower Bounds & Upper Bounds & $\begin{array}{c}\text { Two-Tailed } \\
\text { Significance }\end{array}$ \\
\hline $\begin{array}{l}\text { Conscientiousness to } \\
\text { Safety Performance }\end{array}$ & .045 & .165 & .001 \\
$\begin{array}{l}\text { Agreeableness to } \\
\text { Safety Performance }\end{array}$ & .003 & .055 & .020 \\
$\begin{array}{l}\text { Safety Judgment to } \\
\text { Safety Performance }\end{array}$ & -.025 & .016 & .585 \\
\hline
\end{tabular}

The results of joint significance testing for hypotheses 10 through 12 are reported in Tables 11 through 13, respectively. Hypothesis 10 predicted that safety 
orientation would mediate the relationship between conscientiousness and safety performance. Conscientiousness ( $\beta=.300$ ) significantly predicted safety orientation (path $a$ ) and safety orientation ( $\beta=.166$ ) significantly predicted safety performance including conscientiousness in the model (path $b$ ). Thus, both $a$ and $b$ paths included in the mediated effect were jointly significant, providing further supportive evidence for hypothesis 10 . The direct relationship between conscientiousness $(\beta=.156)$ and safety performance (path $c^{\prime}$ ) was also significant suggesting that the mediated effect is partial.

\section{Table 11}

Study 2: Joint Significant Test of Safety Orientation as a Mediator of the Relationship Between Conscientiousness and Safety Performance (Hypothesis 10)

\begin{tabular}{lccc}
\hline Independent Variable(s) & $R^{2}$ & $\beta$ & $t$ \\
\hline \multicolumn{2}{l}{ Path $a:$ Conscientiousness to Safety Orientation } & & \\
Conscientiousness & $.300^{* *}$ & .548 & $11.66^{* *}$ \\
Path $b:$ Safety Orientation to Safety Performance & & \\
$\quad$ Conscientiousness & $.044^{*}$ & .065 & .98 \\
Safety Orientation & - & .166 & $2.53^{*}$ \\
Path $c^{\prime}:$ Conscientiousness to Safety Performance & & \\
Conscientiousness & $.024^{*}$ & .156 & $2.80^{*}$ \\
\hline Note. & & \\
$*=p<.05$ & & \\
$* *=p<.001$ & &
\end{tabular}

Hypothesis 11 predicted that safety orientation would mediate the relationship between agreeableness and safety performance. Agreeableness ( $\beta=.314)$ significantly predicted safety orientation (path $a$ ) and safety orientation $(\beta=.179)$ significantly predicted safety performance including agreeableness in the model (path $b$ ). Thus, both paths of the mediated effect were jointly significant, providing further 
supportive evidence for hypothesis 11 . The direct relationship between agreeableness $(\beta=.127)$ and safety performance (path $\left.c^{\prime}\right)$ was significant, suggesting that safety orientation partially mediated the relationship between agreeableness and safety performance.

Table 12

Study 2: Joint Significant Test of Safety Orientation as a Mediator of the Relationship Between Agreeableness and Safety Performance (Hypothesis 11)

\begin{tabular}{lccc}
\hline \multicolumn{1}{l}{ Independent Variable(s) } & $R^{2}$ & $\beta$ & $t$ \\
\hline \multicolumn{2}{l}{ Path $a$ : Agreeableness to Safety Orientation } & & \\
Agreeableness & $.099^{* *}$ & .314 & $5.89^{* *}$ \\
Path $b$ : Safety Orientation to Safety Performance & & \\
$\quad$ Agreeableness & $.045^{* *}$ & .071 & 1.23 \\
Safety Orientation & - & .179 & $3.10^{*}$ \\
Path $c^{\prime}:$ Agreeableness to Safety Performance & & \\
$\quad$ Agreeableness & $.016^{*}$ & .127 & $2.29^{*}$ \\
\hline
\end{tabular}

Note.

$*=p<.05$

$* *=p<.001$

Hypothesis 12 predicted that safety orientation would mediate the relationship between safety judgment and safety performance. Safety judgment ( $\beta=.157$ ) significantly predicted safety orientation (path $a$ ) and safety orientation $(\beta=.200)$ significantly predicted safety performance including safety judgment in the model (path $b$ ). Thus, both paths of the mediated effect were jointly significant, providing further supportive evidence for hypothesis 12 . The direct relationship between safety judgment ( $\beta=.051$ ) and safety performance (path $c^{\prime}$ ) was not significant, suggesting that safety orientation fully mediated the relationship between safety judgment and 
safety performance. These results will be discussed in light of the indirect effect findings in the discussion section.

Table 13

Study 2: Joint Significant Test of Safety Orientation as a Mediator of the Relationship Between Safety Judgment and Safety Performance (Hypothesis 12)

\begin{tabular}{lccc}
\hline \multicolumn{1}{l}{ Independent Variable(s) } & $R^{2}$ & $\beta$ & $t$ \\
\hline \multicolumn{2}{l}{ Path $a:$ Safety Judgment to Safety Orientation } & & \\
$\quad$ Safety Judgment & $.025^{*}$ & .157 & $2.81^{*}$ \\
Path $b$ : Safety Orientation to Safety Performance & & \\
$\quad$ Safety Judgment & $.042^{* *}$ & .020 & .36 \\
Safety Orientation & - & .200 & $3.57^{* *}$ \\
Path $c^{\prime}:$ Safety Judgment to Safety Performance & & \\
$\quad$ Safety Judgment & .003 & .051 & 0.91 \\
\hline Note. & & \\
$*=p<.05$ & & \\
$* *=p<.001$ & &
\end{tabular}

\section{Incremental Validity of Safety Orientation}

The incremental validity of safety orientation on safety performance over and above conscientiousness, agreeableness, and safety judgment (hypothesis 13) was tested using hierarchical regression (see Table 14 for results). Personality predictors and safety judgment were entered in step 1, and safety orientation was entered in step 2. Safety orientation explained $1.90 \%$ of the variance in safety performance above and over conscientiousness, agreeableness, and safety judgment, supporting hypothesis 13 . 
Table 14

Study 2: Incremental Validity of Safety Orientation on Safety Performance Over Conscientiousness, Agreeableness and Safety Judgment (Hypothesis 13)

\begin{tabular}{lccc}
\hline & \multicolumn{3}{c}{ Safety Performance } \\
\hline Independent Variables & $\beta$ & $R^{2}$ & $\Delta R^{2}$ \\
\hline Step 1 & & $.028^{*}$ & \\
$\quad$ Conscientiousness & $.147^{*}$ & & \\
Agreeableness & .056 & & $.019^{*}$ \\
$\quad$ Safety Judgment & -.003 & $.046^{*}$ & \\
Step 2 & & & \\
$\quad$ Safety Orientation & $.120^{*}$ & & \\
\hline Note. & & & \\
$*=p<.05$ & & &
\end{tabular}

\section{Safety Performance and Job Performance}

In addition to replicating Study 1, Study 2 sought to investigate the relationship between safety performance and job performance. Overall, the model accounted $49 \%$ of the variance in job performance. Added direct effects predicted that conscientiousness (hypothesis 14) and safety performance (hypothesis 15) related to job performance. Both path coefficients were statistically significant. Hypothesis 14 was supported, for every 1 unit increase in conscientiousness, job performance increased by .141 units. Hypothesis 15 was also supported, for every 1 unit increase in safety performance, job performance increased by .668 units. Table 15 presents the $95 \%$ confidence intervals for hypotheses 14 and 15 . 
Table 15

Study 2: 95\% Bias-Corrected Confidence Intervals for Indirect Effects (Hypotheses 14 and 15)

\begin{tabular}{lcccc}
\hline \multicolumn{1}{c}{ Path } & Estimate & $\begin{array}{c}\text { Lower } \\
\text { Bounds }\end{array}$ & $\begin{array}{c}\text { Upper } \\
\text { Bounds }\end{array}$ & $\begin{array}{r}\text { Two-Tailed } \\
\text { Significance }\end{array}$ \\
\hline $\begin{array}{l}\text { Conscientiousness to } \\
\text { Job Performance }\end{array}$ & .141 & .055 & .227 & .002 \\
$\begin{array}{l}\text { Safety Performance to } \\
\text { Job Performance }\end{array}$ & .668 & .595 & .734 & .001 \\
\hline
\end{tabular}

Hypothesis 16 predicted that safety performance would mediate the relationship between predictors of safety performance and job performance. Table 16 reports the bias-corrected $95 \%$ confidence intervals associated with these indirect effects. All indirect effects, but the indirect effect of safety judgment on job performance, were significant providing partial support for hypothesis 16 .

Table 16

Study 2: Bias-Corrected 95\% Confidence Intervals For Indirect Effects (Hypothesis 16)

\begin{tabular}{lccc}
\hline \multicolumn{1}{c}{ Mediated Effect } & Lower Bounds & Upper Bounds & $\begin{array}{c}\text { Two-Tailed } \\
\text { Significance }\end{array}$ \\
\hline $\begin{array}{l}\text { Agreeableness to } \\
\text { Job Performance } \\
\text { Conscientiousness to }\end{array}$ & .002 & .036 & .018 \\
$\begin{array}{l}\text { Job Performance } \\
\text { Safety Judgment to }\end{array}$ & .030 & .111 & .001 \\
$\begin{array}{l}\text { Job Performance } \\
\text { Safety Orientation to }\end{array}$ & .064 & .011 & .582 \\
Job Performance & & .208 & .001 \\
\hline
\end{tabular}

Follow up joint significant testing focused on safety performance as a mediator between the most proximal predictor of safety performance (safety orientation) and job performance (see Table 17$)$. Safety orientation $(\beta=.202)$ 
significantly predicted safety performance (path $a)$ and safety performance $(\beta=.628)$ significantly predicted job performance including safety orientation in the model (path $b$ ). Thus, both paths of the mediated effect were jointly significant, providing further supportive evidence for hypothesis 12 . The direct relationship between safety orientation ( $\beta=.167)$ and job performance (path $c^{\prime}$ ) was significant, suggesting that safety performance partially mediates the relationship between safety orientation and job performance.

Table 17

Study 2: Joint Significant Test of Safety Performance as a Mediator of the Relationship Between Safety Orientation and Job Performance (Hypothesis 16)

\begin{tabular}{|c|c|c|c|}
\hline Independent Variable(s) & $R^{2}$ & $\beta$ & $t$ \\
\hline \multicolumn{4}{|c|}{ Path $a$ : Safety Orientation to Safety Performance } \\
\hline Safety Orientation & $.041 * *$ & .202 & $3.67 * *$ \\
\hline \multicolumn{4}{|c|}{ Path $b$ : Safety Performance to Job Performance } \\
\hline Safety Orientation & $.406^{* *}$ & .040 & 0.91 \\
\hline Safety Performance & - & .628 & $14.18^{* *}$ \\
\hline \multicolumn{4}{|c|}{ Path $c^{\prime}$ : Safety Orientation to Job Performance } \\
\hline Safety Orientation & $.028^{*}$ & .167 & $3.01 *$ \\
\hline
\end{tabular}

$$
\begin{aligned}
& \text { Note. } \\
& *=p<.05 \\
& * *=p<.001
\end{aligned}
$$

Additional analyses were performed to investigate the relationship between dimensions of safety performance and performance area dimensions. These results are reported in Table 18 and discussed in Chapter V. 
Table 18

Correlations Among Dimensions of Safety Performance and Performance Area Dimensions

\begin{tabular}{|c|c|c|c|c|c|}
\hline & $M$ & $S D$ & $\begin{array}{c}\text { Safety } \\
\text { Compliance }\end{array}$ & $\begin{array}{c}\text { Safety } \\
\text { Participation }\end{array}$ & $\begin{array}{c}\text { Safety } \\
\text { Performance }\end{array}$ \\
\hline $\begin{array}{l}\text { Effort and } \\
\text { Productivity }\end{array}$ & 5.00 & 1.19 & $.44 *$ & $.54 *$ & $.53 *$ \\
\hline Dependability & 5.24 & 1.24 & $.43 *$ & $.50^{*}$ & $.50 *$ \\
\hline $\begin{array}{l}\text { Integrity and } \\
\text { Professionalism }\end{array}$ & 4.93 & 1.23 & $.43^{*}$ & $.52 *$ & $.52 *$ \\
\hline $\begin{array}{l}\text { Working with } \\
\text { Others }\end{array}$ & 5.02 & 1.19 & $.38 *$ & $.49^{*}$ & $.47^{*}$ \\
\hline Drive for Results & 5.00 & 1.24 & $.44^{*}$ & $.50^{*}$ & $.51 *$ \\
\hline $\begin{array}{l}\text { Confidence and } \\
\text { Independence }\end{array}$ & 4.98 & 1.24 & $.43 *$ & $.54^{*}$ & $.53 *$ \\
\hline Organization & 4.72 & 1.24 & $.43 *$ & $.52 *$ & $.52 *$ \\
\hline Work Quality & 4.92 & 1.25 & $.50^{*}$ & $.50^{*}$ & $.55^{*}$ \\
\hline Performance Area & 4.98 & 1.04 & $.51 *$ & $.60 *$ & $.61 *$ \\
\hline
\end{tabular}




\section{DISCUSSION}

The present dissertation sought to address two related purposes. Study 1 added a unique contribution to the safety literature by exploring the role of behavioral constructs in understanding employee safety behaviors. Selective hiring procedures used to predict safety performance have typically focused solely on the use of personality measures. Presently, a situational judgment test (SJT) and a biographical data test (biodata) were used to measure safety judgment and safety orientation, respectively, in two high-risk industries. These types of behavioral predictor methods are commonly used in employment selection contexts, but until now, were largely ignored in the safety literature. Study 1 specifically focused on investigating relationships among two personality factors (conscientiousness and agreeableness), safety judgment, safety orientation, and safety performance. Analyses centered on investigating safety orientation, or an individual's inclination to act safely, as a determinant of safety performance. Study 2 replicated Study 1 and explored the relationship between safety performance and job performance, answering a recent call for research by Kaplan and Tetrick (2010). Distinctly, Study 2 aimed to demonstrate the utility of using selection as an effective safety management strategy by answering the question: are safe workers better workers? Both studies extended past research by using supervisory ratings of safety and job performance criteria instead of self-report measures.

\section{Summary of Results and Contributions}

Predicting safety performance. Both Study 1 and Study 2 found conscientiousness, agreeableness, and safety orientation to be predictive of safety 
performance. Consistent with existing research, results demonstrated a positive association between conscientiousness and safety performance (e.g., Buck, 2008; Christian et al., 2009). The direct relationship between agreeableness and safety performance was inconsistent across studies. Though in Study 1 the relationship was not significant, in Study 2 agreeableness was significantly related to safety performance. Agreeableness was, however, consistently indirectly related to safety performance through safety orientation in both Study 1 and Study 2 .

Conscientiousness was also indirectly related to safety performance through safety orientation across both studies. These indirect relationships are consistent with previous findings that show safety motivation mediates the relationship between personality and safety performance (e.g., Buck, 2008; Christian et al., 2009). Conscientiousness and agreeableness were also strongly related to both safety orientation and safety judgment, such that individuals high on conscientiousness and agreeableness were also likely to demonstrate an orientation towards behaving safely and good judgment when presented with unsafe situations.

In general, results surrounding safety judgment proved to be inconsistent, suggesting there may be some measurement issues with the construct. Though the indirect effect of safety judgment on safety performance was not significant in model testing, the joint significance tests in both Study 1 and Study 2 demonstrated otherwise, suggesting the safety orientation fully mediated the relationship between safety judgment and safety performance. Thus, results in regard to safety orientation as a mediator of the relationship between safety judgment and safety performance remain inconclusive. The following section on limitations explains these findings 
with particular focus on the measurement of safety judgment used in the present study.

Study 1 and Study 2 found safety orientation to be a proximal determinant of safety performance, supported by incremental validity results and the mediation evidence described above. Together, these findings echo previous research that evaluated employee's motivation to follow workplace safety practices (e.g., Buck, 2008; Christian et al., 2009; Griffin \& Neal, 2000; Vinodokumar \& Bhasi, 2010). Previous research has also suggested that employees with high safety motivation are likely to demonstrate safety performance improvements over time (safety participation, Neal \& Griffin, 2006; safety compliance, Probst \& Brubaker, 2001). Thus, hiring safety-oriented candidates may ensure lasting effects on safety performance, further supporting the use of safety orientation assessments in selection proceedings. In sum, while both personality and biodata instruments tend to be perceived equally favorable by job applicants (see Hausknecht, Day, \& Thomas, 2004), the present results suggest that there are additional predictor methods that are relevant in the study of safety performance, both from a theoretical and practical perspective, that are more proximal to the criterion of interest.

Safety performance and job performance. Study 2 makes a valuable contribution to the existing safety performance literature by revealing a strong association between safety performance and job performance. The relationship between both criterion measures not only demonstrates the utility of using selection procedures to hire safer employees, it also supports the viability of personnel selection as means of promoting safety in organizations. Further, Study 2 evidence 
indicates that safety and job performance are not mutually exclusive as previously claimed (Faverge, 1980; Janssens, Brett \& Smith, 1995; Kjellen, 1984; Leplat \& Rasmussen, 1984). Intuitively, the relationship may be a product of the similarity of problems that arise when both criteria are collectively low (Heinrich, 1980), and the similarity of benefits when both criteria are high. For example, effective safety behavior decreases the amount of time spent addressing workplace accidents and expenditures on workers compensation and production losses, thereby increasing overall job performance (Anasiewicz, 1962). When organizational resources are maintained through high safety performance, more efforts can be placed toward productivity and job demands. Likely, workers who are safe are also effective at completing job tasks, thus making them desirable employees. The relationship between safety performance and global performance (employee re-hireability and overall capability match) observed in Study 2 supports this claim; supervisors identified employees with high safety performance as the kind they would like to continue hiring in the future.

Additional analyses further strengthened evidence of a relationship between safety performance and job performance. Specifically, the relationship between the dimension of effort and productivity and safety performance directly challenges previous assumptions that safe employees are not as productive as those willing to forego safety practices in order to meet production demands (Janssens et al., 1995). Except for work quality, job performance dimensions tended to be more strongly related to discretionary safety behaviors suggesting that workers that engage in safety 
participation behaviors are more likely to demonstrate more effective job performance behaviors.

Although measures of safety performance (e.g., Neal et al., 2001) have laid the foundation for more effective and accurate measurement of workplace safety, the majority of these measures have relied on self-reported worker behaviors (cf. Burke et al., 2002). Subsequently, the reported relationships between various antecedents and self-reported safety behavior suffer from various limitations. Here, safety performance and job performance were rated by supervisors. Supervisor ratings present information regarding observations of incumbent safety behavior, thereby provide a judgmental measure of safety performance. Research has demonstrated that supervisor ratings are more highly related to job performance than any other source of feedback (Becker \& Klimoski, 1989). Further, the composite job performance measure assessed multiple dimensions of performance relevant to the jobs studied and likely to be applicable to a variety of jobs (e.g., effort and productivity, integrity and professionalism, and working with others).

\section{Limitations and Future Directions}

Across both studies support for the proposition that safety judgment would be positively correlated with safety orientation and safety performance was not found. In addition to poor internal consistency reliability, item limitations, contextual considerations, and limitations of SJTs in general may help to explain these findings. First, safety judgment was measured with only four items, which likely limited the scope of the hypothetical situations participants were asked to evaluate and also greatly degraded the overall reliability of the measure. Additional analyses were 
implemented to explore how safety judgment related to the individual dimensions of safety performance across both samples (safety compliance and safety participation). Though only marginally significant, results imply that safety judgment was more strongly related to safety participation $(r s=.07, p=.10)$ than safety compliance $(r s=$ $.00, n s)$. Indeed, a review of the individual safety judgment items revealed a prevalent focus on participatory behaviors (e.g., asking for help, coworker interactions), explaining the disparity. Future measures of safety judgment should include a larger set of items that assess both compliance and participatory safety behaviors more comprehensively.

Second, contextual or situational factors such as safety climate play an important role in safety behavior (e.g., Griffin \& Neal, 2000; Hoffman \& Stetzer, 1996; Neal \& Griffin, 2006). For example, an employee may have favorable safety attitudes but organizational constraints (e.g., lack of management support or frequent routine violations) may decrease the probability that the employee will choose to behave in accordance with their safety attitude and knowledge of safety policies. Further, TPB (Ajzen, 1985, 1991; Fishbein \& Ajzen, 1975) emphasizes the importance of contextual variables in behavior. Specifically, TPB proposes that behavioral intentions are influenced not only by individual attitudes but also the perceived social pressures to perform or avoid certain behaviors (subjective norm). Further, the influence of subjective norms is determined by the individual's perception of the extent to which others think they should engage in the behavior (normative beliefs) and the degree to which they are motivated to comply with others' perceptions. In addition, the lack of consideration for situational factors such as safety 
climate provides a probable explanation for why the variance explained in safety performance across both studies was low. Due to the focus on personnel selection, the inclusion of safety climate was deemed out of scope for the present research. These conclusions clearly point to the need for future research to consider the moderating effect of safety climate on the relationship between safety judgment and safety performance.

Yet another possibility is that participants had difficulty imagining how they would react if actually faced with the scenarios presented to them. Breckler (1984) suggests that SJTs struggle to communicate the true "power" of real-time hazardous situations. The scenarios considered in the present dissertation were more common and innocuous than the hazardous situations Becker (1984) referenced, however, it would be interesting for future research to consider using higher fidelity assessments (e.g., simulations, assessment centers) to predict safety behavior. Using these predictor methods could also allow researchers to evaluate additional contextual variables such as risk and hazard perception, which have demonstrated significant relationships with safety performance (e.g., Gellar, 1996; Mearns \& Flin, 1995; Rundmo, 1996). Research shows that biased perception of risk can lead to misjudgments of potentially dangerous situations and further, that poor judgment of risk is likely to cause inapt reactions, inappropriate decisions about which safety measures to apply, and accidents or injuries (Rundmo, 1996).

In addition to the limitations of safety judgment, there were additional limitations related to the participants used in Study 1 and Study 2. First, the data was collected from multiple organizational samples of incumbents, which may serve as a 
statistical limitation. Ideally, data would have been collected from a sample of job applicants, given the possibility that validity coefficients may be lower in the incumbent population as a consequence of range restriction. Further, without performance incentives for participating incumbents, the research setting was not representative of the high stakes environment typically associated with personnel selection. Thus, future studies should attempt to replicate the present findings using a predictive validation design.

Second, the majority of participants were males working in blue-collar industries. It would be interesting and informative to replicate the present dissertation using a sample that included more women in white-collar industries. For example, using a sample of nurses and/or doctors working in hospital settings would support generalizability of the models evaluated here. Given that nurses and doctors are typically evaluated on their ability to safely provide quality care to patients, it is likely that results from such a study would further support the relationship between safety performance and job performance. In addition, safety judgment may be of particular relevance in emergency situations where a patient's life can be saved or lost on the basis of decisions made by those directly in charge of the patient's care plan.

To effectively implement safety judgment and safety orientation predictors in a real hiring context, job experience requirements for the open position should be evaluated carefully. Logically, an applicant's degree of job experience is likely to influence their level of safety judgment and safety orientation. In the literature, job experience has demonstrated positive relationships with job performance (McDaniel, Schmidt, \& Hunter, 1988; Schmidt \& Hunter, 1998) and safety performance (Hansen, 
1989). Thus, though measuring specific knowledge of safety requirements and proper decision-making in particular hazardous situations would be appropriate for a job that required some level of experience, it may not be for an entry-level position. Because entry-level applicants lack experience working in jobs requiring safe behavior, predictors would need to focus on more general safety behaviors and attitudes. Training entry-level candidates on more specific safety standards and expectations would be critical after hire. Effectively, safety training would bring about the desired level of safety judgment and safety orientation necessary to enact desirable safety behaviors after hire.

Lastly, though the relationships among predictors, errors, and violations were discussed in Chapter II, the present dissertation did not directly evaluate these relationships. Future studies should continue the study of how violations and errors differentially relate to predictors, particularly in the context of selection. Based on what is known about errors and violations, it may be more important to eliminate candidates with negative safety attitudes because attitudes are more resistant to change, and errors can be reduced through training. Clearly, empirical support for these claims is needed.

\section{Implications and Conclusions}

This research is a valuable first step to creating effective hiring strategies to identify safer workers; hence, supporting personnel selection as a proactive approach to safety management. This is not to say that interventions should be abandoned or that the situational or environmental context of work is not critically relevant in understanding safety performance. Instead, it is suggested that individual selection 
decisions are likely to have a wide spread impact on safety and organizational outcomes (Kaplan \& Tetrick, 2010) and hiring an unsafe employee may pose a serious threat to the integrity of any safety management system.

To date, the safety and selection literatures have primarily focused on personality to select individuals into safety-oriented jobs, largely ignoring other predictor methods known to demonstrate associations with a wide range of performance criteria. Here, two common behavioral predictor methods (biodata and SJT) were considered in addition to personality variables. If selection is to be used as safety management strategy, it is imperative that predictors used in hiring processes are reflective of current selection best practices in construct measurement. In addition to comprehensively assessing applicant capabilities, selection systems must also consider organizational needs and requirements as well as the particular requirements of the job itself.

The findings presented here are among the first to show that safe workers are likely better workers. Effectively, the long held belief that employees who engage in safe work practices do so at the expense of job performance was directly challenged. This is good news for organizations within high-risk industries interested in pursuing selective hiring as a safety management strategy. In general, hiring safer workers may prevent future corrective interventions and engender safer work environments, allowing more time to be spent on meeting job demands. Hiring for safety also sends the message that safety is important to incumbents and applicants, further communicating the value of safety as a top organizational priority and contributing to more positive organizational safety climates. 


\section{REFERENCES}

Ajzen, I. (1985). From intentions to actions: A theory of planned behavior. In J. Kuhl \& J. Beckman (Eds.), Action-control: From cognition to behavior (pp. 11-39). Heidelberg, Germany: Springer.

Ajzen, I. (1991). The theory of planned behavior. Organizational Behavior and Human Decision Processes, 50, 179-211.

Alexander, M., Cox, S. and Cheyne, A. (1995, February). The concept of safety culture within a UK offshore organisation. Paper presented at the Understanding Risk Perception Conference, The Robert Gordon University, Aberdeen.

Anasiewicz, A. (1962). The influence of safety at work on productivity. proceedings of the $3^{\text {rd }}$ World Congress on the Prevention of Risk at Work. Paris: Institut National de Securite.

Anderson, J.R. (1985). Cognitive psychology and its implications ( $2^{\text {nd }}$ ed.). New York: W.H. Freeman.

Arthur, W., \& Doverspike, D. (2001). Predicating motor vehicle crash involvement from a personality measure and a driving knowledge test. Journal of Prevention and Intervention in the Community, 22, 35-42.

Arthur, W., \& Graziano, W.G. (1996). The five factor model, conscientiousness, and driving accident involvement. Journal of Personality, 63, 593-618.

Arthur, W., \& Villado, A. J. (2008). The importance of distinguishing between constructs and methods when comparing predictors in personnel selection research and practice. Journal of Applied Psychology, 93, 435-442

Barrick, M. R., \& Mount, M. K. (1991). The Big Five personality dimensions and job performance: A meta-analysis. Personnel Psychology, 44, 1-26.

Barrick, M. R., Mount, M. K., \& Judge, T. A. (2001). The FFM personality dimensions and job performance: Meta-Analysis of meta-analyses [Special issue]. International Journal of Selection and Assessment, 9, 9-30.

Barling, J., Kelloway, E.K., \& Iverson, R.D. (2003). High-quality work, job satisfaction, and occupational injuries. Journal of Applied Psychology, 88, 276-283.

Becker, T.E. \& Klimoski, R.J. (1989). A field study of the relationship between the organizational feedback environment and performance. Personnel Psychology, 42, 343-358. 
Beirness, D. J. (1993). Do we really drive as we live? The role of personality factors in road crashes. Alcohol, Drugs and Driving, 6, 129-143.

Binning, J.F. \& Barrett, G.V. (1989). Validity of personnel decisions: A conceptual analysis of the inferential and evidential bases. Journal of Applied Psychology, 74, 478-494.

Borman, W. C., \& Motowidlo, S. J. (1993). Expanding the criterion domain to include elements of contextual performance. In N. Schmitt, \& W. C. Borman (Eds.), Personnel selection in organizations (pp. 71-98). San Francisco: Jossey-Bass.

Broadbent, D. E., Cooper, P. F., Fitzgerald, P., \& Parkes, K. R. (1982). The cognitive failures questionnaire (CFQ) and its correlates. British Journal of Clinical Psychology, 21(1), 1-16. doi: 10.1111/j.2044-8260.1982.tb01421.x

Brown, K.A., Willis, P.G., \& Prussia, G.E. (2000). Predicting safe employee behavior in the steel industry: Development and test of sociotechnical model. Journal of Operations Management, 18, 445-465.

Buck, M. A. (2008). Proactive personality and big five traits in supervisors and workgroup members: Effects on safety climate and safety motivation. Dissertation Abstracts International: Section B: The Sciences and Engineering, 5607-5607.

Burke, M. J., Sarpy, S. A., Tesluk, P. E., \& Smith-Crowe, K. (2002). General safety performance: A test of a grounded theoretical model. Personnel Psychology, $55,429-457$.

Campbell, J. P. (1990). Modeling the performance prediction problem in industrial and organizational psychology. In M. D. Dunnette \& L. M. Hough (Eds.), Handbook of Industrial and Organizational Psychology (pp. 687-732). Palo Alto, CA: Consulting Psychologists Press, Inc.

Campbell, J. P., McCloy, R. A., Oppler, S. H., \& Sager, C. E. (1993). A theory of performance: In N. Schmitt \& W. C. Borman (Eds.), Personnel Selection in Organizations (pp. 35-70). San Francisco: Jossey-Bass.

Casillas, A., Robbins, S., McKinniss, T., Postlethwaite, B., \& Oh, I. (2009). Using narrow facets of an integrity test to predict safety: A test validation study. International Journal of Selection and Assessment, 17(1), 119-125. doi: http://dx.doi.org/10.1111/j.1468-2389.2009.00456.x

Clarke, S. (2006). The relationship between safety climate and safety performance: A meta-analytic review. Journal of Occupational Health Psychology, 11, 315327. 
Clarke, S. (2010). An integrative model of safety climate: Linking psychological climate and work attitudes to individual safety outcomes using meta--analysis. Journal of Occupational and Organizational Psychology, 83, 553-578.

Clarke, S., \& Robertson, I.T. (2005). A meta-analytic review of the Big Five personality factors and accident involvement in occupational and nonoccupational settings. Journal of Occupational and Organizational Psychology, 78, 355-376.

Clarke, S. \& Robertson, I. (2008). An examination of the role of personality in work accidents using meta-analysis. Applied Psychology: An International Review 57, 94-108. doi:10.1111/j.1464-0597.2007.00267.x

Cellar, D. F., Nelson, Z. C., York, C. M., \& Bauer, C. (2001). The five-factor model and safety in the workplace: Investigating the relationships between personality and accident involvement. Journal of Prevention \& Intervention in the Community, 22, 43-52.

Chan, D., \& Schmitt, N. (2002). Situational judgment and job performance. Human Performance, 15, 233-254.

Chen, C. (2009). Personality, safety attitudes and risky driving behaviors-Evidence from young Taiwanese motorcyclists. Accident Analysis and Prevention, 41, 963-968.

Christian, M.S., Bradley, J.C., Wallace, J.C., \& Burke, M.J. (2009). Workplace safety: A meta-analysis of the roles of person and situation factors. Journal of Applied Psychology, 94, 1103-1127.

Christian, M.S., Edwards, B.D., \& Bradley, J.C. (2010). Situational judgment tests: Constructs assessed and a meta-analysis of their criterion-related validities. Personnel Psychology, 63, 83-117.

Conger, J.J., Gaskill, H.S., Glad, D.D., Hassell, L. Rainey, R.V., \& Sawrey, W.L. (1959). Psychological and psychophysical factors in motor vehicle accidents. Journal of American Medical Association, 169, 1581-1587.

Cohen, A. (1977). Factors in successful occupational safety programs. Journal of Safety Research, 9, 168-178.

Conway, J. M., \& Huffcutt, A. I. (1997). Psychometric properties of multisource performance ratings: A meta-analysis of subordinate, supervisor, peer, and self-ratings. Human Performance, 10(4), 331-360. doi:10.1207/s15327043hup1004_2

Costa, P. T., \& McCrae, R. R. (1985). The NEO Personality Inventory manual. Odessa, FL: Psychological Assessment Resources. 
Cox, S., \& Cox, T. (1991). The structure of employee attitudes to safety: A European example. Work \& Stress, 5(2), 93-106. doi:10.1080/02678379108257007

Cox, S. J., \& Cheyne, A. J. T. (2000). Assessing safety culture in offshore environments. Safety Science, 34(1-3), 111-129. doi: http://dx.doi.org/10.1016/S0925-7535(00)00009-6

Davids, A., \& Mahoney, J.T. (1959). Personality dynamic and accident proneness in an industrial setting. Journal of Applied Psychology, 41, 303-309.

Dedobbeleer, N. \& Beland, F. (1991). A safety climate measure for construction sites. Journal of Safety Research, 22, 97-103.

Dillman, B.G., \& Lee, J.R. (2006). Utilizing situational judgment tests (SJT) for pilot decision-making. International Journal of Applied Aviation Studies, 6, 145154.

Driskill, W. E., Weissmuller, J. J., Quebe, J. C., Hand, D. K., \& Hunter, D. R. (1998). Evaluating the decision-making skills of general aviation pilots (Tech. Rep. No. DOT/FAA/AM-98/7). Washington, DC: Federal Aviation Administration.

Donald, I., \& Canter, D. (1994). Employee attitudes and safety in the chemical industry. Journal of Loss Prevention in the Process Industries, 7, 203-208.

Eklof, M. \& Torner, M. (2002). Perception and control of occupational injury risks in fishery-A pilot study. Work \& Stress, 16, 58-69.

Fay, D. \& Tissington, P. (2004). Safety and risks: Errors and accidents in difference occupations. In C. Spielberger (Ed), Encyclopedia of Applied Psychology (pp. 299- 307). New York: Academic Press.

Faverge, J. M. (1980). The interpretation of a two-mode factorial analysis: An illustration using the study of self- and other-images of the personnel of an industrial area. Revue De Psychologie Appliquée, 30(3), 185-196.

Fazio, R.H. (1986). How do attitudes guide behavior? In R.M. Sorrentino \& E.T. Higgins (Eds.), Handbook of Motivation and Cognition: Foundations of Social Behavior (pp. 204-243). New York: Guilford.

Fingar, A.R., Hopkins, R.S., \& Nelson, M. (1992). Work-related injuries in Athens County, 1982 to 1986: A comparison of emergency department and workers' compensation data. Journal of Occupational Medicine, 34, 779-787.

Fishbein, M. \& Ajzen, I. (1975). Belief, attitude, intention and behavior: An introduction to theory and research. Reading, MA: Addison-Wesley.

Gellar, E.S. (1996). The psychology of safety: How to improve safety behaviors and attitudes on the job. Radnor, PA: Chilton Book. 
Geller, A.I., Clarke, S.G., \& McKenna, E.F. (2006). Human safety and risk management ( $\left.2^{\text {nd }} E d s\right)$. Boca Raton: CRC Press.

Greenwood, M., \& Woods, H. M. (1919). A report on the incidence of industrial accidents with special reference to multiple accidents (Industrial Fatigue Research Board Report No. 4). London: Her Majesty’s Stationery Office.

Griffin, M.A. \& Neal, A. (2000). Perceptions of safety at work: A framework for linking safety climate to safety performance, knowledge and motivation. Journal of Occupational Health Psychology, 5, 347-358.

Goldberg, L.R. (1990). An alternative "description of personality": The Big-Five factor structure. Journal of Personality and Social Psychology, 59, 12161229. doi: 10.1037/0022-3514.59.6.1216

Guion, R.M. (1965). Personnel testing. New York: McGraw-Hill

Hale, A. R., \& Hale, M. (1972). A review of the industrial accident literature. London: Her Majesty's Stationary Office.

Hale, A.R. \& Glendon, A.I. (1987). Individual behavior in the control of danger. Amsterdam: Elsevier.

Hansen, C.P. (1988). Personality characteristics of the accident involved employee. Journal of Business and Psychology, 2, 326-365.

Hansen, C. P. (1989). A causal model of the relationship among accidents, biodata, personality and cognitive factors. Journal of Applied Psychology, 74, 81-90.

Harrell, W. A. (1990). Perceived risk of occupational injury: Control over pace of work and blue-collar versus white-collar work. Perceptual and Motor Skills, 70, 1351-1359. doi:10.2466/PMS.70.4.1351-1359

Harris, M. M., \& Schaubroeck, J. (1988). A meta-analysis of self-supervisor, selfpeer, and peer-supervisor ratings. Personnel Psychology, 41, 43-62.

Hayes, B.E., Perander, J., Smecko, T., \& Trask, J. (1998). Measuring perceptions of workplace safety: Development and validation of the work safety scale. Journal of Safety Research, 29, 145-161.

Heinrich, H.W., Peterson, D., \& Roos, N. (1980). Industrial accident prevention $\left(5^{\text {th }}\right.$ ed.). New York: McGraw-Hill.

Henning, J. B., Stufft, C. J., Payne, S. C., Bergman, M. E., Mannan, M. S., \& Keren, N. (2009). The influence of individual differences on organizational safety attitudes. Safety Science, 47(3), 337-345. doi:10.1016/j.ssci.2008.05.003 
Hofmann, D.A., Jacobs, R., \& Landy, F. (1995). High reliability process industries: Individual, micro and macro organisational influences on safety performance. Journal of Safety Research, 26, 131-141.

Hofmann, D. A., \& Stetzer, A. (1996). A cross-level investigation of factors influencing unsafe behaviors and accidents. Personnel Psychology, 49, 307339.

Hough, L.M. (1992). The 'Big Five' personality variables-construct confusion: Description versus prediction. Human Performance, 5, 139-155.

Hunter, D.R. (2003). Measuring general aviation pilot judgment using a situational judgment technique. The International Journal of Aviation Psychology, 13, 373-386.

Hunter, D.R. (2005). Measurement of hazardous attitudes among pilots. The International Journal of Aviation Psychology, 15, $23-43$.

Hunter, D. R., \& Burke, E. F. (1994). Predicting aircraft pilot training success: A meta-analysis of published research. International Journal of Aviation Psychology, 4, 297-313.

Hunter, J.E., \& Hunter R.F. (1984). Validity and utility of alternative predictors of job performance. Psychological Bulletin, 96, 72-98.

Janssens, M., Brett, J. M., \& Smith, F. J. (1995). Confirmatory cross-cultural research: Testing the viability of a corporation-wide safety policy. Academy of Management Journal, 38(2), 364-382. doi: http://dx.doi.org/10.2307/256684

Kahneman, D. (1973). Attention and Effort. Englewood Cliffs, NJ: Prentice Hall.

Kanfer, R., \& Ackerman, P.L. (1989). Motivation and cognitive abilities: An integrative-aptitude-treatment interaction approach to skill acquisition. Journal of Applied Psychology, 74, 657-690.

Kelley, R. (1996). Worker psychology and safety attitudes. Professional Safety, 41, 14-17.

Kjellen, U. (1984). The deviation concept in occupational accident control. Accident Analysis and Prevention, 16, 289-323.

Kilborne, C. (2009). 5 Keys to Improving Worker Safety Attitude. Safety Daily Advisor. Retrieved 1/10/2012 from http://safetydailadvisor.blr.com/archive/2009/04/28/safety_attitude_economy_ creative_training.aspx.

Kohn, M., \& Schooler, C. (1983). Work and personality: An inquiry into impact of social stratification. Ablex, Norwood, NY. 
Larson, G.E., Alderton, D.L., Neideffer, M., \& Underhill, E. (1997). Further evidence on dimensionality and correlates of the Cognitive Failures Questionnaire. British Journal of Psychology, 88, 29-38.

Larson, G.E., \& Merritt, C.R. (1991). Can accidents be predicted? An empirical test of the Cognitive Failures Questionnaire. Applied Psychology: An International Review, 40, 37-45.

Larsson, S., Pousette, A., \& Törner, M. (2008). Psychological climate and safety in the construction industry-mediated influence on safety behaviour. Safety Science, 46(3), 405-412. doi: http://dx.doi.org/10.1016/j.ssci.2007.05.012

Lawton, R., \& Parker, D. (1998). Individual differences in accident liability: A review and integrative approach. Human Factors, 40, 655-671.

Leplat, J. and Rasmussen, J. (1984). Analysis of human errors in industrial incidents and accidents for improvement of work safety. Accident Analysis and Prevention, 16, 77-88.

Liberty Mutual Research Institute for Safety. (2011). 2011 Liberty Mutual workplace safety index. Retrieved from http://www.libertymutualgroup.com/ researchinstitute.

McCrae, R. R., \& Costa, P. T., Jr. (1996). Toward a new generation of personality theories: Theoretical contexts for the Five-Factor Model. In J. S. Wiggins (Ed.), The Five-Factor Model of personality: Theoretical perspectives (pp. 5187). New York: Guilford Press.

McDaniel, M.A., Hartman, N.S., \& Grubb W.L., III. (2003, April). Situational judgment tests, knowledge, behavioral tendency, and validity: A metaanalysis. Paper presented at the $18^{\text {th }}$ annual conference of the Society for Industrial and Organizational Psychology, Inc., Orlando, FL.

McDaniel, M.A., Schmidt, F.L., \& Hunter, J.E. (1988). Job experience correlates of job performance. Journal of Applied Psychology, 70, 342-353.

McDaniel, M.A. \& Whetzel, D.L. (2007). Situational Judgment Tests. In D.L. Whetzel, \& G.R Wheaton (Eds.) Applied measurement: Industrial psychology in human resources management (pp. 235 -255). Mahwah, NJ: Lawrence Erlbaum Associates, Publishers.

McGovern. P.M., Vesley, D., Kochevar, L., Gershon, R.R.M., Rhame, F.S., \& Anderson, E. (2000). Factors affecting universal precautions compliance. Journal of Business and Psychology, 15, 149-169.

McLain, D.L. (1995). Responses to health and safety risk in the work environment. The Academy of Management Journal, 38, 1726-1743. 
Mearns, K., \& Flin, R. (1995). Risk perception and attitudes to safety by personnel in the offshore oil and gas industry: A review. Journal of Loss Prevention Process Industry, 8, 299-305.

Mearns, K., Flin, R., Fleming, M., \& Gordon, R. (1998). Measuring safety climate on offshore installations. Work \& Stress, 12, 238-254.

Mearns, K. Flin, R. Gordon, R., \& Fleming, M. (2001). Human and organizational factors in offshore safety. Work and Stress, 15, 144-160.

Miller T.R., Waehrer G.M., Leigh J.P., Lawrence B.A., \& Sheppard M.A. (2002) Costs of occupational hazards: A microdata approach. National Institute of Occupational Safety and Health; Washington, D.C.

Murphy, P.L., Sorock, G.S., Courtney, T.K., Webster, B.S., \& Leamon, T.B. (1996). Injury and illness in the American workplace: A comparison of data sources. American Journal of Industrial Medicine, 30, 130-141.

Nahrang, J. D., Morgeson, F. P., \& Hofmann, D. A. (2011). Safety at work: A meta-analytic investigation of the link between job demands, job resources, burnout, engagement, and safety outcomes. Journal of Applied Psychology, 96(1), 71-94.

Neal, A., Griffin, M.A. \& Hart, P.M. (2000). The impact of organizational climate on safety climate and individual behavior. Safety Science, 34, 99-101.

Neal, A. \& Griffin, M.A. (2004). Safety climate and safety at work. In J. Barling and M.R. Frone (Eds.). The Psychology of Workplace Safety. Washington, DC: American Psychological Association.

Neal, A. \& Griffin, M.A. (2006). A study of the lagged relationship among safety climate, safety motivation, safety behavior and accident at the individual and group levels. Journal of Applied Psychology, 91, 946-953.

Newnam, S., Griffin, M.A., Mason, C. (2008). Safety in work vehicles: A multilevel study linking safety values and individual predictors to work-related driving crashes. Journal of Applied Psychology, 93, 632-644.

Organ, D.W. (1988). Organizational citizenship behavior: The good soldier syndrome. Lexington, MA: Lexington Books.

Parker, S. K., Axtell, C. M., \& Turner, N. (2001). Designing a safer workplace: Importance of job autonomy, communication quality, and supportive supervisors. Journal of Occupational Health Psychology, 6(3), 211-228. doi: http://dx.doi.org/10.1037/1076-8998.6.3.211

Parker, D., Reason, J.T., Manstead, A.S.R., \& Stradling (1995). Driving errors, driving violations and accident involvement. Ergonomics, 38, 1036-1048. 
Paul, P. S., \& Maiti, J. (2007). The role of behavioral factors on safety management in underground mines. Safety Science, 45(4), 449-471. doi:10.1016/j.ssci.2006.07.006

Pfeffer, J. (1998). The human equation: Building profits by putting people first. Boston: Harvard Business School Press.

Pransky, G., Snyder, T., Dembe, A., \& Himmelstein, J. (1999). Under-reporting of work-related disorders in the workplace: A case study and review of the literature. Ergonomics, 42, 171-182.

Probst, T. M. (2004). Safety and insecurity: Exploring the moderating effect of organizational safety climate. Journal of Occupational Health Psychology, 9, $3-10$.

Probst, T. M., \& Brubaker, T. L. (2001). The effects of job insecurity on employee safety outcomes: Cross sectional and longitudinal explorations. Journal of Occupational Health Psychology, 6, 139-159.

Raouf, A. \& Dhillon, B.S. (1994). Safety Assessment: A Quantitative Approach. Boca Raton, FL: CRC Press, Inc.

Rasmussen, J. (1982). Human errors: A taxonomy for describing human malfunction in industrial installations. Journal of Occupational Accidents, 4, 311-333.

Rasmussen, J. (1983). Skills, rules, and knowledge; signals, signs, and symbols; and other distinctions in human performance models. IEEE Transactions on Systems, Man, and Cybernetics, 13, 257-266.

Rich, G. A., Bommer, W. H., MacKenzie, S. B., Podsakoff, P. M., \& Johnson, J. L. (1999). Apples and apples or apples and oranges? A meta-analysis of objective and subjective measures of salesperson performance. Journal of Personal Selling \& Sales Management, 19(4), 41-52.

Reason, J. (1990). Human error. New York, NY, US: Cambridge University Press.

Reason, J. T., Manstead, A., Stradling, S., \& Baxter, J. S. (1990). Errors and violations on the roads: A real distinction? Ergonomics, 33(10-11), 13151332. doi: 10.1080/00140139008925335

Reason, J., Parker, D., \& Lawton, R. (1998). Organizational controls and safety: The variety of rule-related behavior. Journal of Occupational and Organizational Psychology, 71, 289-304.

Reason, J. Parker, D., \& Free, R. (1994). Bending the rules: The varieties, origins and management of safety violations. (Leiden: Rijks Universiteit Leiden). 
Roth, P.L., Bobko, P., McFarland, L.A., \& Buster, M. A. (2008). Work sample test ethnic group differences in personnel selection: A meta-analysis of overall and exercise scores. Personnel Psychology, 61, 635-659.

Roy, G.S., \& Choudhary, R.K. (1985). Driver control as a factor in road safety. Asian Journal of Psychology and Education, 16, 33-37.

Rundmo, T. (1994). Associations between safety and contingency measures and occupational accidents on offshore petroleum platforms. Scandinavian Journal of Work, Environment and Health, 20, 128-131.

Rundmo, T. (1996). Associations between risk perception and safety. Safety Science, 24, 197-209.

Rundmo, T., \& Hale, A. R. (2003). Manager's attitudes towards safety and accident prevention. Safety Science, 41(7), 557-574. doi: 10.1016/S09257535(01)00091-1

Sah, A.P. (1989). Personality characteristics of accident free and accident involved Indian railway drivers. Journal of Personality and Clinical Studies, 5, 203206.

Salgado, J. F. (1997). The five factor model of personality and job performance in the European Community. Journal of Applied Psychology, 82, 30-43.

Salgado, J. (2002). The Big Five personality dimensions and counterproductive behaviors. International Journal of Selection and Assessment, 10, 117-125.

Salminen, S., \& Tallberg, T. (1996). Human errors in fatal and serious occupational accidents in Finland. Ergonomics, 39(7), 980-988.

doi:10.1080/0014013960896451

Schmidt, F.L., Thoresen, C., Le, H., Ilies, R. and Holland, E. (2001) Report on development and validation of the Index of Work Attitudes (IOWA). Unpublished report, Department of Management, University of Iowa, Iowa City, IA.

Seligman, P. J., Sieber, W. K., Pederson, D. H., Sundin, D. S., \& Frazier, T. M. (1988). Compliance with OSHA record-keeping requirements. American Journal of Public Health, 78, 1218-1219.

Shaw, L. (1965). The practical use of projective personality tests as accident predictors. Traffic Safety Research Review, 9, 34-72.

Shaw, L., \& Sichel, H. S. (1971). Accident proneness. Oxford, England: Pergamon Press. 
Sjöberg, L., \& Drottz-Sjöberg, B.M. (1991). Knowledge and risk perception among nuclear power plant employees. Risk Analysis, 11, 607-618.

Smith, C.S., Silverman, G.S., Heckert, T.M., Brodke, M.H., Hayes, B.E., Silverman M.K., \& Mattimore, L.K. (2001). A comprehensive method for the assessment of industrial injury events. Journal of Prevention \& Intervention in the Community, 22, 5-20.

Smith, M. J., Cohen, H. H., Cohen, A., \& Cleveland, R. J. (1978). Characteristics of successful safety programs. Journal of Safety Research, 10, 5-15.

Society for Industrial and Organizational Psychology. (2003). Principles for the validation and use of personnel selection procedures (4th ed.). Bowling Green, $\mathrm{OH}$ : Author.

Spector, P. E. (1994). Using self-report questionnaires in OB research: A comment on the use of a controversial method. Journal of Organizational Behavior, 15, 385-392. doi:10.1002/job.4030150503

Suchman, E.A. (1970). Accidents and social deviance. Journal of Health and Social Behaviour, 11, 4-15.

Tomás, J. M., Meliá, J. L., \& Oliver, A. (1999). A cross-validation of a structural equation model of accidents: Organizational and psychological variables as predictors of work safety. Work \& Stress, 13(1), 49-58. doi:10.1080/026783799296183

Ulleberg, P., \& Rundmo, T. (2003). Personality, attitudes and risk perception as predictors of risky driving behaviour among young drivers. Safety Science, 41, 427-443.

U.S. Bureau of Labor Statistics, U.S. Department of Labor (2012, October 25). Workplace Injuries and Illnesses - 2011. Retrieved from http://www.bls.gov/news.release/osh.nr0.htm

Vinodkumar, M. N., \& Bhasi, M. (2010). Safety management practices and safety behaviour: Assessing the mediating role of safety knowledge and motivation. Accident Analysis and Prevention, 42(6), 2082-2093. doi: http://dx.doi.org/10.1016/j.aap.2010.06.021

Viswesvaran, C., Ones, D.S., Schmidt, F.L. (1996). Comparative analysis of the reliability of job performance ratings. Journal of Applied Psychology, 81, 557574.

Wallace, C., \& Chen, G. (2006). A multilevel integration of personality, climate, selfregulation, and performance. Personnel Psychology, 59, 529-557. 
Wallace, J.C., \& Vodanovich, S.J. (2003a). Workplace safety performance: Conscientiousness, cognitive failure, and their interaction. Journal of Occupational Health Psychology, 8, 316-327.

Wallace, J.C., \& Vodanovich, S.J. (2003b). Can accidents and industrial mishaps be predicted? Further investigation in the relationship between cognitive failure and reports of accidents. Journal of Business and Psychology, 17, 503-514.

Weddle, M. G. (1996). Reporting occupational injuries: The first step. Journal of Safety Research, 27(4), 217-223.

Weekley, J.A., \& Jones, C. (1999). Further studies of situational tests. Personnel Psychology, 52, 679-700.

Weekley, J.A., \& Ployhart, R.E. (2005). Situational judgment: Antecedents and relationships with performance. Human Performance, 18, 81-104.

West, R.J., Elander, J., \& French, D. (1993). Mild social deviance, Type-A behaviour pattern and decision-making style as predictors of self-reported driving style and traffic accident risk. British Journal of Psychology, 84, 207-219.

Wickens, C.D. (1996). Designing for stress. In J. Driskell \& E. Salas (Eds.), Stress and human performance (pp.279-295). Mahwah, NJ: Erlbaum.

Wilcox, R. (1997). Introduction to robust estimation and hypothesis testing. San Diego: Academic Press.

Wilcox, R. (1999). Fundamentals of modern statistical methods. New York: Springer.

Wilcox, R. (2003). Applying contemporary statistical techniques. San Diego: Academic Press.

Williamson, A.M., Feyer, A.M., Cairns, D. \& Biancotti, D. (1997). The development of a measure of safety climate: The role of safety perceptions and attitudes. Safety Science, 25, 1-3.

Zacharatos, A. \& Barling, J. (2004). High-performance work systems and occupational safety. In J. Barling \& M.R. Frone (Eds) The Psychology of Workplace Safety (pp. 203-222). Washington, DC: American Psychological Association.

Zacharatos, A., Barling, J. \& Iverson. R.D. (2005). High-performance work systems and occupational safety. Journal of Applied Psychology, 90, 77-93.

Zohar, D. (1980). Safety climate in industrial organizations: Theoretical and applied implications. Journal of Applied Psychology, 65, 95-102. 
Zohar, D. (2004). Work safety. In C. Spielberger (Ed), Encyclopedia of Applied Psychology (pp. 719-724). New York: Academic Press.

Zohar, D. (2010). Thirty years of safety climate research: Reflections and future directions. Accident Analysis and Prevention, 42, 1517-1522. 


\section{VITA}

\section{ERICA NOELLE DREW}

Born, Berkeley, California

2007

B.A., Psychology, with High Distinction

University of Colorado at Colorado Springs

Colorado Springs, Colorado

2008

Talent Development Intern

Burger King Corporation

Miami, Florida

2012

M.S., Industrial/Organizational Psychology

Florida International University

Miami, Florida

2012-2013

Talent Development Consultant

Burger King Corporation

Miami, Florida

2012-2014

Doctoral Candidate

Florida International University

Miami, Florida

Teaching Assistant

Florida International University

Miami, Florida

\section{PUBLICATIONS AND PRESENTATIONS}

Drew, E.N., \& Viswesvaran, C. (2013). Lost in translation: Disparate impact reduction strategies and legal stakeholders. Industrial and Organizational Psychology, 6, 463-466.

Bruk-Lee, V., Drew, E.N., \& Hawkes, B. (2013). Candidate reactions to simulations and media-rich assessments in personnel selection. In M. Fetzer and K. Tuzinski (Eds) Simulations for Personnel Selection (pp. 43-62). New York: Springer

Drew, E.N., \& Viswesvaran, C. (2013, August). Attorney decision making in an employment discrimination dispute involving hiring procedures. Paper presented at the annual meeting of the Academy of Management, Orlando, FL. 
Reaves, A., Drew, E.N., \& Michel, J. (2013, May). Work-to-school enrichment as a mediator of the creativity-school performance relationship. Paper presented at the Work, Stress and Health Conference, Los Angeles, CA.

Drew, E.N, Bruk-Lee, V. \& Guteriez, S. (2013, May). Safety first: A predictive model for selecting safer workers. Paper presented at the Work, Stress and Health Conference, Los Angeles, CA.

Drew, E.N., \& Viswesvaran, C. (2013, April). Attorney evaluations of validation, scoring and adverse impact reduction strategies. Paper presented at the annual meeting of the Society for Industrial and Organizational Psychology, Houston, TX.

Reaves, A., Drew, E.N., \& Pace, V. (2013, April). Revisiting the conscientiousnesscreativity relationship. Poster presented at the annual meeting of the Society for Industrial and Organizational Psychology, Houston, TX.

Drew, E.N., Bruk-Lee, V., Gutierrez, S. (2013, April). The nature of safety performance: Dimensionality and relationship to antecedents. Poster presented at the annual meeting of the Society for Industrial and Organizational Psychology, Houston, TX.

Drew, E.N., Bruk-Lee, V., Wrenn, K. \& Levine, P. (2013, April). Test taker dispositions in response to a multimedia SJT. Paper presented at the annual meeting of the Society for Industrial and Organizational Psychology, Houston, TX.

Matamala, A., Sawhney, E., Drew, E., Viswesvaran, C., Thomas, J. (2012, August) Worthwhile or Worthless? A Meta-analysis of Diversity Training Effectiveness. Paper presented at the 71st Annual Meeting of the Academy of Management, Boston, MA.

Drew, E.N., Lamer, J.J., Bruk-Lee, V. LeVine, P.J., \& Wrenn, K.A. (2012, April). Keeping up with the Joneses: Applicant reactions to multimedia SJTs. Poster presented at the annual meeting of the Society for Industrial and Organizational Psychology, San Diego, CA.

Tulinksi, K., Drew, E.N., Bruk-Lee, V., \& Fetzer, M. (2012, April), Applicant perceptions of multimedia situational judgment tests. Paper presented at the annual meeting of the Society for Industrial and Organizational Psychology, San Diego, CA.

Sanderson, K., Drew, E. Bruk-Lee, V. LeVine, P.J., \& Wrenn, K.A. (2012, April). For your eyes only? Reactions to Internet based Multimedia SJTs. Paper presented at the annual meeting of the Society for Industrial and Organizational Psychology, San Diego, CA. 
Drew, E., Reaves, A., \& Sanderson, K. (2011, April). Best practices in graduate student retention: Do we practice what we preach? Poster Presented at the annual meeting of the Society for Industrial and Organizational Psychology, Chicago, IL.

Wrenn, K., Drew, E., Buxo, N., Bruk-Lee, V., \& Levine, P.J. (2011, April), Applicant perceptions of multimedia situational judgment tests. Paper presented at the annual meeting of the Society for Industrial and Organizational Psychology, Chicago, IL.

Drew, E.N. \& Winter, R.J. (2009, March). Punitive damage awards: One million for the plaintiff; Ten million for charity? Poster presented at the annual meeting of the American Psychology and Law Society Conference, San Antonio, TX.

Drew, E. \& Greene, E. (2008, March). The effect of apologies on potential litigant legal reasoning. Poster presented at the American Psychology and Law Society Conference, Jacksonville, FL.

Greene, E., \& Drew, E. (2007). Resources for Teaching Undergraduate Psychology and Law Courses. Available from http://www.apls.org/education/OtherTeaching.php. 